\title{
Photostability of Luminescent Ruthenium (II) Complexes in Water and Acid
}

\author{
Hae Lim Ji \\ Burke, VA
}

A.S., Northern Virginia Community College, 2008

B.S., University of Virginia, 2010

A Thesis presented to the Graduate Faculty of the University of Virginia in Candidacy for the Degree of Master of Science

Department of Chemistry

University of Virginia

December, 2013 


\section{Abstract}

Luminescence spectroscopy is widely used as an analytical technique in many fields due to its high sensitivity, simple instrumentation, and low cost. Luminophores as sensors are used to measure various analytes such as $\mathrm{CO}_{2}, \mathrm{O}_{2}$, glucose, anions, metal ions, pressure, temperature and $\mathrm{pH}$, to name a few. When used as a probe, the photostability of a luminophore is important for validating the accuracy of measurements to develop a better sensor.

However, measurements of quantitative photodecomposition yield $\left(\varphi_{d}\right)$ of luminophores require either complicated instrumentation or long experimental times. Herein, an instrument was developed to rapidly and accurately measure the photostability of quite stable luminophores.

The accuracy of the developed instrument was confirmed with fluorescein isothiocyanate in $\mathrm{H}_{2} \mathrm{O}$. The instrument has a good reproducibility of less than $2 \%$ relative standard deviation on three consecutive measurements of the identical sample of $\mathrm{Ru}(\mathrm{bpy})_{3}{ }^{2+}$ in $\mathrm{H}_{2} \mathrm{O}$. The instrument measures $\varphi_{d}$ of relatively very stable $\mathrm{Ru}(\mathrm{II})$ polypyridyl complexes with $\varphi_{d}$ of $10^{-6}$ to $10^{-7}$, in less than 30 minutes.

Photodecomposition yield, $\varphi_{N_{2} 0}$, and photooxidation yield, $\varphi_{O_{2} 0}$, of Ru(II) polypyridyl complexes in $\mathrm{H}_{2} \mathrm{O}$ were obtained. $\mathrm{Ru}\left[4,7-\left(\mathrm{C}_{6} \mathrm{H}_{5}\right)_{2} \text { phen }\right]_{3}{ }^{2+}$ is one of the most photostable complexes among $R u(I I)$ polypyridyl complexes investigated. The $R u(b p y)_{3}{ }^{2+}$ 
compound is less photostable than $\mathrm{Ru}(\text { phen })_{3}{ }^{2+}$ in general. Tentative rules on the design of stable sensor molecules are given.

Under acidic conditions, the emission intensity of the luminophores decreased drastically in the first minute unlike typical photolysis decay in $\mathrm{H}_{2} \mathrm{O}$. This unusual shape of photolysis decay curves is due to oxidation of the excited state $R$ (II) to $R u(I I I)$ by an oxidizer present in the acid and additional unknown kinetics. The behavior can be prevented by addition of a reducing agent, such as ascorbic acid to promptly reduce the $\mathrm{Ru}(I I I)$ back to $\mathrm{Ru}(\mathrm{II})$. The rate of photolysis under acidic conditions is about ten times faster than in water. However, it is yet unknown what oxidizer causes an oxidation of $\mathrm{Ru}(\mathrm{II})$ in acid. It is highly likely that it is caused by impurities, as both $\mathrm{H}_{2} \mathrm{SO}_{4}$ and trichloroacetic acid have the same phenomenon. A possible oxidant is a proton; however, this cannot explain all the data.

In summary, an instrument to measure the quantitative photostability of luminescent complexes was successfully developed. The measurements made by the instrument are reproducible and accurate. Photolysis time to decompose luminophores is less than $30 \mathrm{~min}$, which is significantly less than in the previous work. 


\section{Acknowledgments}

I would like to express my appreciation to Dr. James Demas for being a wonderful advisor. I know it is not possible to have a more supportive advisor than Dr. Demas. Ever since I joined the lab as an undergraduate researcher, the time I have spent in the lab has been great. His deep understanding of luminescence as a researcher and endless patience as a teacher has inspired me. Also, it is nice to have another sweet tooth nearby.

I would like to express gratitude to Dr. Ian Harrison and Dr. Carl Trindle for being on my committee and spending time to read my thesis. I would like to mention Dr. Robert Burnett for his constant help. Many thanks go to current and former member of the Demas lab. I acknowledge support from the Department of Chemistry and many research laboratories in the department. It will be easier for me to count the labs that I have not borrowed any materials from. I will miss the friendly environment. I would like to thank Mr. Wily Shoup for information on light pipes and the gift of the quartz light pipe.

Last but not the least, I would like to thank my family and friends for their support and love that allowed me to complete the graduate program. 


\section{Table of Contents}

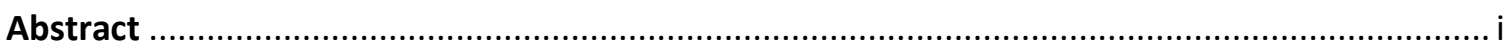

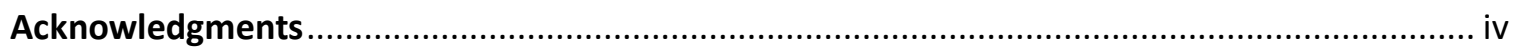

Chapter 1 Introduction to Luminescence and Photochemistry.................................................. 1

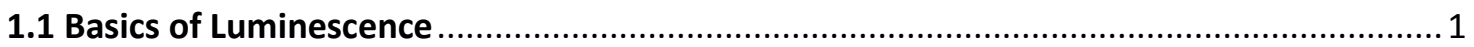

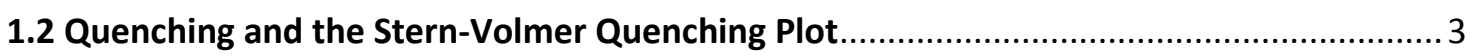

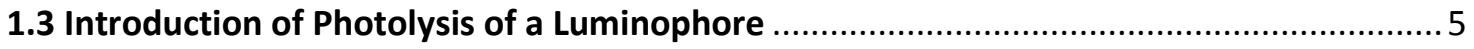

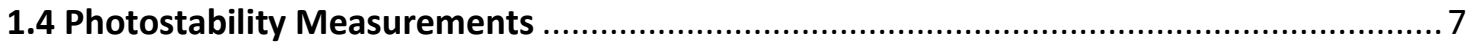

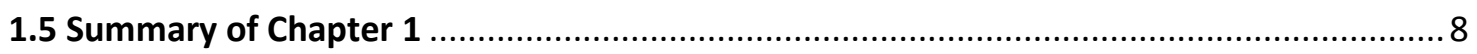

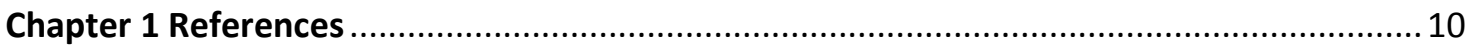

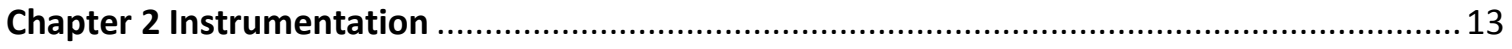

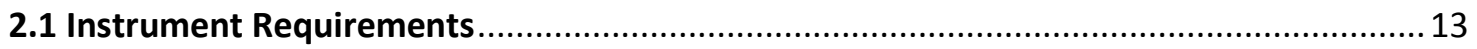

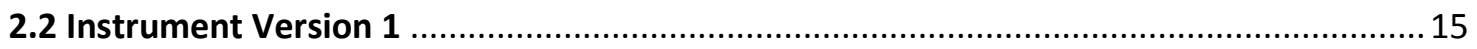

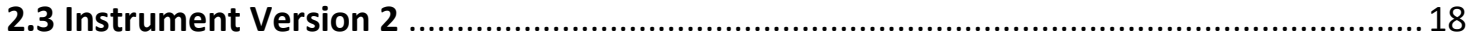

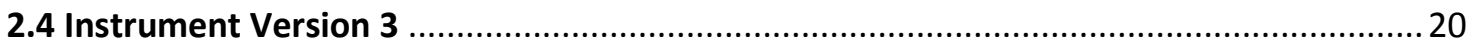

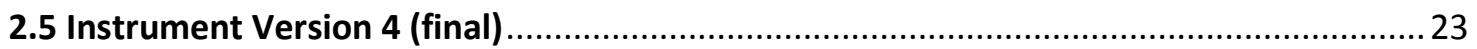

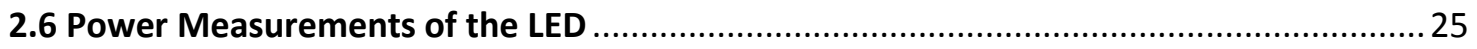

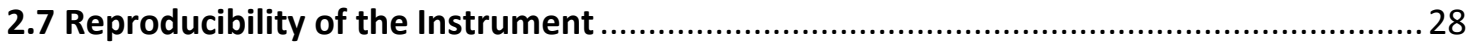

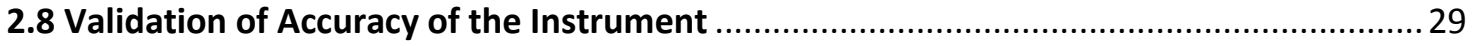

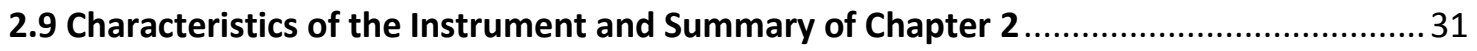

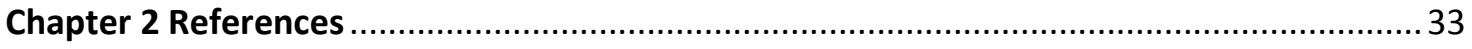

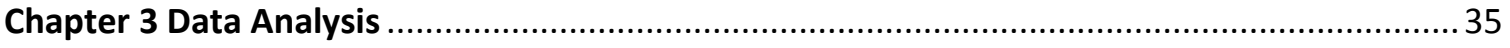

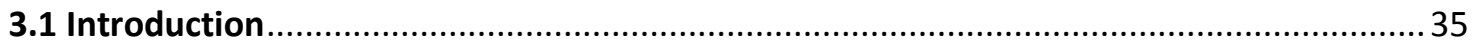

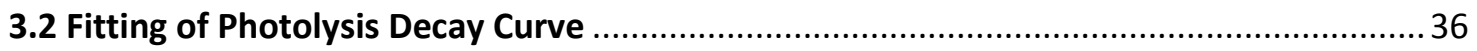

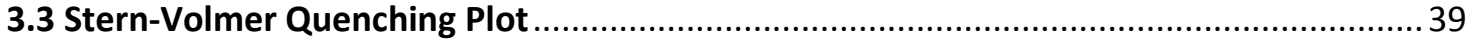

3.4 Photodecomposition Yield Calculation ….................................................................... 41

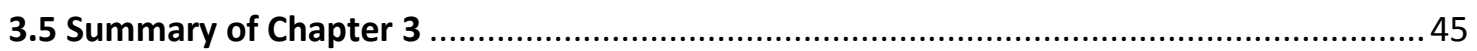

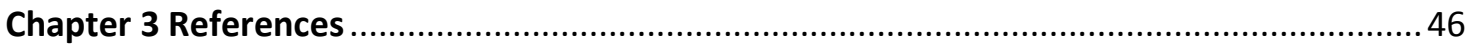

Chapter 4 Photolysis Experimental Data and Results ............................................................. 47

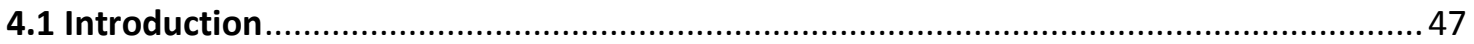




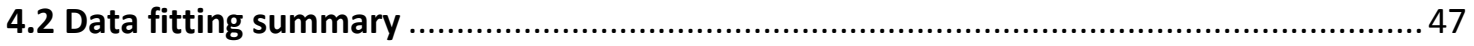

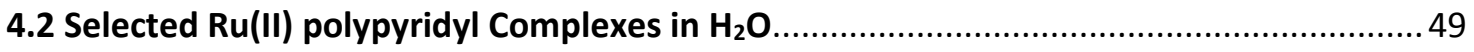

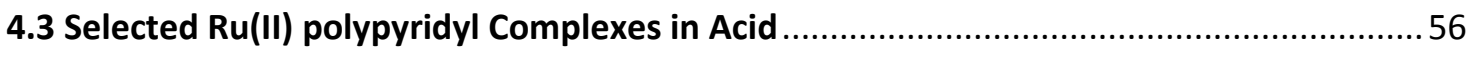

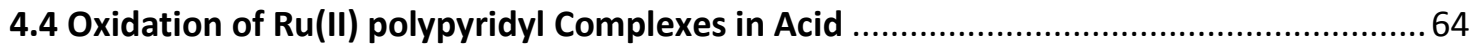

4.5 Photolysis Ru(II) polypyridyl Complexes in Acid in the Presence of a Reducing Agent.... 70

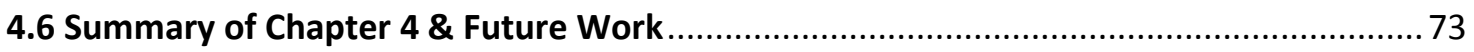

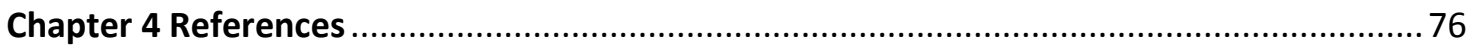

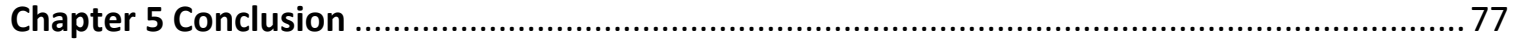

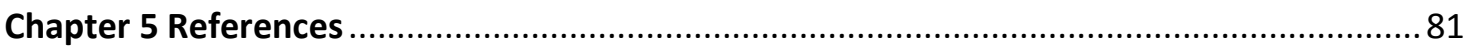




\section{Chapter 1 Introduction to Luminescence and Photochemistry}

\subsection{Basics of Luminescence}

Luminescent phenomena are encountered in everyday life. From simple children's toys to sophisticated scientific tools ${ }^{1}$, these phenomena can be observed in various ways. Due to its sensitivity and rather simpler instrumentation, luminescent sensors have more advantages compared to other analytical tools, such as mass spectrometry, gas chromatography, or NMR. Luminophores as a sensor are used to

analyze various compounds, such as $\mathrm{CO}_{2}{ }^{2}, \mathrm{O}_{2}{ }^{3,4}$, glucose ${ }^{5}$, anions ${ }^{6}$ and metal ions such as zinc $^{7}$, potassium ${ }^{8}$, to name a few. Pressure ${ }^{9}$, temperature ${ }^{10}$ and $\mathrm{pH}^{11}$ can be measured by luminescent sensors.

Biologists have also benefited from luminescence. Luminescence species have been used to sequence DNA ${ }^{12}$ or visualize different cellular components ${ }^{13}$. Luminophores have been used as a molecular ruler based on Forster resonance energy transfer ${ }^{14,15}$. Detection of dipicolinic acid in bacteria spores was utilized to detect anthrax ${ }^{16}$. The basic principles of luminescence need to be explained to understand how luminophores can be used as a sensor.

When a compound absorbs energy and becomes excited, it has several different pathways to follow. The Jablonski diagram, Figure 1.1, explains different photophysical 
processes that an excited state species can follow. Initial absorption of energy excites a molecule from the singlet ground state $\left(S_{0}\right)$ to one of the higher electronic states $\left(S_{1}, S_{2}\right.$, $\ldots, \mathrm{S}_{\mathrm{N}}$ ). Due to internal conversion (IC), the molecule relaxes to the lowest singlet excited state $\left(S_{1}\right)$. From $S_{1}$, the excited molecule can return to $S_{0}$ by emitting a photon, this is only one of several decay paths from $S_{1}$, which defines fluorescence. As the spin of an excited electron does not change during the decay process, fluorescence is an allowed transition with fast lifetime, typically in the low nanoseconds.

The excited molecule can relax to the ground state without the emission of a photon. This case is referred as non-radiative decay and marked as NR in Figure 1.1.

Another path that the excited state molecule can take is phosphorescence. An excite molecule in a singlet state can change spin multiplicity by intersystem crossing to the lowest excited triplet state, $T_{1}$. The triplet excited molecule then can relax back to the singlet ground state, So. As this process involves an electron spin flip, it is spin forbidden. The lifetime of phosphorescence is on the order of milliseconds and relatively rare at room temperature, although a number of sensors for mechanoluminescence and oxygen are based on luminophores in polymer systems ${ }^{17,18}$. Luminescence is a term to describe both fluorescence and phosphorescence. 


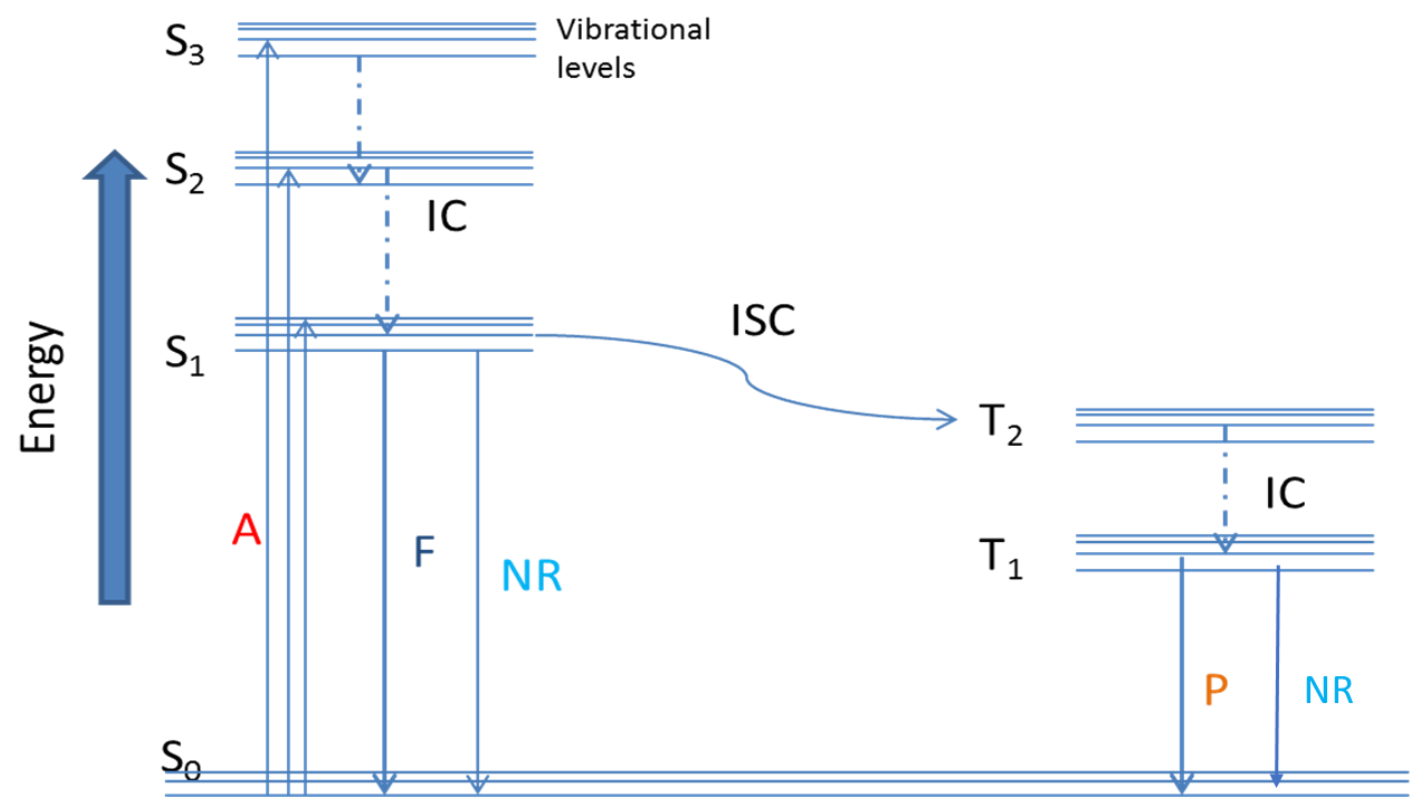

Figure 1.1 The Jablonski diagram to explain luminescence ${ }^{19}$ A, F, NR, P, IC, ISC denote absorption, fluorescence, non-radiative decay, phosphorescence, internal conversion, intersystem crossing, respectively.

\subsection{Quenching and the Stern-Volmer Quenching Plot}

Luminophores can be used as oxygen sensors based on quenching. Bimolecular quenching is a phenomenon in which another molecule, a quencher, interacts with an excited state luminophore by collision and causes deactivation of the excited state. Catalytic deactivation and in particular electron transfer does not give back the ground state by an oxidized or reduced species. The excited species relaxes back to ground state without emission of photon. Quenching of a luminescent Ru(II) complex is illustrated in Figure 1.2. Three samples in the figure contain the same concentration of 
the $\mathrm{Ru}(\mathrm{II})$ polypyridyl complex and are excited by black light with the same intensity. However, the left vial is purged with nitrogen to achieve $0 \%$ oxygen. The middle vial is under air where the luminophore is quenched by oxygen and has less emission intensity then the left sample. The far right vial with $100 \%$ oxygen saturation exhibits the least emission intensity due to the greatest amount of oxygen quenching. The systematic change in emission intensity at different concentrations of a quencher allows one to quantitatively measure a concentration of a quencher.

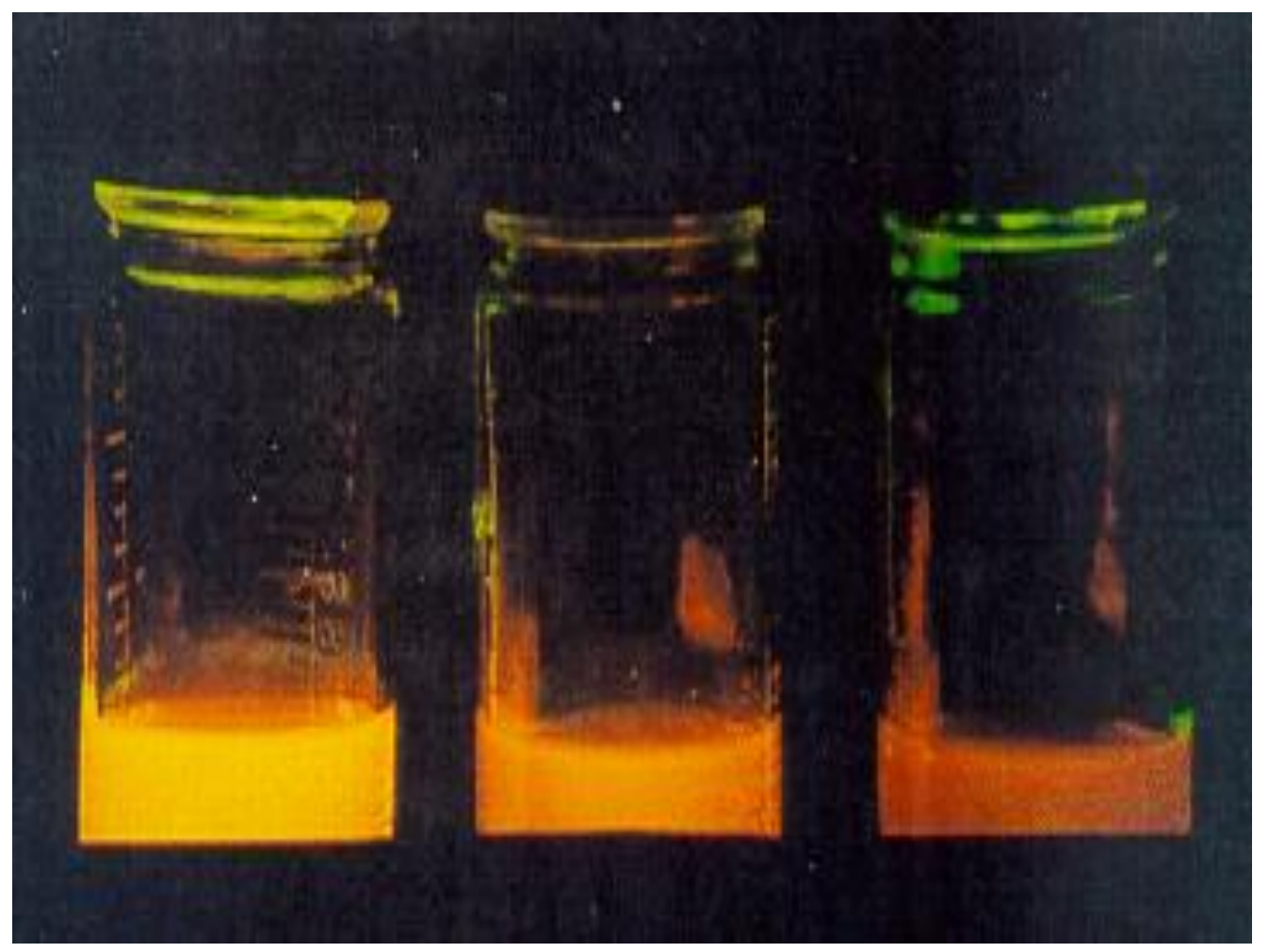

Figure 1.2 Quenching of a luminescent Ru(II) complex under nitrogen (left), air (middle), and oxygen (right) $^{20}$ 
The Stern-Volmer (SV) equation provides an explanation of quenching of luminescence:

$$
\frac{I_{0}}{I}=\frac{\tau_{0}}{\tau}=1+K_{s v}[Q]
$$

where $I_{0}$ and $I$ are intensities of luminophores in the absence of a quencher and in the presence of a quencher, respectively. $\tau_{0}$ and $\tau$ are lifetimes of luminophores in the absence of a quencher and in the presence of a quencher, respectively. The ratio of $I_{0}$ and $I$ or the ratio of $\tau_{0}$ and $\tau$ has a linear relationship with quencher concentration, $[Q]$. The SV quenching constant, $K_{s v}$, can be used as a measure of how sensitive a sensor is toward a quencher. A luminescent species with a greater value of $K_{s v}$ is more sensitive to the quencher than another species with a lesser value of $K_{s v}$.

The Stern-Volmer quenching plot (SVQP) provides a linear relationship between the characteristics of a luminophore, such as lifetimes or intensities, and a concentration of a quencher. Based on this equation 1.1, luminophores can be used as analytical sensors to detect a quencher concentration.

\subsection{Introduction of Photolysis of a Luminophore}

Luminescent complexes are widely used as analytical sensors based on the aforementioned unique characteristics. When used as an analytical probe, the stability 
of the luminophores is important to ensure the validity of measurements. It is especially important when detecting a single molecule with luminescent dyes ${ }^{21} 22$. It is well known that the widely used inorganic complex sensors are subject to photodegradation.

However, measurements of photodecomposition yield are not easy, because luminescent inorganic complexes are usually very photostable.

Equations 1.2 to 1.5 describe different processes that a luminophore can take during a photolysis.

$$
\begin{gathered}
D^{*} \rightarrow D+h v \text { or } \Delta \\
D^{*} \rightarrow P \\
D^{*}+O_{2} \rightarrow D+O_{2}{ }^{1} \\
O_{2}{ }^{1}+D \rightarrow D O_{2}
\end{gathered}
$$

where $D$ and $D^{*}$ are a ground state and an excited state species, respectively, $\Delta$ is heat, $\mathrm{P}$ is a product, $\mathrm{O}_{2}$ is a ground state triplet oxygen, $\mathrm{O}_{2}{ }^{1}$ is a singlet oxygen, and $\mathrm{DO}_{2}$ is an oxygenated species. In the case of Ru(II) inorganic complexes, the photolysis product is often one where the ligands are replaced by a solvent molecule or a photosolvation.

Eq. 1.2 denotes the excited state luminophore relaxing back to the ground state by emitting a photon or by non-radiative decay. When the excited species undergoes photolysis, one product is often a solvated complex such as $\mathrm{RuL}_{2} \mathrm{~S}_{2}$ (eq. 1.3). In the presence of oxygen, the photolysis processes become more complicated. The excited 
state species can interact with the triplet ground state oxygen and generate the ground state luminophore and singlet oxygen species by energy transfer (eq. 1.4). This quenching event has two consequences. It reduces the probability of photosolvation. Also, the singlet oxygen reacts with the luminophore, thereby generating oxygenated products via photooxidation (eq. 1.5).

In the absence of oxygen, when the sample is purged with nitrogen gas, only the two processes described in eq. 1.2 and eq. 1.3 occur. In the presence of oxygen, both photodecomposition (eq. 1.3) and photooxidation (eq. 1.5) take place. It is in a researcher's interests to accurately measure photodecomposition yield, $\varphi_{d}$, and photooxidation yield, $\varphi_{O_{2} 0}$.

\subsection{Photostability Measurements}

Photostability of a luminophore can be measured in several ways. Researchers have used Raman spectroscopy ${ }^{23}$, HPLC $^{24}$, capillary electrophoresis ${ }^{24-26}$, and luminescence spectroscopy $y^{27,28}$ to study photochemistry.

When luminescence spectroscopy is utilized in photolysis, a luminophore is photodecomposed by an intense excitation light source, and the emission intensities are recorded during photolysis ${ }^{22} 29$. When the photolyzed products are non-emissive and emission is only from the unphotolyzed luminophore, changes in the emission intensity 
can be directly related to changes in emissive luminophore concentrations when the sample is optically dilute.

Even though the basic principle behind the photolysis is rather simple, measurements of photostability of Ru(II) polypyridyl complexes require significant amounts of experimental time due to its stable nature. Ru(II) polypyridyl complexes have typical photodecomposition yields, $\varphi_{d}$, of $10^{-5}$ to $10^{-7}$. In the past, the measurement of photostability of $\mathrm{Ru}(\mathrm{II})$ sample required more than 24 hours of irradiation ${ }^{28}$. Due to improvements of experimental settings, in recently years, one photolysis experiment required 90 minutes of photodecomposition of the sample ${ }^{27}$. However, this technique did not allow the measurement of absolute quantum yields, only relative ones. Thus, development of an instrument that measures quantitative photostability of low quantum yield for photolysis Ru(II) complexes more efficiently, precisely, and in less time is desired.

\subsection{Summary of Chapter 1}

Luminescence spectroscopy has been used as an analytical tool in various fields due to its simpler instrumentation and high sensitivity. When luminophores are used as a sensor, photophysical and photochemical properties are required to improve the sensor. However, measurement of photodecomposition yield of Ru(II) polypyridyl complexes has been a time consuming process, as they are photostable. In the next 
chapter, requirements of an instrument to measure photostability efficiently will be discussed. Developments and subsequent modifications of the instrument and will be also discussed. 


\section{Chapter 1 References}

(1) DeGraff, B. A.; Demas, J. N. Luminescence-Based Oxygen Sensors. In Reviews in Fluorescence 2005 SE - 6; Geddes, C.; Lakowicz, J., Eds.; Springer US, 2005; Vol. 2005, pp. 125-151.

(2) Amao, Y.; Nakamura, N. Optical CO2 Sensor with the Combination of Colorimetric Change of $\alpha$-Naphtholphthalein and Internal Reference Fluorescent Porphyrin Dye. Sensors Actuators B Chem. 2004, 100, 347-351.

(3) Bacon, J. R.; Demas, J. N. Determination of Oxygen Concentrations by Luminescence Quenching of a Polymer-Immobilized Transition-Metal Complex. Anal. Chem. 1987, 59, 2780-2785.

(4) Carraway, E. R.; Demas, J. N.; DeGraff, B. a.; Bacon, J. R. Photophysics and Photochemistry of Oxygen Sensors Based on Luminescent Transition-Metal Complexes. Anal. Chem. 1991, 63, 337-342.

(5) Choudhury, B.; Shinar, R.; Shinar, J. Glucose Biosensors Based on Organic LightEmitting Devices Structurally Integrated with a Luminescent Sensing Element. J. Appl. Phys. 2004, 96, 2949-2954.

(6) Chen, B.; Wang, L.; Zapata, F.; Qian, G.; Lobkovsky, E. B. A Luminescent Microporous Metal - Organic Framework for the Recognition and Sensing of Anions. J. Am. Chem. Soc. 2008, 130, 6718-6719.

(7) Hanaoka, K.; Kikuchi, K.; Kojima, H.; Urano, Y.; Nagano, T. Development of a Zinc Ion-Selective Luminescent Lanthanide Chemosensor for Biological Applications. J. Am. Chem. Soc. 2004, 126, 12470-6.

(8) Thibon, A.; Pierre, V. C. A Highly Selective Luminescent Sensor for the Time-Gated Detection of Potassium. J. Am. Chem. Soc. 2009, 131, 434-5.

(9) Engler, R. H.; Klein, C.; Trinks, O. Pressure Sensitive Paint Systems for Pressure Distribution Measurements in Wind Tunnels and Turbomachines. Meas. Sci. Technol. 2000, 11, 1077-1085.

(10) Harrigan, R. W.; Hager, G. D.; Crosby, G. A. Evidence for Multiple-State Emission from ruthenium(II) Complexes. Chem. Phys. Lett. 1973, 21, 487-490. 
(11) Wong, K. M.-C.; Tang, W.-S.; Lu, X.-X.; Zhu, N.; Yam, V. W.-W. Functionalized Platinum(II) Terpyridyl Alkynyl Complexes as Colorimetric and Luminescence pH Sensors. Inorg. Chem. 2005, 44, 1492-1498.

(12) Sanger, F.; Coulson, A. R. A Rapid Method for Determining Sequences in DNA by Primed Synthesis with DNA Polymerase. J. Mol. Biol. 1975, 94, 441-448.

(13) Hu, C.-D.; Chinenov, Y.; Kerppola, T. K. Visualization of Interactions Among bZIP and Rel Family Proteins in Living Cells Using Bimolecular Fluorescence Complementation. Mol. Cell 2002, 9, 789-798.

(14) Jares-Erijman, E. A.; Jovin, T. M. FRET Imaging. Nat. Biotechnol. 2003, 21, 13871395.

(15) Clapp, A. R.; Medintz, I. L.; Mauro, J. M.; Fisher, B. R.; Bawendi, M. G.; Mattoussi, $\mathrm{H}$. Fluorescence Resonance Energy Transfer Between Quantum Dot Donors and Dye-Labeled Protein Acceptors. J. Am. Chem. Soc. 2003, 126, 301-310.

(16) Yilmaz, M. D.; Hsu, S.-H.; Reinhoudt, D. N.; Velders, A. H.; Huskens, J. Ratiometric Fluorescent Detection of an Anthrax Biomarker at Molecular Printboards. Angew. Chem. Int. Ed. Engl. 2010, 49, 5938-41.

(17) Zhang, G.; Chen, J.; Payne, S. J.; Kooi, S. E.; Demas, J. N.; Fraser, C. L. MultiEmissive Difluoroboron Dibenzoylmethane Polylactide Exhibiting Intense Fluorescence and Oxygen-Sensitive Room-Temperature Phosphorescence. J. Am. Chem. Soc. 2007, 129, 8942-8943.

(18) Zhang, G.; Lu, J.; Sabat, M.; Fraser, C. L. Polymorphism and Reversible Mechanochromic Luminescence for Solid-State Difluoroboron Avobenzone. J. Am. Chem. Soc. 2010, 132, 2160-2162.

(19) Lakowicz, J. Principles of Fluorescence Spectroscopy; 3rd ed.; SpringerScience: New York, NY, 2006; pp. 3-5.

(20) Kneas, K. A.; Xu, W.; Demas, J. N.; DeGraff, B. A. Dramatic Demonstration of Oxygen Sensing by Luminescence Quenching. J. Chem. Educ. 1997, 74, 696.

(21) Deschenes, L. a; Vanden Bout, D. a. Single Molecule Photobleaching: Increasing Photon Yield and Survival Time through Suppression of Two-Step Photolysis. Chem. Phys. Lett. 2002, 365, 387-395. 
(22) Eggeling, C.; Widengren, J.; Rigler, R.; Seidel, C. A. M. Photobleaching of Fluorescent Dyes Under Conditions Used for Single-Molecule Detection: Evidence of Two-Step Photolysis. Anal. Chem. 1998, 70, 2651-9.

(23) Mathies, R.; Oseroff, a R.; Stryer, L. Rapid-Flow Resonance Raman Spectroscopy of Photolabile Molecules: Rhodopsin and Isorhodopsin. Proc. Natl. Acad. Sci. U. S. A. 1976, 73, 1-5.

(24) Bartsch, H.; Eiper, A.; Habiger, K.; Kopelent-Frank, H. Comparison of Analytical Methods for Investigating the Photostability of Isoxicam. J. Chromatogr. A 1999, $846,207-216$.

(25) Pomponio, R.; Gotti, R.; Fiori, J.; Cavrini, V.; Mura, P.; Cirri, M.; Maestrelli, F. Photostability CE Studies on Nicardipine-Cyclodextrin Complexes by Capillary Electrophoresis. J. Pharm. Biomed. Anal. 2004, 35, 267-275.

(26) Pomponio, R.; Gotti, R.; Bertucci, C.; Cavrini, V. Evidences of CyclodextrinMediated Enantioselective Photodegradation of Rac-Nicardipine by Capillary Electrophoresis. Electrophoresis 2001, 22, 3243-50.

(27) Fuller, Z. J.; Bare, W. D.; Kneas, K. A.; Xu, W. Y.; Demas, J. N.; DeGraff, B. A. Photostability of Luminescent ruthenium(II) Complexes in Polymers and in Solution. Anal. Chem. 2003, 75, 2670-2677.

(28) Demas, J. N.; Adamson, A. W. Tris (2,2'-Bipyridine) ruthenium(II) Senstized Reactions of Some Oxalato Complexes. J. Am. Chem. Soc. 1973, 95, 5159-5168.

(29) Peck, K.; Stryer, L.; Glazer, A.; Mathies, R. Single-Molecule Fluorescence Detection : Autocorrelation Criterion and Experimental Realization with Phycoerythrin. Proc. Natl. Acad. Sci. U. S. A. 1989, 86, 4087-4091. 


\section{Chapter 2 Instrumentation}

\subsection{Instrument Requirements}

As mentioned in the previous chapter, the development of a new instrument is required in order to measure the photostability of stable luminescent sensors more conveniently, efficiently, and rapidly. This chapter describes the development and subsequent modifications of the instrument. Firstly, the rate equation of a photolysis needs to be defined to explain characteristics required for the instrument. The rate constant for decomposition is given by

$$
\mathrm{k}=\frac{2.303 \varphi_{d} i_{0} \varepsilon L}{V}
$$

where, $\mathrm{k}$ is the rate constant in $\sec ^{-1}, \varphi_{d}$ is photodecomposition yield, $i_{0}$ is intensity of excitation light source in einsteins per second, $\varepsilon$ is molar absorptivity in $\mathrm{M}^{-1} \mathrm{~cm}^{-1}$, $\mathrm{L}$ is light path length in $\mathrm{cm}$, and $\mathrm{V}$ is the volume of the sample in liters. In order for this equation to hold, the sample has to be optically diluted to yield an absorbance of less than 0.1 . In the optically dilute case the emission intensity is proportional to concentration. Thus, the concentration of emissive luminophores can be followed from emission intensity. Equation 2.1 will be discussed in more depth in chapter 3. 
The rate constant of photolysis is inversely proportional to the lifetime (eq. 2.2)

$$
\mathrm{k}_{1}=\frac{1}{\tau_{1}}
$$

where $k_{1}$ is a rate constant of photolysis and $\tau_{1}$ is a lifetime of photolysis.

Reduction of photolysis time can be achieved in two ways. The first method is to use smaller sample volumes in the photolysis experiment ${ }^{1-3}$. In eq. 2.1 , the rate of a photolysis is inversely proportional to the volume of sample photolyzed. Soper et al. successfully measured photodecomposition yield, $\varphi_{d}$, of relatively very stable complexes with $\varphi_{d}$ of $10^{-5}$ to $10^{-7}$ by using a capillary. When the flow of the sample passing the capillary is adjusted, the amount of luminophore photolyzed in the excitation beam and subsequently the emission intensity of the sensor changes. For example, when the rate of flow is slow, the sample is exposed to the light source longer and is more extensively photolyzed. $\varphi_{d}$ can be obtained by fitting the flow velocity and normalized fluorescence intensity of the sample. However, this approach will require more complex instrumentation and measurements. The beam characteristics must be tightly controlled and known, and the capillary diameter and flow must be known precisely.

Another way to achieve a shorter experimental time is to use a more intense light source. In eq. 2.1, the rate of photolysis is directly proportional to $i_{0}$. Thanks to recent developments in LEDs, efficient LEDs cost significantly less than in the past ${ }^{4}$. A 
blue LED generating maximum $7.5 \mathrm{~W}$ of power costs less than fifty dollars. In this project, the latter approach has been applied.

The final version of the instrument is composed of an excitation light source, a light delivery medium, cooling accessories, fiber optics, and a detector. The instrument has been modified several times to optimize the setup.

\subsection{Instrument Version 1}

Figure 2.1 depicts the very initial setup of the instrument. This version contained an $\mathrm{f} 1.2$ lens as a light delivery medium, a blue LED as a light source, a heat sink to maintain proper temperature in the LED, fiber optics to deliver emission intensity from the sample to a detector, and a fluorimeter as the detector.

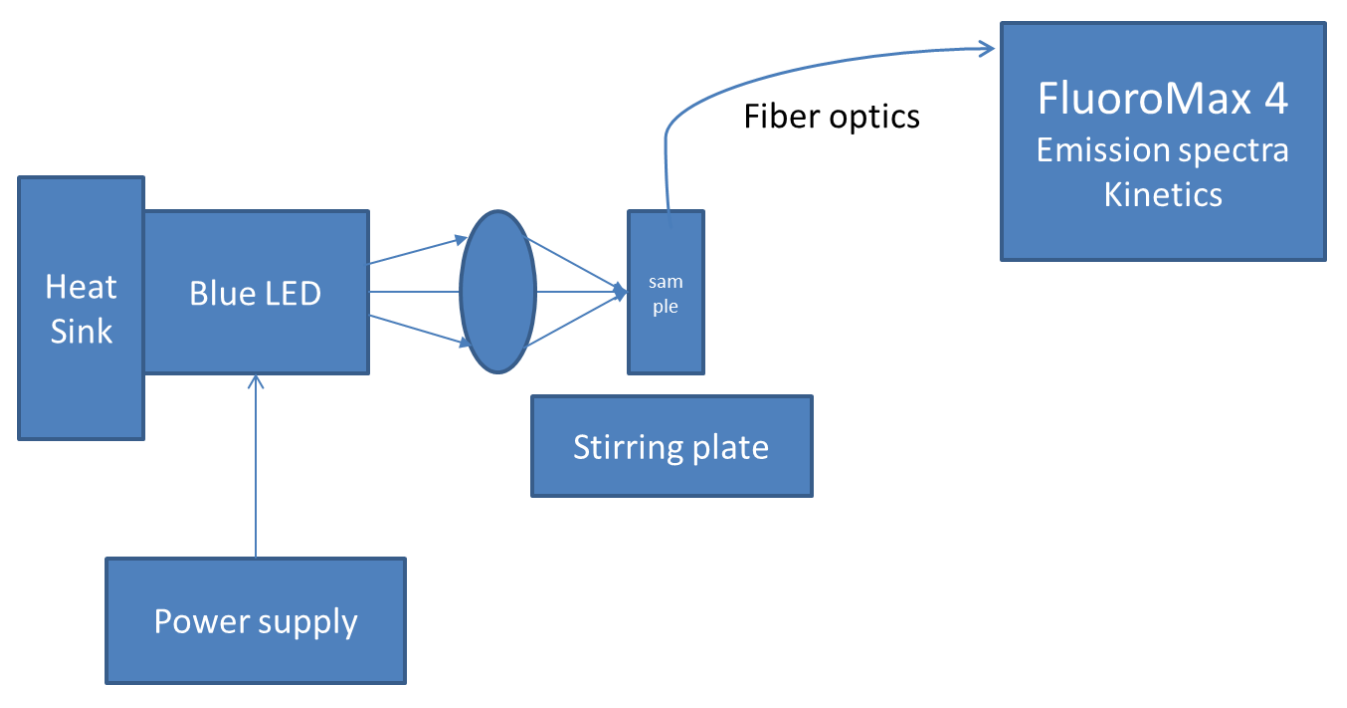

Figure 2.1 Version 1 of instrument composed of a lens, a blue LED, a heat sink, fiber optics and a fluorimeter. 
LEDs have many advantages when used as excitation light sources. Traditional lasers have more selectivity in excitation wavelength; however, they are expensive and required longer warm up time. LEDs are more cost effective than lasers. A PT-54 blue diode from Luminus Device Inc. Billerica, MA was used as a light source. The emitting area is $5.4 \mathrm{~mm}^{2}$ and its maximum output at $13.5 \mathrm{~A}$ is $7.5 \mathrm{~W}$ according to the data sheet supplied by the manufacturer ${ }^{5}$. The emission intensity profile of the LED is shown in Figure 2.2. The peak intensity is at $455 \mathrm{~nm}$.

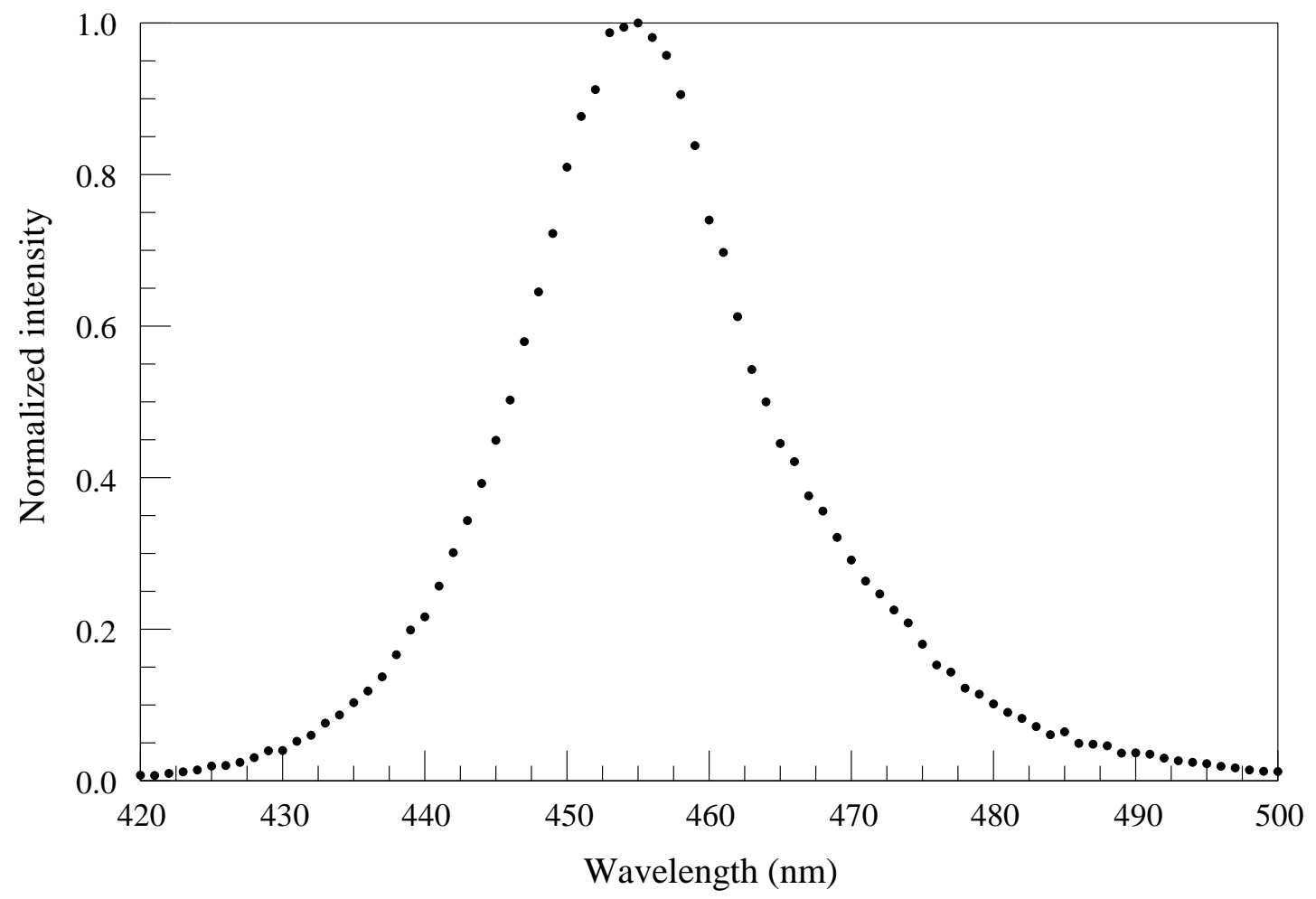

Figure 2.2 Emission profile of LED. The maximum intensity is at $455 \mathrm{~nm}$ which is close to the manufacturer's claim of peak wavelength at $460 \mathrm{~nm}$. 
The LED is mounted on a heat sink (Delta electronics Inc. DHS-B9292-04) to dissipate heat generated by the LED. The heat sink was claimed to have a thermal resistance of $0.237^{\circ} \mathrm{C}$ per $\mathrm{W}$ at 16 cubic foot per minute of air flow ${ }^{6}$.

Because the LED light is highly divergent, a lens was used to focus the excitation light for the LED. The lens has a f number of 1.2.

Several components of the first version were used in the later version of the instrument such as a quartz cuvette, stirring plate, a power supply, FluroMax4, fiber optics. A $3 \mathrm{~mL}$ square quartz cuvette with $1 \mathrm{~cm}$ path length was used as a sample holder to minimize background. During a photolysis, a sample in the cuvette was stirred by a micro magnetic stirrer to ensure proper mixing of the sample. The samples were constantly purged with gas during the experiment so as to ensure the sample is at the same oxygen concentration and also the sample is homogenous during photolysis.

The temperature of the sample was measured by a thermo couple, and power was supplied by Sorensen DCR 20-80B DC power supply that can generate up to 25 volts and $100 \mathrm{~A}^{7}$. A FluroMax $4^{8}$, Horiba Scientific spectrofluorimeter was used as a detector, with which the emission and excitation spectra of a luminophore can be measured. Additionally, the kinetics feature allows the selection of a wavelength to monitor changes in emission intensity in real time. In kinetics mode, different emission intensity and slit width can be selected. Unless otherwise noted, all emission intensities were 
measured at $595 \mathrm{~nm}$, which is close to the emission maximum of the selected ruthenium(II) complexes.

In the photolysis experiment, the spectrofluorimeter xenon light source was blocked by black cloth, because the sample is excited by the LED. This was necessary as the FluoroMax has no provision for shutting off the arc lamp while taking emissions. FluorEssence (version 3.5.1.20) was used in the fluorimeter to record and export the data.

Emission was monitored by the fluorimeter in real time. Due to the instrumental setup limitation, SpectroVis optical fiber by Vernier was used to deliver the emission intensity of sample to the fluorimeter, FluroMax 4, Horiba Scientific. The fiber optics has a rectangular $1 \mathrm{~cm} \times 1 \mathrm{~cm}$ cuvette shape that will fit in to the cuvette holder in the fluorimeter.

\subsection{Instrument Version 2}

This first version was modified because of the temperature increase in the LED. The temperature was monitored by a thermistor mounted on the coreboard of the LED. The temperature rise was about $15 \mathrm{C}$ in the LED which indicated the necessity of having a fan to the heat sink. The temperature increase after 25 minutes of LED usage was $15 \mathrm{C}$ (Figure 2.3). As maintaining junction temperature of the LED in the recommended range 
is important for a long lifetime, according to the manufacturer, and for stable power output, a rotary fan was directed into the base of the heat sink to maximize cooling capacity of the heat sink.

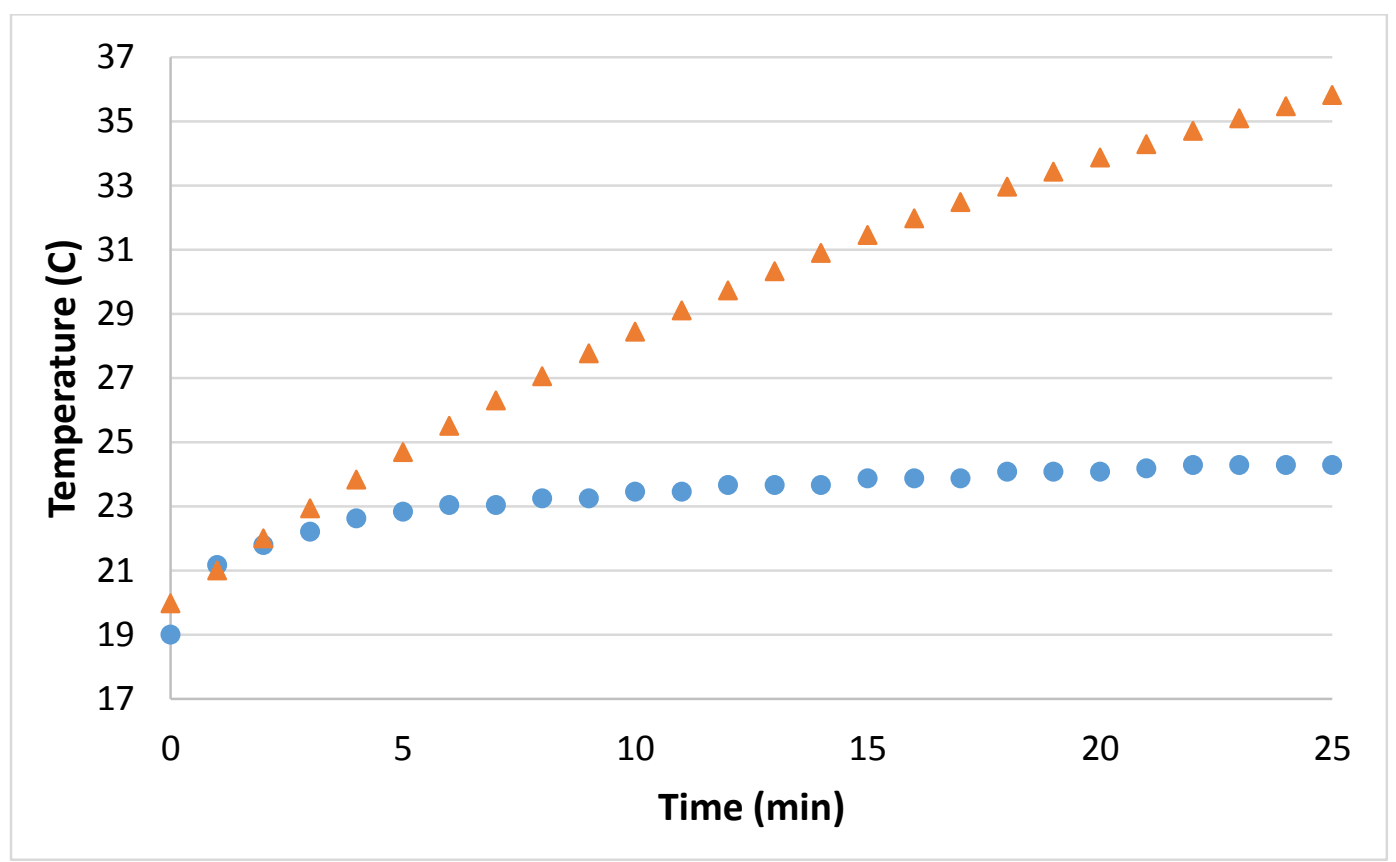

Figure 2.3 Addition of a rotary fan to the heat sink significantly decreases temperature rise in the LED. Temperature change in the absence of a rotary fan (triangle) and in the presence of the fan (circle) are shown above.

This modification significantly decreased temperature increase in LED from 15 C to $4 \mathrm{C}$ as shown in Figure 2.3. A diagram of the second version of instrument is shown in Figure 2.4. However, this version required improvements in the LED excitation light delivered to the sample. The light medium was changed from a lens to a quartz light pipe. This will be discussed in detail in the next section. 


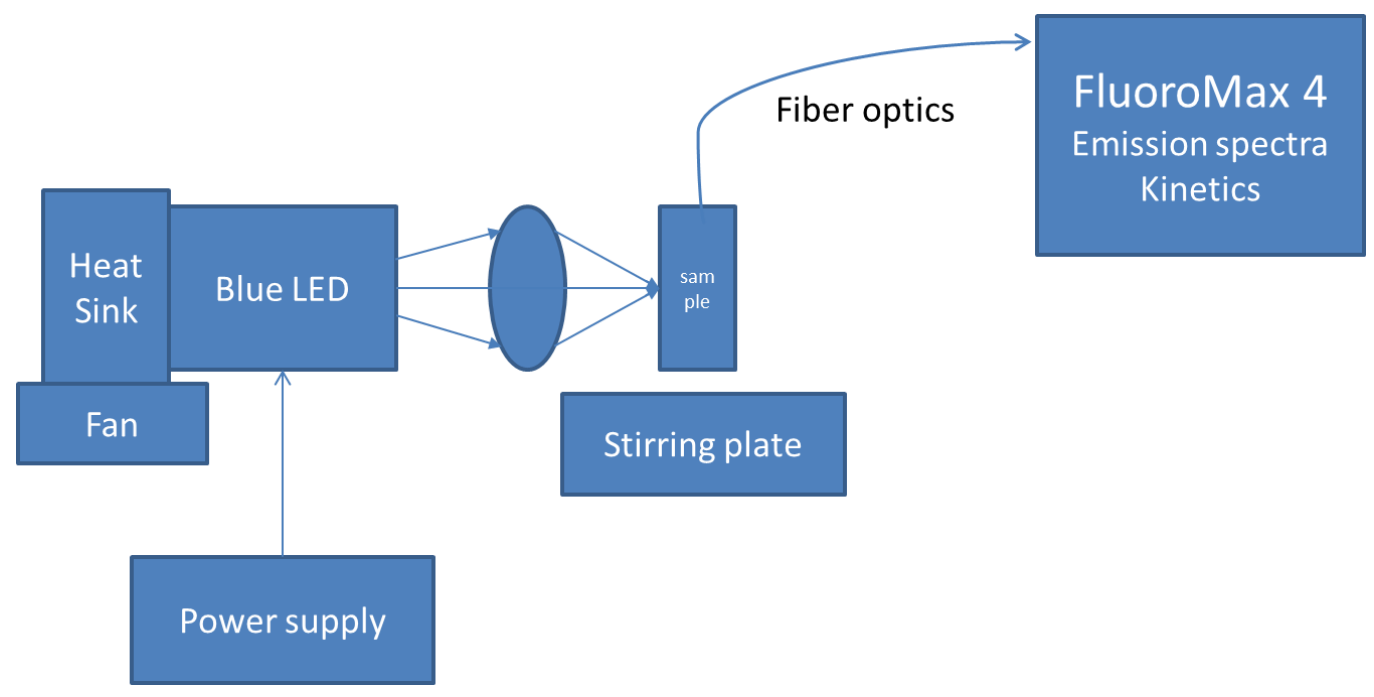

Figure 2.4 Version 2 of instrument, with the addition of a fan to the heat sink to minimize temperature rise in LED.

\subsection{Instrument Version 3}

The third version of the instrument is shown in Figure 2.5. The second version was modified due to inefficient delivery of excitation light by the lens and temperature rise in the sample. The lens was replaced by a quartz light pipe. The light pipe is a cylindrical rod with length of $15 \mathrm{~cm}$ and a diameter of $8 \mathrm{~mm}$. The light pipe works by total internal reflection and proved to be a more efficient delivery medium than the lens. The rates of photolysis was used to compare efficiency of the lens and the light pipe in Table 2.1 The light pipe was held by one clamp to minimize light loss. A 3" by 3" muffin fan was added to minimize temperature change in the sample as shown in Figure 2.6. 


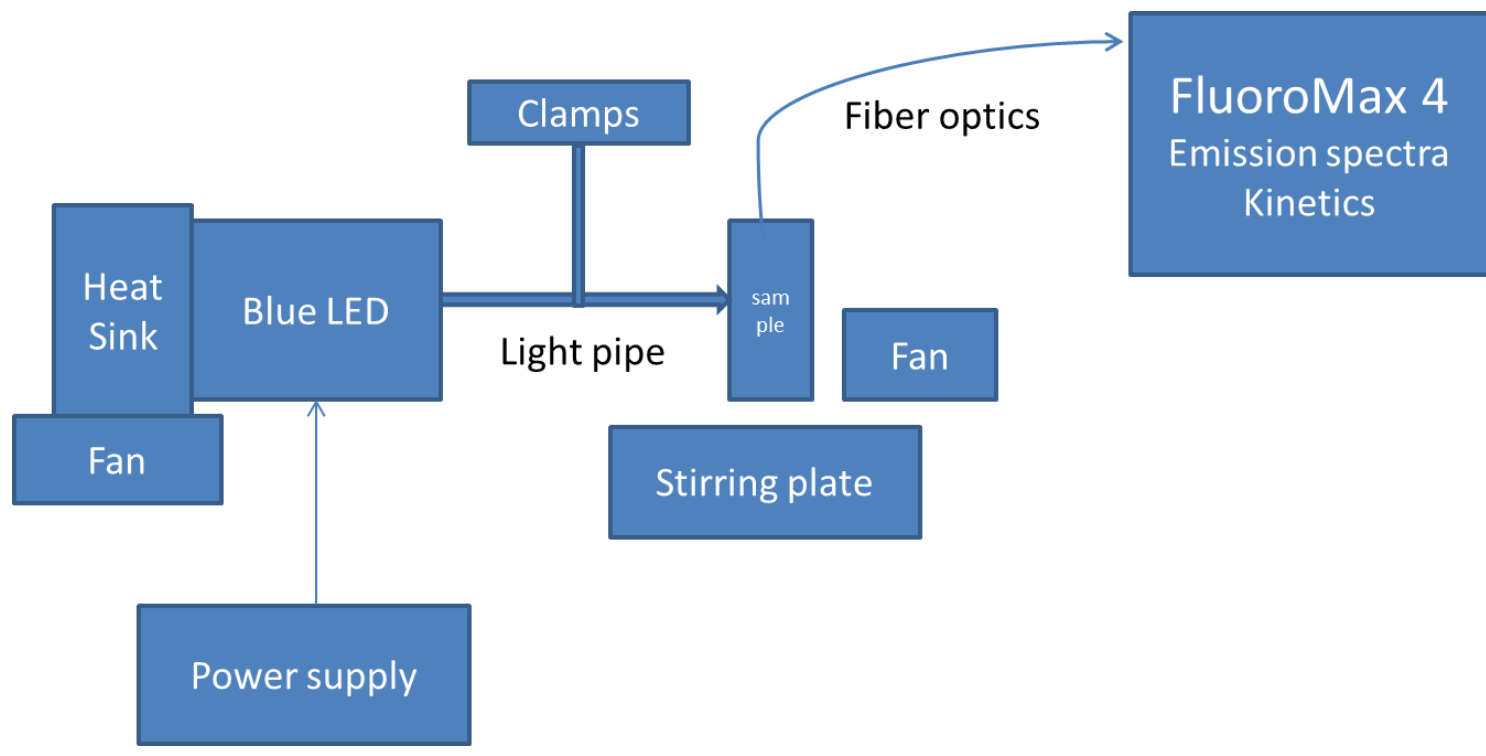

Figure 2.5 Version 3 of instrument. The lens was replaced by a quartz light pipe. A fan was attached to sample holder to minimize temperature rise of the sample.

When a f 1.2 lens was used, the excitation light was inefficiently delivered to the sample and the rate of photolysis was relatively slow. Table 2.1 shows a comparison of rates of photolysis of the same compound, nitrogen purged $\mathrm{Ru}(\mathrm{bpy})_{3}{ }^{2+}$ in $\mathrm{H}_{2} \mathrm{O}$ with the two different light delivery media. The rate of photolysis was 20 times faster when the light pipe was used, which indicates more efficiently delivery of excitation light to the sample. 
Table 2.1 Comparison of light delivery efficiency between a lens and a light pipe.

\begin{tabular}{ccc} 
Light delivery medium & F 1.2 lens & Quartz light pipe \\
\hline Lifetime of photolysis (min) & 203 & 10.4 \\
Rate constant $\left(\mathrm{min}^{-1}\right)$ & 0.00493 & 0.0962 \\
\hline
\end{tabular}

Even when an optically diluted sample with absorbance less than 0.1 was photolyzed, the sample experienced a noticeable increase in temperature. The temperature change in the sample during photolysis is shown in Figure 2.6.

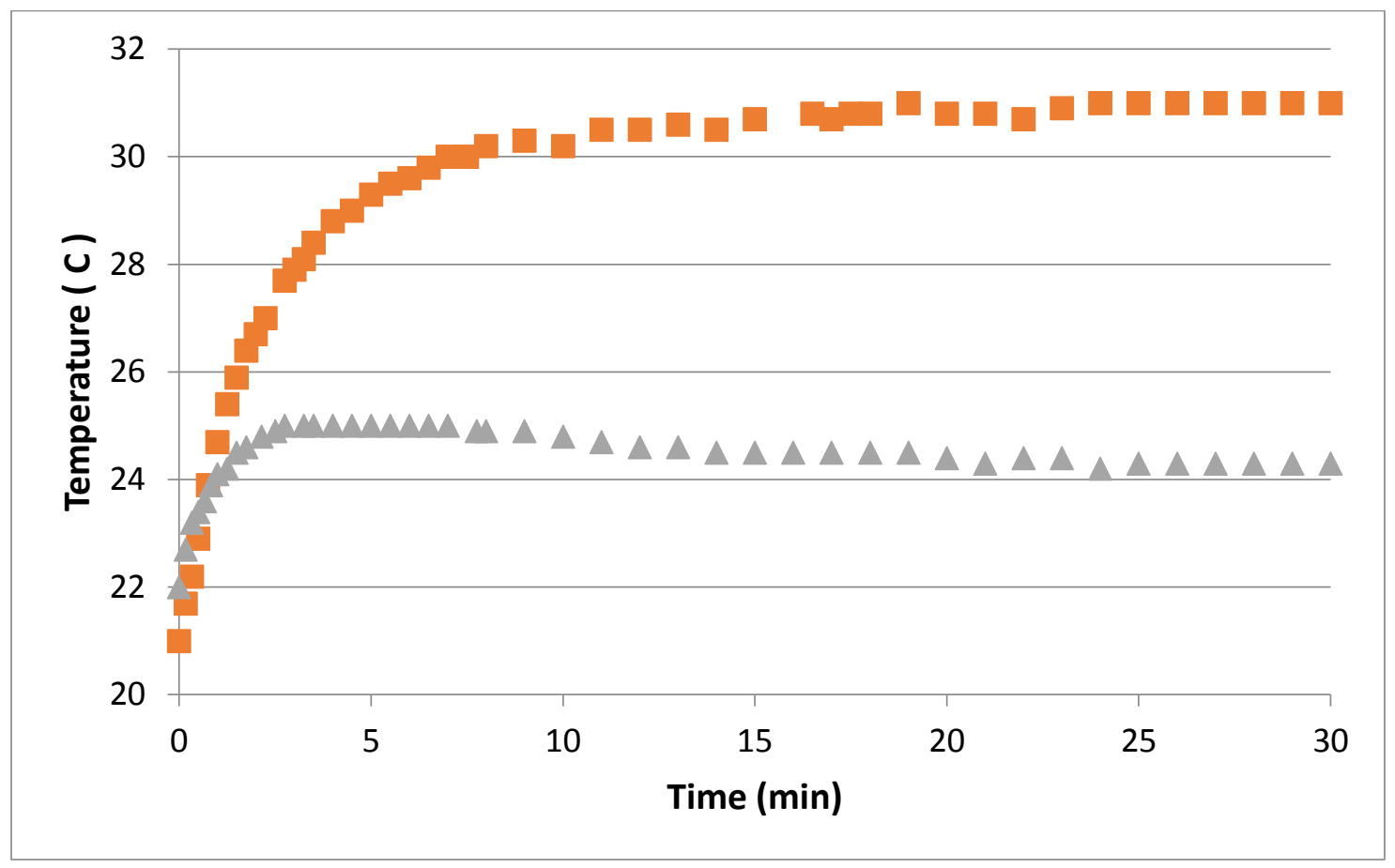

Figure 2.6 Temperature change of a sample during a $\mathbf{3 0}$ minute photolysis. Addition of muffin fan to the sample holder (triangle) decreased the temperature rise relative to the sample without a fan (square). 
An additional mechanical fan was placed to cool the sample. The muffin fan results in a significant decrease in sample temperature rise. Without a fan, the temperature of the sample increased about $10 \mathrm{C}$, while the sample with a cooling accessory reduced the temperature change to $2.3 \mathrm{C}$, which is a $77 \%$ decrease.

\subsection{Instrument Version 4 (final)}

The finalized version of the instrument, which was used to obtain all photolysis data, is shown in Figure 2.7.

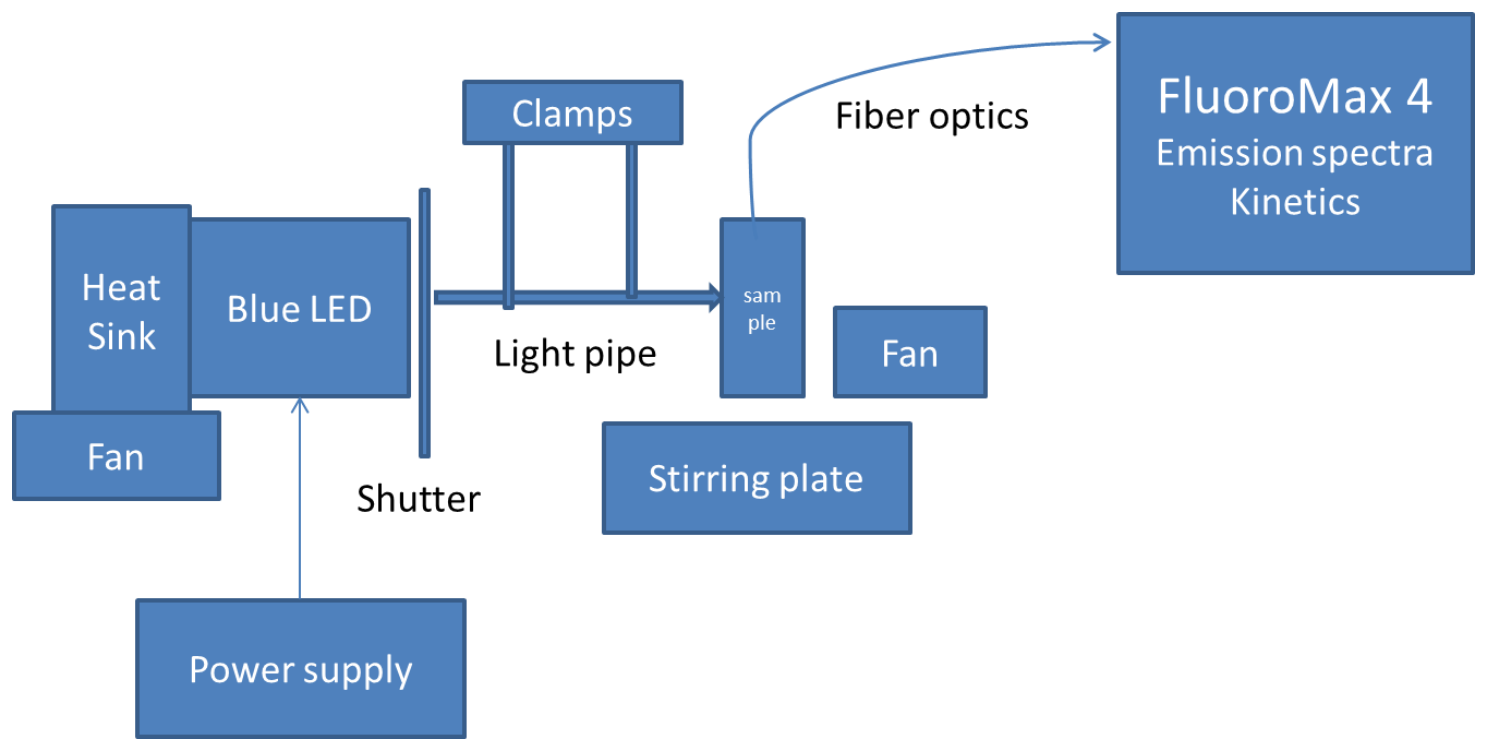

Figure 2.7 Version 4 of instrument. Two clamps hold the light pipe to ensure stability. A shutter was employed to have an exact starting time of photolysis. 
The light pipe was held by two clamps to minimize any alignment changes between different photolysis experiments. A thin aluminum foil was used as a shutter to determine the exact starting time of an experiment. The shutter was placed between the LED and the light pipe. Once the fluorimeter started recording the emission intensity of sample, the shutter was removed to measure the initial intensity and the initial time.

The shutter can be placed either between the LED and the light pipe, or the LED and the sample holder. The shutter was placed between the LED and the light pipe and the light pipe was placed as close as possible to the sample cuvette. This is due to shape of the sample holder. If the shutter was placed between the sample holder and the light pipe, less excitation light is delivered to the sample, because of a larger distance between the cuvette and the light pipe. Also, there is less risk of changing the alignment when the shutter is placed between the sample holder and the light pipe.

Figure 2.8 shows the photolysis experiment with a ruthenium complex by the final version of the instrument. In the center of the figure, the light pipe is shown. The blue light on the left is excitation light from the LED. The orange emission from the ruthenium complex is clearly visible in the cuvette on the right. 


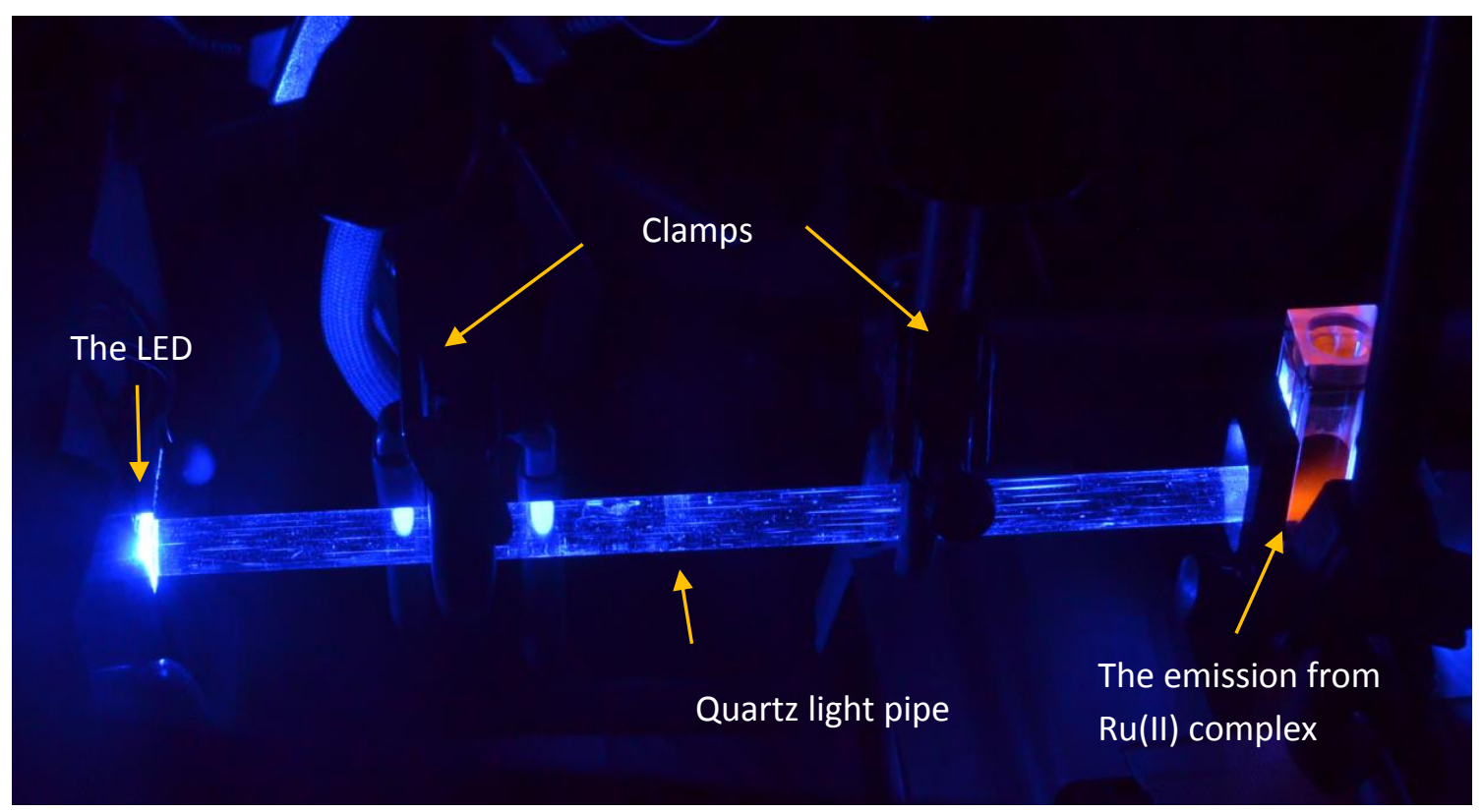

Figure 2.8 A photograph of the instrument showing the LED, the heat sink, the light pipe, the clamps, and a quartz cuvette with a Ru(II) polypyridyl complex being photolyzed. The intense blue light is shown on the left. Orange emission from sample is clearly visible on the right.

\subsection{Power Measurements of the LED}

The Sorensen power supply has an analog meter; however, this was not precise enough. A precision current shunt was employed to measure the exact current supplied to LED. The $20 \mathrm{~A} / 50 \mathrm{mV}$ shunt is manufactured by Murata Power Solutions Inc $^{9}$. The shunt voltage was measured with a multimeter.

The power delivered to the sample was measured by a Scientech laser power meter, $36-0001^{10}$. The maximum power that the meter can measure is $10 \mathrm{~W}$. The analog meter connected to the power meter head did not provide an accurate reading. 
Calibration heat resistance of the meter measured by ohmmeter was $43.0 \Omega$. When direct current is applied to the meter, the power applied to the measure can be calculated from resistance and voltage. The meter has output in $\mathrm{mV}$, and is recorded by a voltmeter. The power applied to the meter and voltage output reading of the meter gives the sensitivity of the meter. The sensitivity measured was $100.19 \mathrm{mV}$ per watts.

Figure 2.9 shows a relationship between current supplied to the LED and the energy of output delivered to the sample. The power measurement matches closely to the Luminus's claim, which is shown in Figure 2.10. Note that the manufacturer only supplies the LED driven current verses luminous flux, which is directly related to the power output. According to Figure 2.10, the power is about $3.2 \mathrm{~W}$ at $5.72 \mathrm{~A}$. However, the power measured by the meter at the sample position at $5.72 \mathrm{~A}$ is $2.3 \mathrm{~W}$. This difference is due to a shutter placed between the LED and the light pipe, and not all of emission from the LED is delivered to the sample.

Two power measurements were taken two months apart. Data shown with circles are the initial power measurement. Both power measurements match one another well, which indicates stability of the instrumental setup and consistency of the LED excitation light delivered to the sample during different photolysis. 


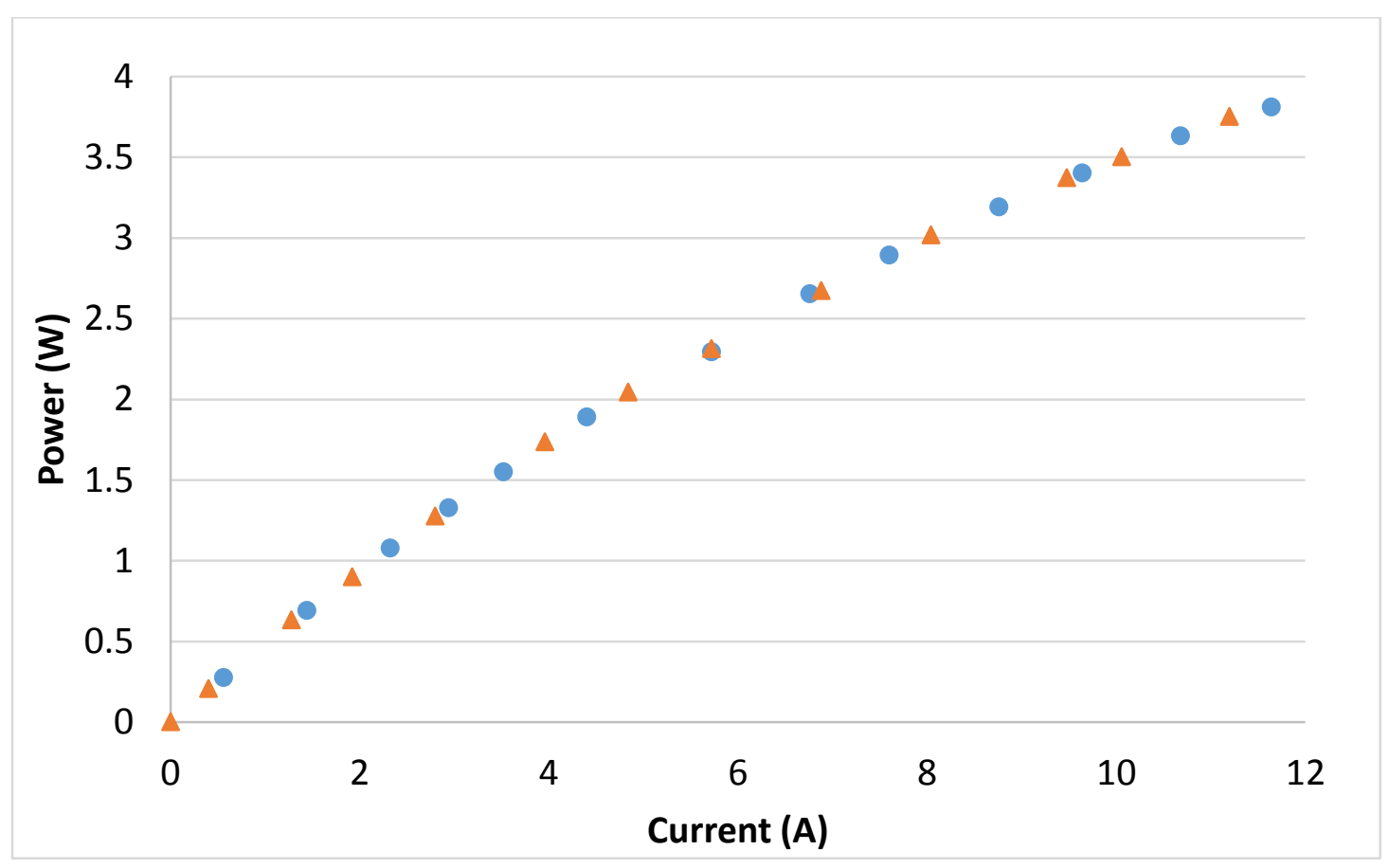

Figure 2.9 The power measurements of the LED in red and blue are taken two months apart. Circle (Sept $3^{\text {rd }}$ 2013) Triangle (Oct $31^{\text {st }}$ 2013)

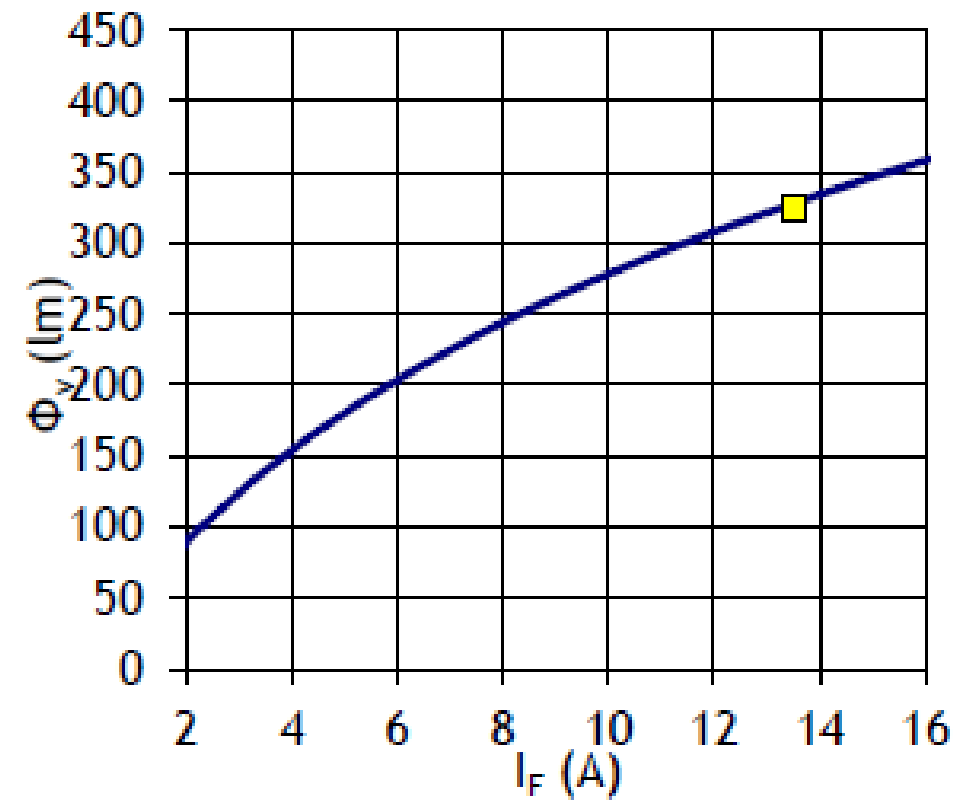

Figure 2.10 The LED manufacturer's information about current supplied to the LED and luminous flux. At 13.5 A, the luminous flux is $350 \mathrm{Im}$ and the power output is $7.5 \mathrm{~W}^{5}$ 


\subsection{Reproducibility of the Instrument}

In order to check the reproducibility of the system, three photolysis trials were run for identical samples. $\mathrm{Ru}(\mathrm{bpy})_{3}{ }^{2+}$ in $\mathrm{H}_{2} \mathrm{O}$ was used to acquire initial emission intensities and the rate of photolysis decay. The experimental data are shown in Table 2.2.

Table 2.2. Photolysis data of $\mathrm{Ru}(\mathrm{bpy}) 3_{3}{ }^{2+}$ at $1.2 \mathrm{ppm}$ to check the reproducibility of the instrument.

\begin{tabular}{cccc}
\hline Ru(bpy $)^{2+}$ & Trial 1 & Trial 2 & Trial 3 \\
\hline Initial intensity (CPS) & 13965 & 13484 & 13841 \\
$\begin{array}{c}\text { Rate of photolysis k } \\
\left(\text { min }^{-1}\right)\end{array}$ & 0.0383 & 0.0397 & 0.0392 \\
\hline
\end{tabular}

The average and relative standard deviation of initial intensity and the rate constants are shown below (Table 2.3). The relative standard deviation on both initial intensity and rate constants obtained by fitting the raw data are less than two percent, which indicates good reproducibility of the measurements. 
Table 2.3. Average and relative standard deviation of initial emission intensities and rate constants, $\mathrm{k}$.

\begin{tabular}{cccccc}
\hline $\begin{array}{c}\text { Average } \\
\text { initial } \\
\text { intensities }\end{array}$ & $\begin{array}{c}\text { Standard } \\
\text { deviation } \\
\text { (CPS) }\end{array}$ & $\begin{array}{c}\text { RSD \% } \\
\text { intensity }\end{array}$ & $\begin{array}{c}\text { Average k } \\
\left(\mathrm{min}^{-1}\right)\end{array}$ & $\begin{array}{c}\text { Standard } \\
\text { deviation } \\
\left(\mathrm{min}^{-1}\right)\end{array}$ & RSD \% k \\
\hline 13763 & 250 & 1.82 & 0.0391 & 0.000682 & 1.74 \\
\hline
\end{tabular}

\subsection{Validation of Accuracy of the Instrument}

Fluorescein isothiocyanate (FITC) in $\mathrm{H}_{2} \mathrm{O}$ was used as a standard to validate the accuracy of photodecomposition yield measurement by the instrument. Figure 2.11 shows a photolysis decay curve of FITC at $0.57 \mathrm{~W}$ of the blue LED. The decay curve was fitted to a single exponential, because the lifetime of photolysis was $3.06 \mathrm{~min}$.

Table 2.4 contains a summary of photolysis data of $8 \mathrm{nM}$ FITC in $\mathrm{H}_{2} \mathrm{O}$. Three photolysis experiments were run at $2.30 \mathrm{~W}$ of LED power, two experiments at $1.15 \mathrm{~W}$, and two experiments at $0.566 \mathrm{~W}$. As the power of the excitation light source increases, the photolysis lifetime decreases as shown in eq. 2.1. FITC data follow the same trend. The lifetime of photolysis is $0.854 \pm 0.022 \mathrm{~min}, 1.574 \pm 0.018 \mathrm{~min}, 3.075 \pm 0.025$ at 2.30 $\mathrm{W}, 1.14 \mathrm{~W}$, and $0.566 \mathrm{~W}$, respectively. The measurements of photolysis lifetime is 
accurate based on low standard deviations within a set of experiments at the same LED power.

When the power of the excitation light source changes, the photodecomposition yield, $\varphi_{d}$, remains constant. $\varphi_{d}$ calculated at different LED powers are consistent as shown in Table 2.4. The average $\varphi_{d}$ for five trials is $1.09 \times 10^{-4}$ with a relative standard deviation of $6 \%$. Literature value ${ }^{11-13}$ of $\varphi_{d}$ for FITC is $1.20 \times 10^{-4}$, which is consistent with experimentally obtained $\varphi_{d}$. Based on $\varphi_{d}$ consistent with literature value, accuracy of measurements by the instrument is confirmed.

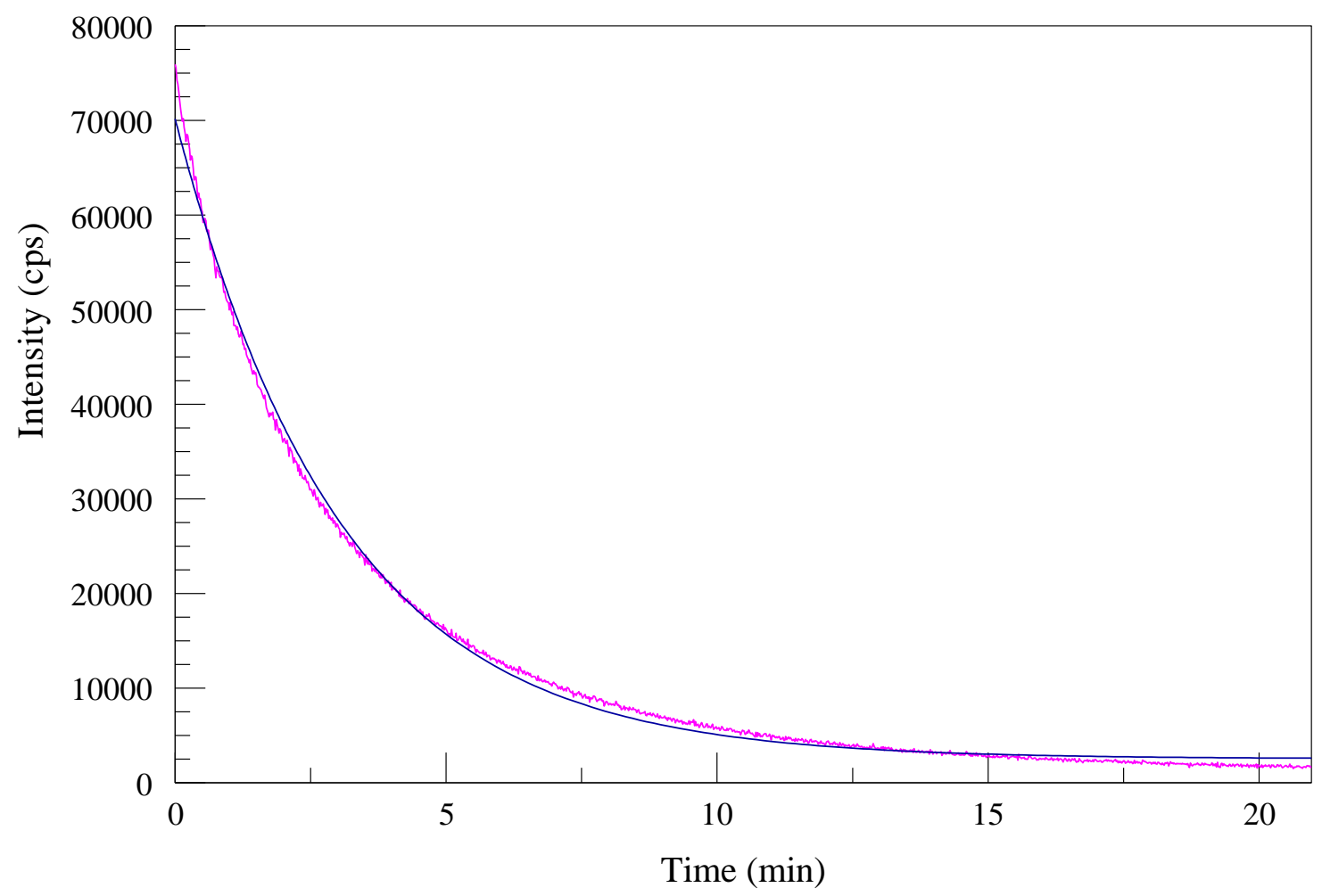

Figure 2.11 Photolysis of $8 \mathrm{nM}$ FITC in $\mathrm{H}_{2} \mathrm{O}$ at $0.57 \mathrm{~W}$ LED power. The lifetime of photolysis is $3.06 \mathrm{~min}$. $\varphi_{d}$ calculated in this run is $1.09 \times 10^{-4}$ compared to literature value of $1.2 \times 10^{-4}$ Experimental data shown in pink and single exponential fit is in dark blue. 
Table 2.4 Photodecomposition yields of fluorescein isothiocyanate in $\mathrm{H}_{2} \mathrm{O}$.

\begin{tabular}{cccccccc}
\hline Power (W) & 2.30 & 2.30 & 2.30 & 1.15 & 1.15 & 0.566 & 0.566 \\
& & & & & & & \\
\hline$\tau(\min )$ & 0.879 & 0.835 & 0.849 & 1.561 & 1.587 & 3.093 & 3.057 \\
$\varphi_{d} \times 10^{4}$ & 0.99 & 1.04 & 1.02 & 1.11 & 1.10 & 1.14 & 1.15 \\
& & & & & & & \\
Avg $\varphi_{d}{ }^{*}$ & & $1.02 \times 10^{-4}$ & & $1.11 \times 10^{-4}$ & $1.15 \times 10^{-4}$ \\
& & & & & & & \\
\hline
\end{tabular}

* Average $\varphi_{d}$ were calculated with sample at the same power of the LED

After validating accuracy of the instrument, photodecomposition yield, $\varphi_{d}$ and photooxidation yield, $\varphi_{\mathrm{O}_{2} 0}$ of selected Ru(II) polypyridyl complexes were measured.

\subsection{Characteristics of the Instrument and Summary of Chapter 2}

The finalized instrument is composed of a blue LED with the peak wavelength at 455nm, a quartz light pipe, a fiber optic for monitoring the emission intensity, a shutter and a fluorimeter. The light pipe efficiently delivers $2.30 \mathrm{~W}$ of blue light to the sample at 5.72 A. Typical photolysis of Ru(II) polypyridyl complexes was run at $5.72 \mathrm{~A}$ at $2.3 \mathrm{~W}$. If more power is required, the LED power can be increased to over $4 \mathrm{~W}$ at higher currents. A rotary fan was attached to the heat sink in order to minimize temperature increase in 
the LED. The sample was stirred by a micro magnetic stirrer as well as being purged by appropriate gas while being photolyzed. Another fan was used to cool the optically dilute sample during photolysis in order to minimize effects of temperature on emission intensity of the luminophore. The emission intensities are delivered to a fluorimeter, FluoroMax 4 by a fiber optics the recorded by the fluorimeter. There are several advantages of this instrument. First, $\varphi_{d}$ of FITC measured by the instrument, $1.09 \times 10^{-4}$ is consistent with literature value of $1.2 \times 10^{-4}$. Second, the instrument measures photodecomposition yield of relatively very stable ruthenium(II) polypyridyl complexes with $\varphi_{d}$ of $10^{-6}$ to $10^{-7}$, in a shorter amount of time, which is usually 25 to 30 minutes. As less than half of the maximum intensity of the LED was used, more stable complexes can be measured at maximum power. Lastly, the instrument has a good reproducibility of less than $2 \%$ relative standard deviation on three consecutive measurements of the identical complex, $\mathrm{Ru}(\text { bpy })_{3}{ }^{2+}$ in $\mathrm{H}_{2} \mathrm{O}$.

The following chapter will discuss how $\varphi_{d}$ of various ruthenium(II) complexes at different oxygen concentrations are calculated from experimentally obtained photolysis decay curves. Also, modeling to calculate photooxidation yield, $\varphi_{\mathrm{O}_{2} \mathrm{O}}$ will be discussed. 


\section{Chapter 2 References}

(1) Soper, S. A.; Nutter, H. L.; Keller, R. A. The Photophysical Constants of Several Fluorescent Dyes Pertaining to Ultrasensitive Fluorescence Sepctroscopy. Photochem. Photobiol. 1993, 57, 972-977.

(2) Bartsch, H.; Eiper, A.; Habiger, K.; Kopelent-Frank, H. Comparison of Analytical Methods for Investigating the Photostability of Isoxicam. J. Chromatogr. A 1999, $846,207-216$.

(3) Pomponio, R.; Gotti, R.; Fiori, J.; Cavrini, V.; Mura, P.; Cirri, M.; Maestrelli, F. Photostability CE Studies on Nicardipine-Cyclodextrin Complexes by Capillary Electrophoresis. J. Pharm. Biomed. Anal. 2004, 35, 267-275.

(4) Megerle, U.; Lechner, R.; Konig, B.; Riedle, E. Laboratory Apparatus for the Accurate, Facile and Rapid Determination of Visible Light Photoreaction Quantum Yields. Photochem. Photobiol. Sci. 2010, 9, 1400-1406.

(5) PT54 LED Product Datasheet; Luminus Devices, Inc: Billerica, MA, 2012; pp. 1-15.

(6) DHS-B9292-04A Heatsink Datasheet; Delta Electronics Corp.: Taipei, Taiwan, 2012; pp. 1-10.

(7) DCS-E 3kW Series DC Power Supplies Operation Manual; AMETEK, Inc.: Berwyn, PA, 2008; pp. 1-94.

(8) FluoroMax ${ }^{\circledR}-4$; Horiba Scientific: Edison NJ; Vol. 44, pp. 2-5.

(9) 50mV and 100mV Base-Mounted DC Shunts; Murata Power Solutions, Inc: Mansfield, MA; pp. 1-4.

(10) Operating Instructions for Model 36-0001; Scientech, Inc.: Boulder, CO; Vol. 80303, pp. 1-5.

(11) Kambara, H.; Nagai, K.; Kawamoto, K. Photodestruction of Fluorophores and Optimum Conditions for Trace DNA Detection by Automated DNA Sequencer. Electrophoresis 1992, 13, 542-546.

(12) Hirschfeld, T. Quantum Efficiency Independence of the Time Integrated Emission from a Fluorescent Molecule. Appl. Opt. 1976, 15, 3135-3139. 
(13) Widengren, J.; Rigler, R. Mechanisms of Photobleaching Investigated by Fluorescence Correlation Spectroscopy. Bioimaging 1996, 4, 149-157. 


\section{Chapter 3 Data Analysis}

\subsection{Introduction}

The basics of luminescence and photolysis and development of an instrument were discussed in chapter 1 and 2 respectively. The finalized instrument records changes of emission intensity as a luminophore is photolyzed. Because the photodecomposed products are non-emissive and the sample is optically dilute, changes in emission intensity are directly proportional to the concentration of a luminophore.

In this chapter, detailed data analysis which requires several steps are explained. The experimentally obtained photolysis decay curve was fitted to obtain the rate of photolysis and Stern-Volmer (SV) quenching constant. The rate of photolysis then is used to calculate photodecomposition yield, $\varphi_{d}$, at different oxygen concentrations. $\varphi_{d}$ at different oxygen concentrations is then used to calculated photooxidation yield, $\varphi_{\mathrm{O}_{2} \mathrm{O}}$, which is the photodecomposition yield when $100 \%$ of excited state is quenched by oxygen. In this chapter, data for $\mathrm{Ru}(\text { phen })_{3}{ }^{2+}$ in $\mathrm{H}_{2} \mathrm{O}$ are used as an example to illustrate a general data fitting routine, which is applied to all other complexes. 


\subsection{Fitting of Photolysis Decay Curve}

The photolysis decay curve in the absence of acid is fitted to a double exponential equation:

$$
D(t)=A_{1} e^{-t / \tau_{1}}+A_{2} e^{-t / \tau_{2}}
$$

where $A_{1}$ and $A_{2}$ are pre-exponential factors giving the contribution of each decay lifetime. $\tau_{1}$ and $\tau_{2}$ are lifetimes for photolysis decay.

In a typical decay, there are two different lifetimes. The main longer lifetime component which is related to the larger pre-exponential factor is the lifetime for photodecomposition. The minor short lifetime is caused by the temperature elevation of sample due to excitation light source ${ }^{1}$. An increase in temperature causes a decrease in emission intensity independent of the photolysis. Two pieces of evidences support the contention that the short lived component is due to temperature rise on the sample. First, the minor lifetime is usually 2 minutes and matches closely the temperature rise measured with the thermocouple, which is usually 2-3 minutes. Furthermore, addition of a rotary fan to cool the sample holder, which decreased the temperature rise from $21 \mathrm{C}$ to $31 \mathrm{C}$ during photolysis, reduced the temperature rise from $22 \mathrm{C}$ to $24.3 \mathrm{C}$. The contribution of the short-lived component also decreased from $10-20 \%$ without the fan to $1-5 \%$ with respect to that with a fan. 
The long lived decay lifetime is converted to a rate constant of photolysis. A rate constant is an inverse of lifetime as shown in eq. 3.2.

$$
\mathrm{k}_{1}=\frac{1}{\tau_{1}}
$$

where $\mathrm{k}_{1}$ is a rate constant of photolysis and $\tau_{1}$ is a lifetime of photolysis. This rate constant of photolysis is used to obtain $\varphi_{d}$.

Figure 3.1 shows typical photolysis data obtained by the instrument. This decay curve is fitted to eq. 3.1 by PSIplot version 9.5 using nonlinear least squares to generate the fitting line which is shown in dark blue in Figure 3.2.

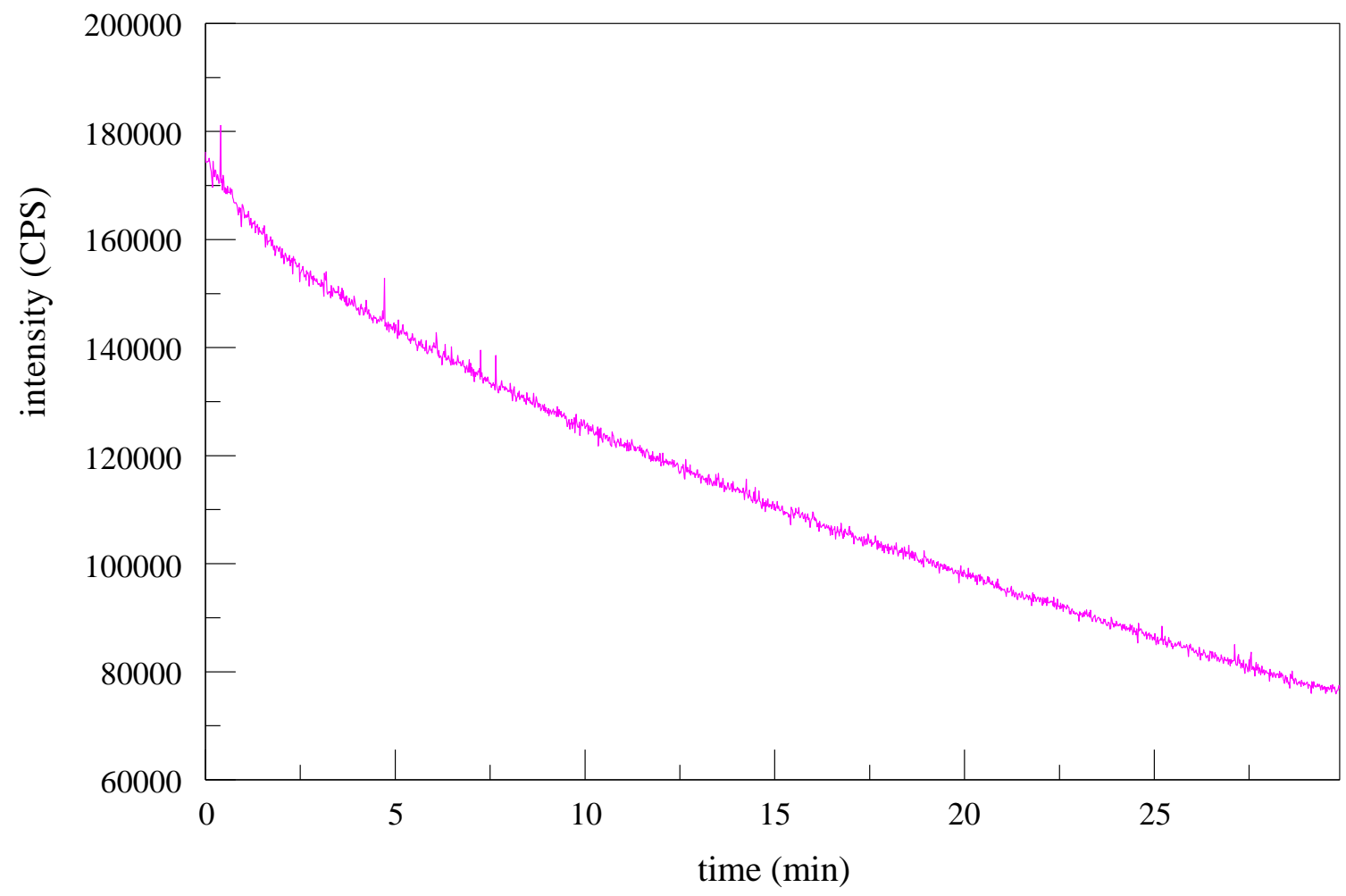

Figure 3.1 Photolysis decay curve for the emission of $\mathrm{Ru}(\mathrm{phen})_{3}{ }^{2+}$ in $\mathrm{H}_{2} \mathrm{O}$ under $\mathrm{N}_{2}$. Emission intensity was monitored at $595 \mathrm{~nm}$. 


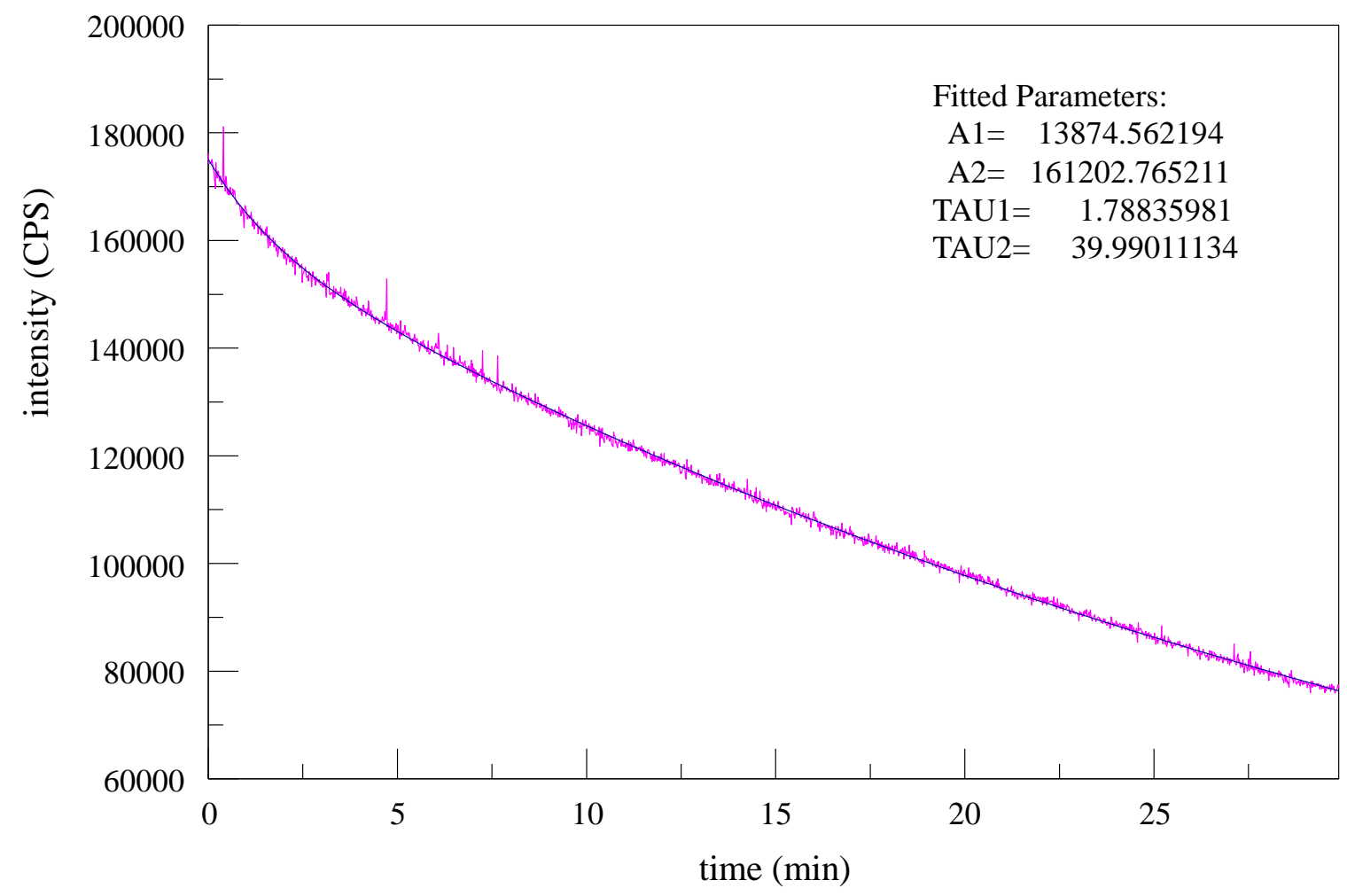

Figure 3.2 Photolysis decay curve of $\mathrm{Ru}(\mathrm{phen})_{3}{ }^{2+}$ in $\mathrm{H}_{2} \mathrm{O}$ under $\mathrm{N}_{2}$. After 30 minutes of experiment, the emission intensity was decreased to $55 \%$ of the initial value. The nonlinear least squares fitting line is shown in dark blue.

The same fitting routine was applied to all of photolysis data. The lifetime of photolysis of Ru(II) polypyridyl complexes investigated ranged from 4 minutes to 130 minutes. 


\subsection{Stern-Volmer Quenching Plot}

As mentioned in the earlier chapter, excited luminophores can relax back to the singlet ground state without emitting photons when energy is transferring to a quencher. In this study, oxygen as a quencher of Ru(II) polypyridyl complexes was investigated. The concentration of a quencher is related to experimentally measurable quantities. The Stern-Volmer (SV) equation describes the relationship between those two.

$$
\frac{I_{0}}{I}=1+K_{s v}[Q]
$$

where $I_{0}$ and $I$ are emission intensities in the absence of a quencher and in the presence of a quencher respectively. $K_{S v}$ is the SV quenching constant and $[Q]$ is a concentration of the quencher.

The SV data were taken from the photolysis experiments rather than a separate measurement on a fluorimeter. This had the advantage of providing sufficient data to calculate two different types of parameters with one experiment. The very first point when the photolysis started was used to plot this SV plot. Figure 3.3 shows a typical oxygen quenching plot generated from photolysis decay curves. The example used is $\mathrm{Ru}(\text { phen })_{3}{ }^{2+}$ in $\mathrm{H}_{2} \mathrm{O}$. The $K_{S v}$ obtained from the SV quenching plot is $4.46 \mathrm{~atm}^{-1}$. 
The fraction quenched or $f_{Q}$ is given by

$$
f_{Q}=1-\frac{I}{I_{0}}
$$

I is the initial intensities of each photolysis decay curves are used to generate $f_{Q}$ as shown in eq. 3.4. $f_{Q}$ was then used to calculate photooxidation yield, $\varphi_{O_{2} 0}$, from photodecomposition yields, $\varphi_{d}$.

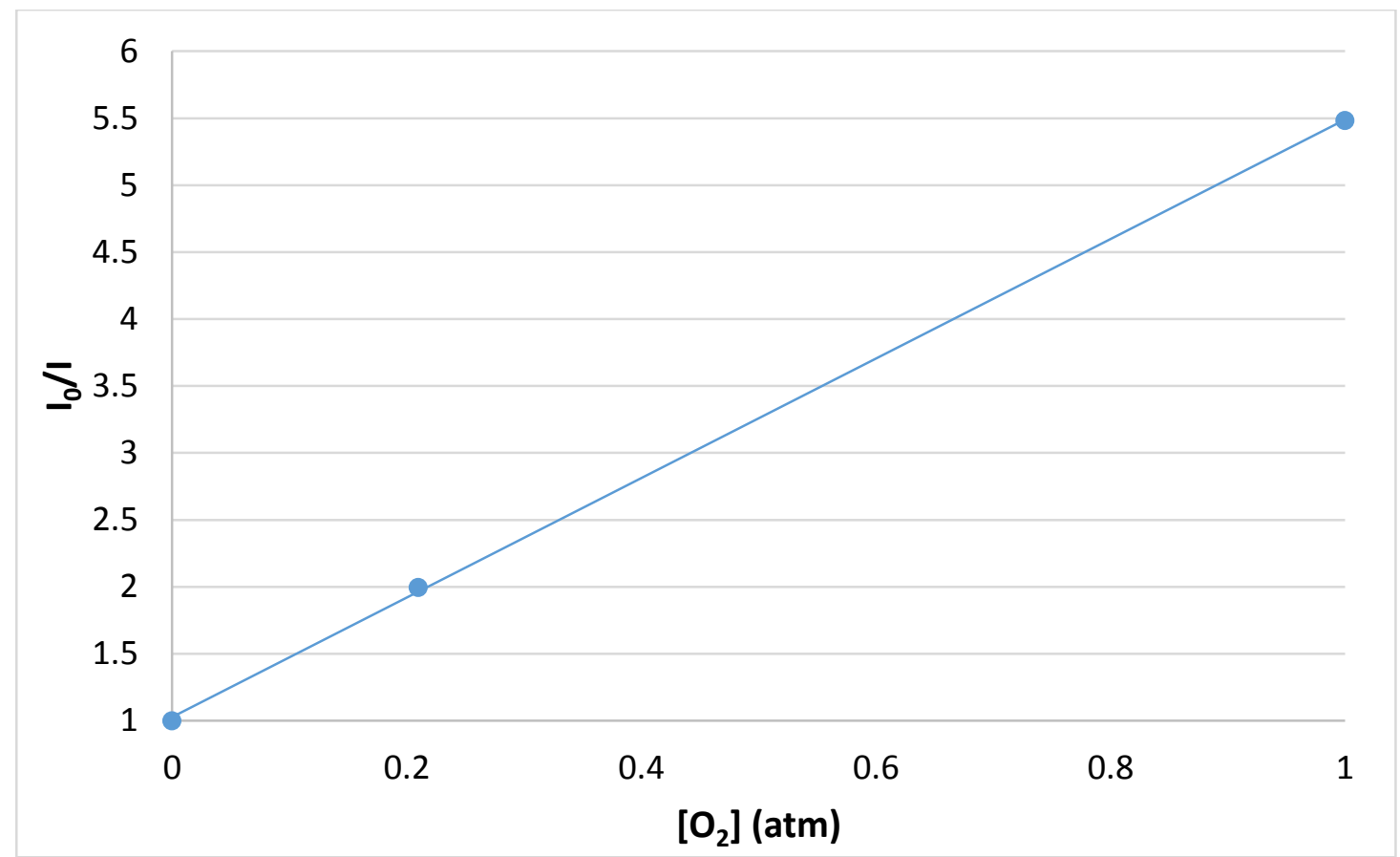

Figure 3.3 Stern-Volmer plot of $\mathrm{Ru}(\text { phen })_{3}{ }^{2+}$ in $\mathrm{H}_{2} \mathrm{O} . \mathrm{X}$ axis is atmospheric oxygen pressure. The best fit line is $y=4.46 x+1.03$ with $R^{2}$ of 0.9998 . 


\subsection{Photodecomposition Yield Calculation}

Initial fitting of photolysis decays to obtain rate constants of photolysis were

discussed in chapter 3.2. Once the rate constants for photodecomposition are obtained, the photodecomposition yield, $\varphi_{d}$, is calculated using

$$
\varphi_{d}=\frac{\mathrm{kV}}{2.303 i_{0} \varepsilon L}
$$

where, $\mathrm{k}$ is the rate constant, $\varphi_{d}$ is photodecomposition yield, $i_{0}$ is intensity of excitation light source in einsteins per second, $\varepsilon$ is molar absorptivity, $L$ is light path length in the sample, and $V$ is the volume of the sample. $L$ was $1 \mathrm{~cm}$ in all experiments. $V$ is in liters.

However, equation 3.5 cannot be used as is. The equation assumes monochromatic light; however, the LED has an emission profile over a range unlike a monochromatic laser. The analysis needs to take into account this distribution. $\bar{\varepsilon}$ is defined as an effective molar absorptivity of the sample over the LED emission profile which can be calculated by eq. 3.6.

$$
\bar{\varepsilon}=\frac{\int \varepsilon_{\lambda} I_{\lambda} d \lambda}{\int I_{\lambda} d \lambda}
$$

By substituting $\varepsilon$ with $\bar{\varepsilon}$ to eq. 3.5

$$
\varphi_{d}=\frac{\mathrm{kV}}{2.303 i_{0} \bar{\varepsilon} L}
$$


This equation 3.7 is used to calculate all of $\varphi_{d}$ unless otherwise noted.

Figure 3.4 shows the proposed mechanism for photodecomposition of luminescent complexes including the effects of oxygen in the photodecomposition of the luminophore. An excited luminophore can follow one of the following paths. An excited luminophore can relax back to the singlet ground state by emitting a photon or by radiationless decay (path 1). Secondly, the excited molecule can be quenched by oxygen and generate a singlet oxygen. The singlet oxygen can react with the luminophore and generate a non-luminescent oxygenated species (path 2). Thirdly, the complex can dissociate and one or more coordination sites on the center transition metal of the luminophore can be coordinated with a solvent molecule producing a nonluminescent solvated product (path 3).

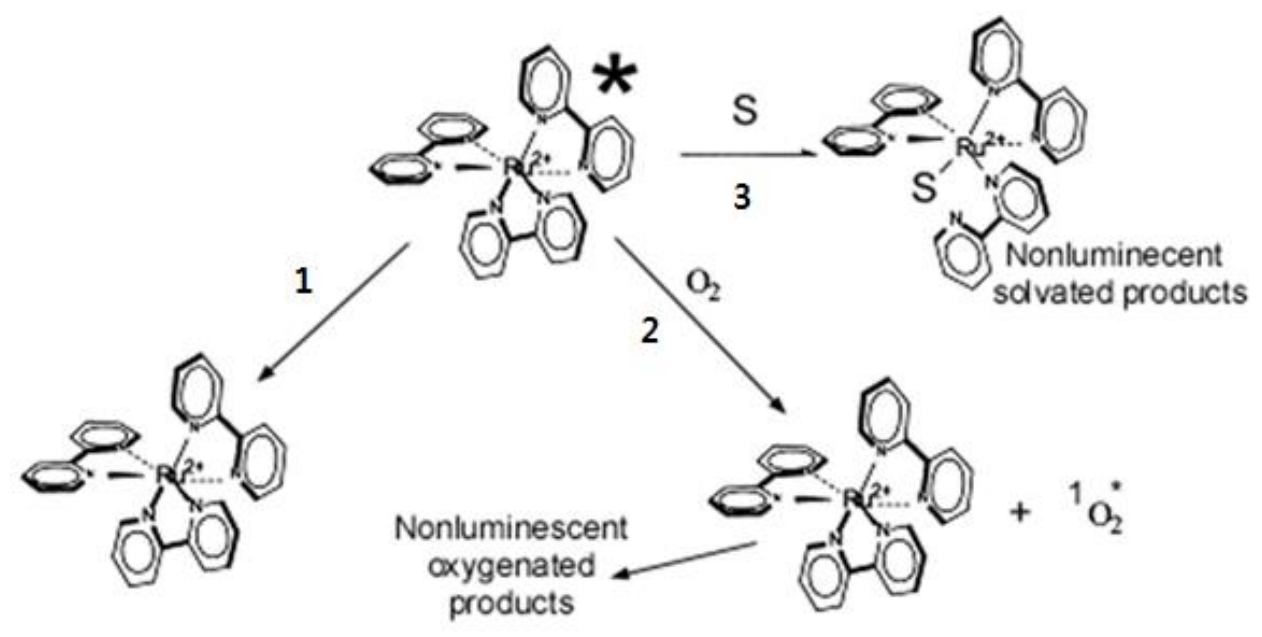

Figure 3.4 Effects of oxygen in photochemistry. $\mathrm{Ru}(\mathrm{bpy}) \mathrm{3}^{2+}$ is used to illustrate possible paths of the excited state molecule. 
Once $\varphi_{d}$ is calculated at different oxygen concentrations, these values are used to calculate the photooxidation yield, $\varphi_{\mathrm{O}_{2} 0}$, which is the photodecomposition yield when the excited state is totally quenched by oxygen.

Several terms must be defined to obtain $\varphi_{\mathrm{O}_{2} 0}$. Equation 3.8 shows a relationship between $\varphi_{\mathrm{O}_{2}}$ and $\varphi_{\mathrm{O}_{2} \mathrm{O}}$.

$$
\varphi_{O_{2}}=\varphi_{O_{2} 0} f_{Q}
$$

where $\varphi_{\mathrm{O}_{2}}$ is an experimentally measured photodecomposition yield at various oxygen concentrations and $\varphi_{\mathrm{O}_{2} 0}$ is the photooxidation yield. The fraction quenched $f_{Q}$ was defined in eq. 3.4.

Lastly $\varphi_{\text {total }}$ is related to $\varphi_{N_{2} 0}$, which is the photodecomposition yield in the absence of oxygen and $\varphi_{\mathrm{O}_{2}}$ (eq. 3.9). Under nitrogen saturation, $f_{Q}$ is zero, thus $\varphi_{\text {total }}=\varphi_{N_{2} 0}$. When the excited state molecules are totally quenched, $\varphi_{\text {total }}=\varphi_{O_{2} 0}$.

$$
\varphi_{\text {total }}=\varphi_{N_{2} 0}\left(1-f_{Q}\right)+\varphi_{O_{2} 0} f_{Q}
$$

The equation can be rearranged as follows,

$$
\varphi_{\text {total }}=\varphi_{N_{2} 0}+f_{Q}\left(\varphi_{O_{2} 0}-\varphi_{N_{2} 0}\right)
$$

As all variables except $\varphi_{\mathrm{O}_{2} \mathrm{O}}$ are experimentally determined, $\varphi_{\mathrm{O}_{2} 0}$ can be determined by plotting $\varphi_{\text {total }}$ vs. $f_{Q}$. Figure 3.5 shows typical data fitted by eq. 3.10 . In the plot, $\varphi_{\mathrm{O}_{2} 0}$ is equal to the sum of the slope and $\varphi_{N_{2} 0}$. Or, $\varphi_{O_{2} 0}$ is the $\mathrm{x}$ intercept of 
the best fit linear regression line. The slope is $-3.76 \times 10^{-6}$ and $\mathrm{x}$ intercept is $2.80 \times 10^{-7}$ Table 3.1 contains different $\varphi_{d}$ at various $f_{Q}$ of $\mathrm{Ru}(\text { phen })_{3}{ }^{2+}$ in $\mathrm{H}_{2} \mathrm{O}$.

Table 3.1. Photodecomposition yield of $\mathrm{Ru}(\text { phen })_{3}{ }^{2+}$ in $\mathrm{H}_{2} \mathrm{O}$

$\begin{array}{lllll}f_{Q} & 0 & 0.50 & 0.82 & 1^{*} \\ \varphi_{d} & 3.98 \times 10^{-6} & 2.33 \times 10^{-6} & 8.69 \times 10^{-7} & 2.80 \times 10^{-7}\end{array}$

* Calculated from eq. 3.10 with $f_{Q}=1$. It is limited photooxidation yield when $100 \%$ of excited state is quenched by oxygen.

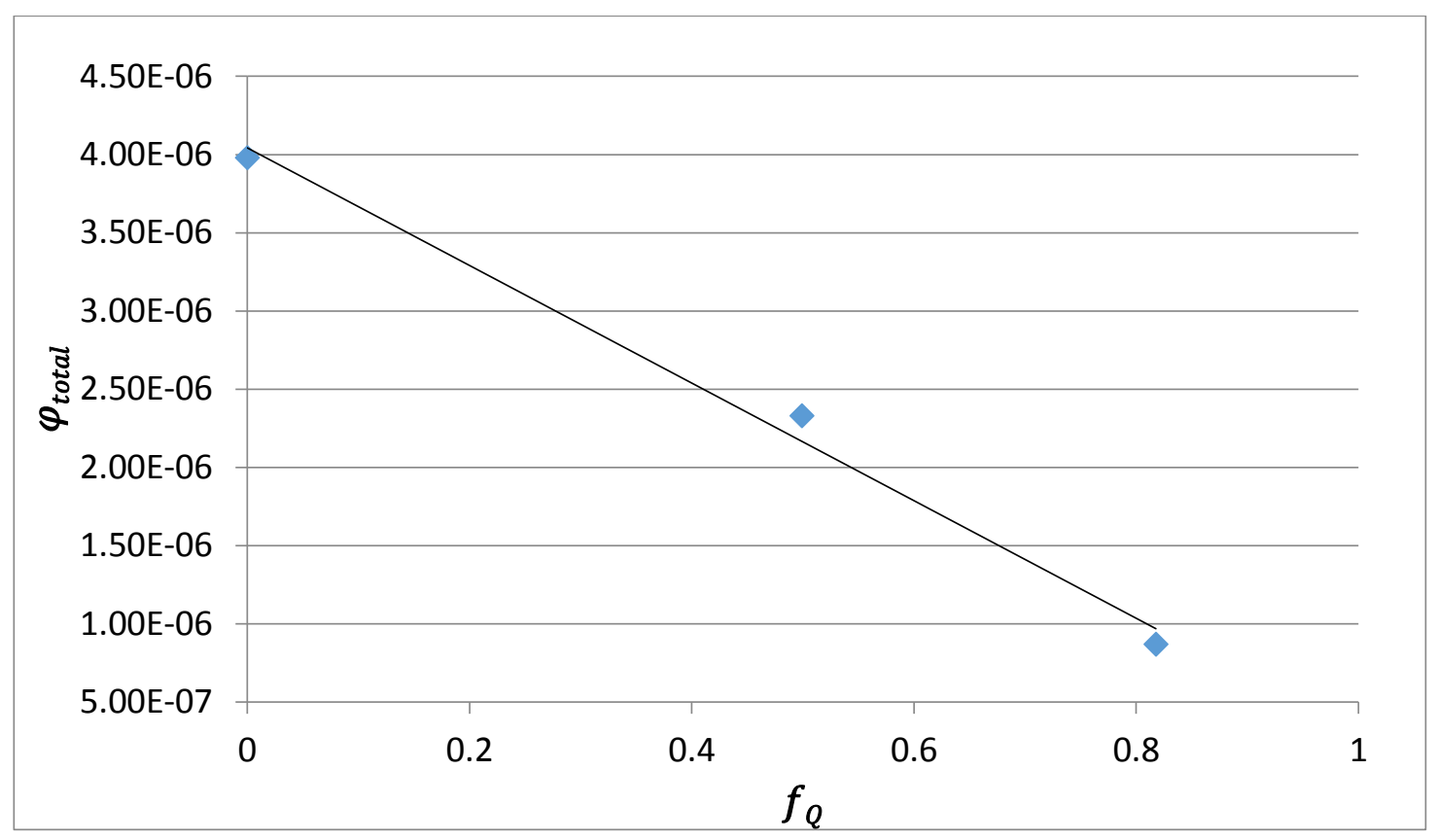

Figure 3.5 Plot of $f_{Q}$ vs. $\phi$ (total) of $\mathrm{Ru}(\text { phen })_{3}{ }^{2+}$ in $\mathrm{H}_{2} \mathrm{O}$. The slope is $-3.76 \times 10^{-6}$ and $\mathrm{R}^{2}=0.992$ 


\subsection{Summary of Chapter 3}

In this chapter, the data fitting procedure has been discussed. Data processing includes a Stern-Volmer oxygen quenching plot, calculation of rate constants from experimentally obtain photolysis decay curves, and calculation of different $\varphi_{d}$ at various $f_{Q}$ based on the model (eq. 3.10). This data analysis routine will be applied to all data unless otherwise noted. The subsequent chapter will describe $\varphi_{d}$ of various $\mathrm{Ru}(\mathrm{II})$ polypyridyl complexes in acids and $\mathrm{H}_{2} \mathrm{O} . \varphi_{d}$ and $\varphi_{\mathrm{O}_{2} 0}$ range from $10^{-5}$ to $10^{-7}$. Ligand structures and trends of $\varphi_{d}$ and $\varphi_{O_{2} 0}$ of Ru(II) polypyridyl complexes will be also discussed. 


\section{Chapter 3 References}

(1) Dressick, W. J.; Cline, J.; Demas, J. N.; DeGraff, B. A. Energy Degradation Pathways and Binding Site Environment of Micelle Bound ruthenium(II) Photosensitizers. J. Am. Chem. Soc. 1986, 108, 7567-7574.

(2) Demas, J. N.; Adamson, A. W. Tris (2,2'-Bipyridine) ruthenium(II) Senstized Reactions of Some Oxalato Complexes. J. Am. Chem. Soc. 1973, 95, 5159-5168.

(3) Mathies, R.; Oseroff, a R.; Stryer, L. Rapid-Flow Resonance Raman Spectroscopy of Photolabile Molecules: Rhodopsin and Isorhodopsin. Proc. Natl. Acad. Sci. U. S. A. 1976, 73, 1-5.

(4) Peck, K.; Stryer, L.; Glazer, A.; Mathies, R. Single-Molecule Fluorescence Detection : Autocorrelation Criterion and Experimental Realization with Phycoerythrin. Proc. Natl. Acad. Sci. U. S. A. 1989, 86, 4087-4091. 


\section{Chapter 4 Photolysis Experimental Data and Results}

\subsection{Introduction}

As previously described luminescent complexes are widely used as an analytical sensors. When used as a probe, the photostability of a luminophore is important to validate the accuracy of measurements. An instrument was developed to efficiently measure quantitative photostability. The instrument is composed of a blue LED, a light pipe, a fluorimeter, and several cooling accessories. Accuracy of the photolysis measurements by the instrument was confirmed with Fluorescein isothiocyanate (FITC) in $\mathrm{H}_{2} \mathrm{O}$. This chapter discusses the photolysis data of $\mathrm{Ru}(\mathrm{II})$ polypyridyl complexes in aqueous environments. Experimental data were fitted to the equations discussed in the chapter 3. Photodecomposition yield, $\varphi_{d}$, and photooxidation yield, $\varphi_{O_{2} 0}=$, of these complexes are measured in $\mathrm{H}_{2} \mathrm{O}$. Later in this chapter photolysis of $\mathrm{Ru}(\mathrm{II})$ polypyridyl complexes under acidic conditions will be discussed.

\subsection{Data fitting summary}

Emission intensity of optically dilute luminescent complexes are directly proportional to the concentration of emissive luminophores. By monitoring emission 
intensity changes during photodecomposition of luminophore, photodecomposition yield can be obtained. Equation 4.1 shows the equations used to fit photolysis decay.

$$
D(t)=A_{1} e^{-t / \tau_{1}}+A_{2} e^{-t / \tau_{2}}
$$

where $A_{1}$ and $A_{2}$ are pre-exponential factors giving the contribution of each decay lifetime. $\tau_{1}$ and $\tau_{2}$ are lifetimes for photolysis decay. There are two lifetimes of decay in the system. A longer lifetime is the photolysis decay lifetime and the other is due to the temperature rise in the sample during photolysis.

The photolysis lifetime is converted to the rate constant of the photolysis. The rate constant is inversely proportional to the lifetime (eq. 4.2)

$$
\mathrm{k}_{1}=\frac{1}{\tau_{1}}
$$

where $k_{1}$ is a rate constant of photolysis and $\tau_{1}$ is a lifetime of photolysis. This rate constant was used to calculate photodecomposition yields.

Equation 4.3 was used to calculate photodecomposition yield, $\varphi_{d}$

$$
\varphi_{d}=\frac{\mathrm{k} \mathrm{V}}{2.303 i_{0} \bar{\varepsilon} L}
$$

where, $\mathrm{k}$ is the rate constant, $\varphi_{d}$ is photodecomposition yield, $i_{0}$ is intensity of excitation light source in einsteins per second, $\bar{\varepsilon}$ is an effective molar absorptivity of the sample over the LED emission profile, $L$ is light path length in the sample, and $V$ is the 
volume of the sample. $L$ was constant in all experiments as $1 \mathrm{~cm}$. Volume in the equation is expressed in liters.

Calculated $\varphi_{d}$ at different oxygen concentrations are used to obtain photooxidation yield, $\varphi_{\mathrm{O}_{2} 0}$ (eq. 4.4)

$$
\varphi_{\text {total }}=\varphi_{N_{2} 0}+f_{Q}\left(\varphi_{O_{2} 0}-\varphi_{N_{2} 0}\right)
$$

where $\varphi_{\text {total }}$ is photodecomposition yield, $\varphi_{N_{2} 0}$ is the photodecomposition yield in the absence of oxygen, $\varphi_{\mathrm{O}_{2} 0}$ is photooxidation yield, and $f_{Q}$ is the fraction quenched. As all variables except $\varphi_{O_{2} 0}$ are experimentally determined, $\varphi_{O_{2} 0}$ can be determined by plotting $\varphi_{\text {total }}$ vs. $f_{Q} \cdot \varphi_{O_{2} 0}$ is equal to the sum of the slope and $\varphi_{N_{2} 0}$. Or, it is the $\mathrm{x}$ intercept of the best fit linear regression line.

\subsection{Selected $\mathrm{Ru}(\mathrm{II})$ polypyridyl Complexes in $\mathrm{H}_{2} \mathrm{O}$}

Photodecomposition yields, $\varphi_{d}$, are not limiting yields and photooxidation yield, $\varphi_{\mathrm{O}_{2} 0}$, of selected $\mathrm{Ru}(\mathrm{II})$ polypyridyl complexes in $\mathrm{H}_{2} \mathrm{O}$ were measured. Photolysis was conducted with the sample purged with nitrogen, air, and oxygen gas. The Stern-Volmer (SV) quenching plot generated for each complex was linear. As the emission maximum is around $600 \mathrm{~nm}$ in many Ru(II) polypyridyl complexes, emission intensity changes during photolysis were recorded at $595 \mathrm{~nm}$. The photolysis decay curves were fitted to eq. 4.1 
in order to obtain the main longer lifetime of photolysis. The lifetime was converted to a rate constant by eq. 4.2. The rate constant of each photolysis was then used to obtain photodecomposition yields, $\varphi_{d}$, at various oxygen concentrations (eq. 4.3 ). When an effective molar absorptivity, $\bar{\varepsilon}$, is calculated, the concentration of sample is calculated by a known molar absorptivity in the available ${ }^{1}$ literature. Photodecomposition yield, $\varphi_{d}$, is used in eq. 4.4 to obtain the photooxidation yield, $\varphi_{\mathrm{O}_{2} 0}$.

To understand photodecomposition and photooxidation yields, different processes that a luminophore can take during a photolysis are examined in (eq. 4.5 to 4.8).

$$
\begin{gathered}
D^{*} \rightarrow D+h v \text { or } \Delta \\
D^{*} \rightarrow P \\
D^{*}+O_{2} \rightarrow D+O_{2}{ }^{1} \\
O_{2}{ }^{1}+D \rightarrow D O_{2}
\end{gathered}
$$

where $D$ and $D^{*}$ are a ground state and an excite states species, $\Delta$ is heat, $P$ is a product, $\mathrm{O}_{2}$ is a triplet oxygen, $\mathrm{O}_{2}{ }^{1}$ is a singlet oxygen, and $\mathrm{DO}_{2}$ is oxygenated species. In the case of $\mathrm{Ru}(\mathrm{II})$ inorganic complexes, the photolysis product is often one where the ligands replaced by a solvent molecule or a photosolvation ${ }^{2}$. This photolysis product such as $\mathrm{RuL}_{2} \mathrm{~S}_{2}$ are non-emissive. 
When a Ru(II) complex is photolyzed under $0 \%$ oxygen, only photodecomposition occurs (eq. 4.6). In the presence of oxygen, the photolysis processes become more complicated. The excited state luminophore can be quenched by oxygen and generate singlet oxygen species by energy transfer (eq. 4.7). This reduces the probability of photosolvation by reducing number of excited state luminophores. The singlet oxygen can react with a luminophore and generate a product by photooxidation (eq.4.8).

Table 4.2 contains $\varphi_{d}$ and $\varphi_{O_{2} 0}$ of various Ru(II) complexes. As previous studies reported $\varphi_{d}$ of $\mathrm{Ru}(\mathrm{II})$ polypyridyl complexes range from $10^{-5}$ to $10^{-7}$. A smaller value of $\varphi_{N_{2} 0}$ and $\varphi_{O_{2} 0}$ indicate that the complex is photostable compared to a compound with a larger value of $\varphi_{\mathrm{N}_{2} \mathrm{O}}$ and $\varphi_{\mathrm{O}_{2} \mathrm{O}}$.

Table 4.2 Summary of photodecomposition and photooxidation yields of selected $\mathrm{Ru}(\mathrm{II})$ polypyridyl complexes

\begin{tabular}{llcc}
\hline & Complexes & $\varphi_{N_{2} 0 \times 10^{6}}$ & $\varphi_{O_{2} 0 \times 10^{6}}$ \\
\hline $\mathbf{1}$ & $\mathrm{Ru}(\text { bpy })_{3}^{2+a}$ & 10.80 & 1.77 \\
$\mathbf{1}$ & $\mathrm{Ru}(\text { bpy })_{3}^{2+b}$ & 9.89 & 2.13 \\
$\mathbf{2}$ & $\mathrm{Ru}(\text { phen })_{3}{ }^{2+}$ & 3.98 & 0.28 \\
$\mathbf{3}$ & $\mathrm{Ru}\left[3,4,7,8-\left(\mathrm{CH}_{3}\right)_{4} \text { phen }\right]_{3}{ }^{2+}$ & 32.78 & 22.2 \\
$\mathbf{4}$ & $\mathrm{Ru}[5-\mathrm{Cl}(\text { phen })]_{3}{ }^{2+}$ & 3.88 & 0.48 \\
$\mathbf{5}$ & $\mathrm{Ru}\left[4,4^{\prime}-(\mathrm{CH})_{2} \mathrm{bpy}_{3}{ }^{2+}\right.$ & 5.80 & 4.07 \\
$\mathbf{6}$ & $\mathrm{Ru}\left[(\text { phen })(\text { bpy })_{2}\right]^{2+}$ & 12.94 & 2.90
\end{tabular}


$7 \mathrm{Ru}\left[5-\mathrm{Cl}(\text { phen)(bpy) })^{2+}\right.$

$8 \mathrm{Ru}\left[5-\mathrm{COOCH}_{3}(\text { phen })\right]_{3}{ }^{2+}$

$9 \mathrm{Ru}\left[4,7-\left(\mathrm{C}_{6} \mathrm{H}_{5}\right)_{2} \text { phen }\right]_{3}^{2+}$
13.95

3.53

2.33
3.85

0.87

0.51

${ }^{\mathrm{a}}$ and ${ }^{\mathrm{b}}$ are the same complex at $1.2 \mathrm{ppm}$ and at $15 \mathrm{ppm}$ respectively.

Based on eq. 4.3, $\varphi_{d}$ is independent of concentration of a luminophore. This is experimentally confirmed by $\mathrm{Ru}(\mathrm{bpy})_{3}{ }^{2+}$ in Table 4.2. $\varphi_{\mathrm{N}_{2} 0}$ and $\varphi_{\mathrm{O}_{2} 0}$ of $\mathrm{Ru}(\mathrm{bpy})_{3}{ }^{2+}$ at $1.2 \mathrm{ppm}$ are $1.08 \times 10^{-5}$ and $1.77 \times 10^{-6}$ respectively. $\varphi_{N_{2} 0}$ and $\varphi_{O_{2} 0}$ of $\mathrm{Ru}(\mathrm{bpy})_{3}{ }^{2+}$ at $15 \mathrm{ppm}$ are $9.89 \times 10^{-6}$ and $2.13 \times 10^{-6}$ respectively. Average $\varphi_{N_{2} 0}$ of $\mathrm{Ru}(\mathrm{bpy})_{3}{ }^{2+}$ is $1.03 \times 10^{-5} \pm$ $0.06 \times 10^{-5}$ and average $\varphi_{O_{2} 0}$ is $1.95 \times 10^{-6} \pm 0.25 \times 10^{-6}$.

A spectrochemical series of photodecomposition yield, $\varphi_{N_{2} 0}$ is listed below.

$\mathrm{Ru}\left[3,4,7,8-\left(\mathrm{CH}_{3}\right)_{4}\right.$ phen $_{3}{ }^{2+}>\mathrm{Ru}\left[5-\mathrm{Cl}(\text { phen })(\mathrm{bpy})_{2}\right]^{2+} \approx \mathrm{Ru}\left[(\text { phen })(\mathrm{bpy})_{2}\right]^{2+}, \mathrm{Ru}(\mathrm{bpy})_{3}{ }^{2+}>$ $\mathrm{Ru}\left[4,4^{\prime}-\left(\mathrm{CH}_{3}\right)_{2} \mathrm{bpy}\right]_{3}{ }^{2+}>\mathrm{Ru}(\text { phen })_{3}{ }^{2+} \approx \mathrm{Ru}[5-\mathrm{Cl}(\text { phen })]_{3}{ }^{2+} \approx \mathrm{Ru}\left[5-\mathrm{COOCH}_{3}(\text { phen })\right]_{3}{ }^{2+}$, $\mathrm{Ru}\left[4,7-\left(\mathrm{C}_{6} \mathrm{H}_{5}\right)_{2} \text { phen }\right]_{3}{ }^{2+}$

Spectrochemical series of photooxidation yield, $\varphi_{\mathrm{O}_{2} 0}$ is listed below.

$$
\begin{aligned}
& \mathrm{Ru}\left[3,4,7,8-\left(\mathrm{CH}_{3}\right)_{4} \text { phen }\right]_{3}{ }^{2+}>\mathrm{Ru}\left[4,4^{\prime}-\left(\mathrm{CH}_{3}\right)_{2} \mathrm{bpy}\right]_{3}{ }^{2+} \approx \mathrm{Ru}\left[5-\mathrm{Cl}(\text { phen })(\mathrm{bpy})_{2}\right]^{2+}, \\
& \mathrm{Ru}\left[(\text { phen })(\mathrm{bpy})_{2}\right]^{2+}>\mathrm{Ru}(\text { bpy })_{3}{ }^{2+}>\mathrm{Ru}\left[5-\mathrm{COOCH}_{3}(\text { phen })\right]_{3}{ }^{2+}>\mathrm{Ru}\left[4,7-\left(\mathrm{C}_{6} \mathrm{H}_{5}\right)_{2} \text { phen }\right]_{3}{ }^{2+} \approx \\
& \mathrm{Ru}[5-\mathrm{Cl}(\text { phen })]_{3}{ }^{2+}>\mathrm{Ru}(\text { phen })_{3}{ }^{2+}
\end{aligned}
$$


Phenanthroline (phen) is a significantly more photostable ligand than bipyridine (bpy) both from the standpoint of photodecomposition and photooxidation. Both $\varphi_{N_{2} 0}$ and $\varphi_{O_{2} 0}$ of $\mathrm{Ru}(\mathrm{bpy})_{3}{ }^{2+}(\mathbf{1})$ are greater than those of $\mathrm{Ru}(\text { phen })_{3}{ }^{2+}(2)$ which indicates 1 is less stable than 2. $\varphi_{N_{2} 0}$ of $\mathbf{2}$ is $3.98 \times 10^{-6}$ which is significantly less than $\varphi_{N_{2} 0}$ of $\mathbf{1}$ at $1.03 \times 10^{-5} . \varphi_{O_{2} 0}$ of $\mathbf{2}$ is $2.80 \times 10^{-7}$ which is significantly less than $\varphi_{O_{2} 0}$ of 1 at $1.95 \times 10^{-6}$. Phen is a more sterically hindered ligand than bpy, which makes both formation of solvated products by photodecomposition and formation of oxygenated products by photooxidation more difficult.

Addition of four methyl groups to 2 results in formation of $\mathrm{Ru}[3,4,7,8$ $\left(\mathrm{CH}_{3}\right)_{4}$ phen $]_{3}^{2+}(\mathbf{3}) \cdot \varphi_{N_{2} 0}$ of $\mathbf{3}$ is $3.28 \times 10^{-5}$ which is and order of magnitude greater than $\varphi_{N_{2} 0}$ of $\mathbf{2}$ at $3.98 \times 10^{-6} . \varphi_{O_{2} 0}$ of $\mathbf{3}$ is $2.22 \times 10^{-5}$ which is greater than $\varphi_{O_{2} 0}$ of $\mathbf{2}$ at $2.80 \times 10^{-7}$. Methyl groups make 3 unstable compared to 2. $\varphi_{N_{2} 0}$ of $\mathbf{3}$ increased by a factor of 10 compared to $\varphi_{N_{2} 0}$ of 2. $\varphi_{O_{2} 0}$ of $\mathbf{3}$ increased by a factor of 100 . This is expected, as a singlet oxygen is known to attack electron rich species ${ }^{3}$. Addition of electron donating methyl group on phen will make the ligand more vulnerable to decomposition by the singlet oxygen.

Addition of chloride on phen ligand does not have a significant effect on $\varphi_{N_{2} 0}$ and $\varphi_{\mathrm{O}_{2} \mathrm{O}} \cdot \varphi_{\mathrm{N}_{2} \mathrm{O}}$ and $\varphi_{\mathrm{O}_{2} \mathrm{O}}$ of $\mathbf{4}$ are similar to those of 2 . Initially 4 is expected to have the lower photostability compared to $\mathbf{2}$, as chlorine is an electron withdrawing group. 
However, with the current data, photostability of $\mathbf{4}$ and $\mathbf{2}$ are similar. More chlorine on phen might have measurable effects on photostability.

Addition of two methyl groups on bipyridine (bpy) ligand, 5, contributes to a lower $\varphi_{N_{2} 0}$ and a higher $\varphi_{\mathrm{O}_{2} 0}$ than 1 . When two methyl groups are added to 4 position of bipyridine ligand, $\varphi_{\mathrm{N}_{2} \mathrm{O}}$ decreased from $1.03 \times 10^{-5}$ to $5.80 \times 10^{-6}$ while $\varphi_{\mathrm{O}_{2} 0}$ increased from $1.95 \times 10^{-6}$ to $4.07 \times 10^{-6}$. A decrease of $\varphi_{N_{2} 0}$ of 5 compared to 1 suggests that addition of two methyl group stabilize the complex from photodecomposition. However, an increase of $\varphi_{\mathrm{O}_{2} 0}$ of 5 compared to 1 indicates that photooxidation occurs more readily with 5 .

As the use of mixed ligand complexes is common to tailor the characteristics of the complexes, we wish to see how mixing ligands affected photosensitivity relative to the tris complexes. When one of three ligands on 1 is replaced by phenanthroline, $\varphi_{N_{2} 0}$ and $\varphi_{\mathrm{O}_{2} 0}$ increase slightly compared to 1 but increase greatly compared to 2. $\varphi_{N_{2} 0}$ of $\operatorname{Ru}\left[(\text { phen })(\mathrm{bpy})_{2}\right]^{2+}(6)$ is $1.29 \times 10^{-5}$ which is slightly greater than $\varphi_{N_{2} 0}$ of 1 at $1.03 \times 10^{-5}$. $\varphi_{O_{2} 0}$ of 6 is $2.9 \times 10^{-6}$ which is slightly greater than $\varphi_{O_{2} 0}$ of 1 at $1.95 \times 10^{-6}$. The photostability of a mixed ligand is similar to the photostability of the least stable ligand.

Addition of chlorine on phen ligand of 6 results in a slight increase of $\varphi_{N_{2} 0}$ and $\varphi_{\mathrm{O}_{2} 0}$ compared to 6. $\varphi_{N_{2} 0}$ of $\mathrm{Ru}\left[5-\mathrm{Cl}(\text { phen })(\mathrm{bpy})_{2}\right]^{2+}(7)$ is $1.40 \times 10^{-5}$ which is slightly greater than $\varphi_{N_{2} 0}$ of 6 at $1.29 \times 10^{-5} . \varphi_{O_{2} 0}$ of 7 is $3.85 \times 10^{-6}$ which is slightly greater than 
$\varphi_{\mathrm{O}_{2} 0}$ of 6 at $2.90 \times 10^{-6}$. Chlorine does not have a significant effect on as previously observed with compound 2 and 4.

When a hydrogen on carbon 5 on phen is replaced by methyl ester, it forms $\mathrm{Ru}\left[5-\mathrm{COOCH}_{3} \text { (phen) }\right]_{3}{ }^{2+}(\mathbf{8}) \cdot \varphi_{N_{2} 0}$ of $\mathbf{8}$ is $3.53 \times 10^{-6}$ which is similar to $\varphi_{N_{2} 0}$ of $\mathbf{2}$ at $3.98 \times 10^{-6} \cdot \varphi_{O_{2} 0}$ of 8 is $8.70 \times 10^{-7}$ which is slightly greater than $\varphi_{O_{2} 0}$ of 2 at $2.80 \times 10^{-7}$. Replacement of hydrogen by methyl ester in $\mathrm{Ru}(\text { phen })_{3}{ }^{2+}$ does not have a significant effect on photostability.

$\mathrm{Ru}\left[4,7-\left(\mathrm{C}_{6} \mathrm{H}_{5}\right)_{2} \text { phen }\right]_{3}{ }^{2+}(9)$ is a widely used as an oxygen sensor ${ }^{4}$. It is one of the most photostable complexes among the selected polypyridyl complexes investigated in this project. $\varphi_{N_{2} 0}$ of 9 is $2.33 \times 10^{-6}$ which is less than $\varphi_{N_{2} 0}$ of 2 at $3.98 \times 10^{-6} \cdot \varphi_{O_{2} 0}$ of 9 is $5.10 \times 10^{-7}$ which is slightly greater than $\varphi_{O_{2} 0}$ of 2 at $2.80 \times 10^{-7}$. This complex is 14 times more stable in photodecomposition than the most reactive complex, 3. Ru[4,7$\left(\mathrm{C}_{6} \mathrm{H}_{5}\right)_{2}$ phen $]_{3}{ }^{2+}$ is 44 times more stable in photooxidation than 3 . This results can be explained by steric hindrance as well. 4,7- $\left(\mathrm{C}_{6} \mathrm{H}_{5}\right)_{2}$ phen is significantly more sterically hindered compared other complexes investigated. Steric hindrance would challenge formation of solvated products by photodecomposition and formation of oxygenated products by photooxidation.

$\mathrm{Ru}(\mathrm{II})$ polypyridyl complexes investigated in $\mathrm{H}_{2} \mathrm{O}$ have a higher $\varphi_{\mathrm{N}_{2} \mathrm{O}}$ than $\varphi_{\mathrm{O}_{2} \mathrm{O}}$. This indicates that oxygen quenches the excited state molecules more efficiently than photooxidation occurs in the presence of oxygen. 


\subsection{Selected Ru(II) polypyridyl Complexes in Acid}

Photostability in different environments is also the interest of many researchers. Literature suggests ${ }^{5}$ a faster rate of photolysis under acidic conditions. Initially, the ideal single exponential decay curve as in as aqueous environment was expected. However, an unexpected behavior of photodecomposition was observed. As shown in Figure 4.1 the emission intensity drastically dropped at the beginning of the photolysis $\mathrm{Ru}(\mathrm{bpy}) \mathrm{3}^{2+}$ in $\mathrm{H}_{2} \mathrm{SO}_{4}$. Initial intensities decreased by $26 \%$ in nitrogen, $49 \%$ in air, and $53 \%$ in oxygen 30 seconds after the photolysis started. During this period of rapid decline, the formation of dark nonluminescent swirls, which appeared black under photolysis conditions, was visually observed in the sample. After the initial steep decline, the rest of photolysis seemed to follow the typical decay. Stern-Volmer (SV) quenching plot of this complex, Figure 4.2., has $\mathrm{R}^{2}$ value of 0.9984 , which confirms all samples were purged with different gas sufficiently and initial emission intensities of photolysis decay curves were accurately measured. The rate constants for the decay was obtained by fitting the data to a single exponential decay excluding the first three minutes of photolysis. The rate constants in nitrogen, air, oxygen saturated sample were $0.36,0.17$, and $0.16 \mathrm{~min}^{-1}$ respectively. As suggested in previous work ${ }^{5}$, the photodecomposition is significantly faster in acidic condition than in water. The rate constants of $R u(b p y) 3^{2+}$ in water in nitrogen, air, oxygen are $0.057,0.041,0.027 \mathrm{~min}^{-1}$ respectively. The rate of 
photolysis increased by about a factor of 10 in acidic condition than in aqueous condition.

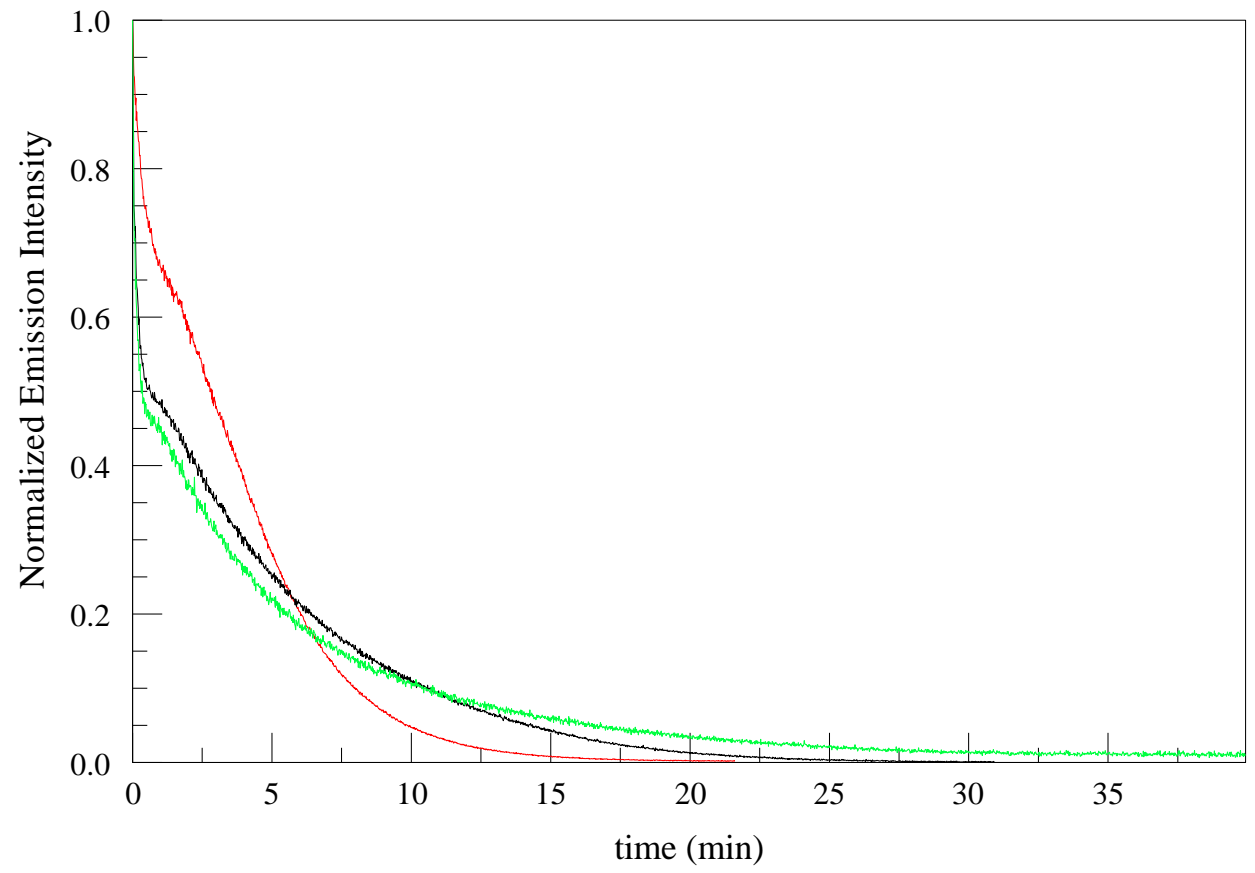

Figure 4.1 Photolysis decay curve of $\mathrm{Ru}(\mathrm{bpy}){ }_{3}{ }^{2+}$ in $0.048 \mathrm{M} \mathrm{H}_{2} \mathrm{SO}_{4}$. Sample under nitrogen (Red), air (black) and oxygen (green). However, the rate of photolysis excluding first 3 minutes of photolysis is faster in nitrogen than in oxygen.

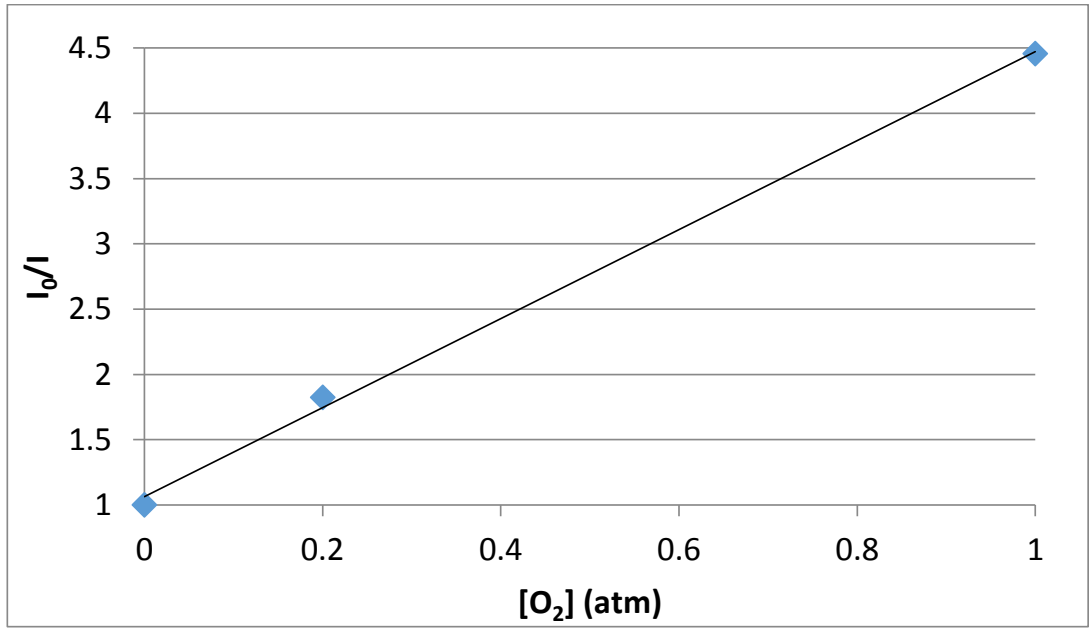

Figure 4.2 Stern-Volmer oxygen quenching plot of $\mathrm{Ru}(\mathrm{bpy})_{3}{ }^{2+}$ in $0.048 \mathrm{M} \mathrm{H}_{2} \mathrm{SO}_{4}$. The $\mathrm{SV}$ quenching constant is $3.4 \mathrm{~atm}^{-1}$ and $\mathrm{R}^{2}=0.9984$ 
Photolysis of Ru(phen) ${ }_{3}{ }^{2+}$ was also investigated due to an unexpected behavior of $\mathrm{Ru}(\mathrm{bpy})_{3}{ }^{2+}$ in $\mathrm{H}_{2} \mathrm{SO}_{4}$. Figure 4.3 shows photolysis decay curves of $\mathrm{Ru}(\text { phen })_{3}{ }^{2+}$ in $0.045 \mathrm{M}$ $\mathrm{H}_{2} \mathrm{SO}_{4}$ at different oxygen concentrations. The similar initial steep drop of emission intensity is as pronounced as in Ru(phen) ${ }_{3}^{2+}$. However, the degree of decease is far greater. Initial intensities decreased by $90 \%$ in 60 seconds under nitrogen, $95 \%$ in 30 seconds under air or oxygen. After initial drop, emission intensity increased gradually for next ten minutes. After 10 minutes of recovery, the intensity reached at $21 \%, 16 \%$, and $15 \%$ of initial intensity under nitrogen, air, oxygen, respectively.

The rate constants for photolysis were obtained by fitting the data to a single exponential decay, omitting the first 20 minutes where a steep drop and recovery of emission intensity occurred. The rate of photolysis omitting initial drop and recovery are $0.19,0.16$, and $0.0093 \mathrm{~min}^{-1}$ under nitrogen, air, oxygen, respectively. Despite the unusual shape of decay, the rate of photolysis follows the same trend. The rate of decay is faster in the absence of oxygen than in the presence of oxygen. Figure 4.4 shows Stern-Volmer quenching plot of $\mathrm{Ru}(\text { phen })_{3}{ }^{2+}$ in $\mathrm{H}_{2} \mathrm{SO}_{4}$ generated by the initial intensity points from the photolysis decay curves. A high $R^{2}$ of 0.9992 confirms samples were properly purged by different gases and the accuracy of the intensity measurements. 


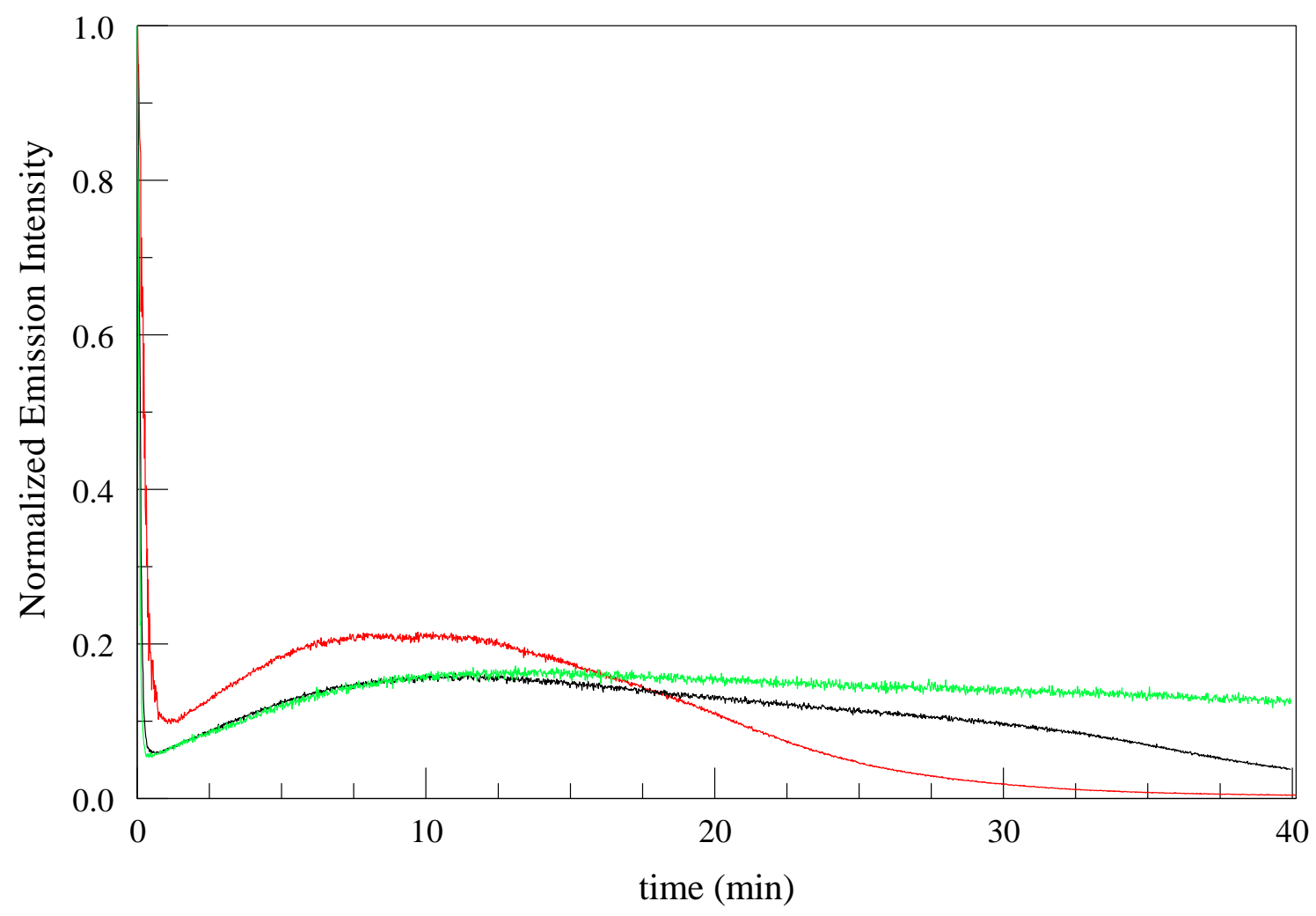

Figure 4.3 Photodecomposition of $\mathrm{Ru}(\text { phen })_{3}{ }^{2+} 0.045 \mathrm{M} \mathrm{H}_{2} \mathrm{SO}_{4}$ Photolysis decay in nitrogen (red), air (black), and oxygen (green).

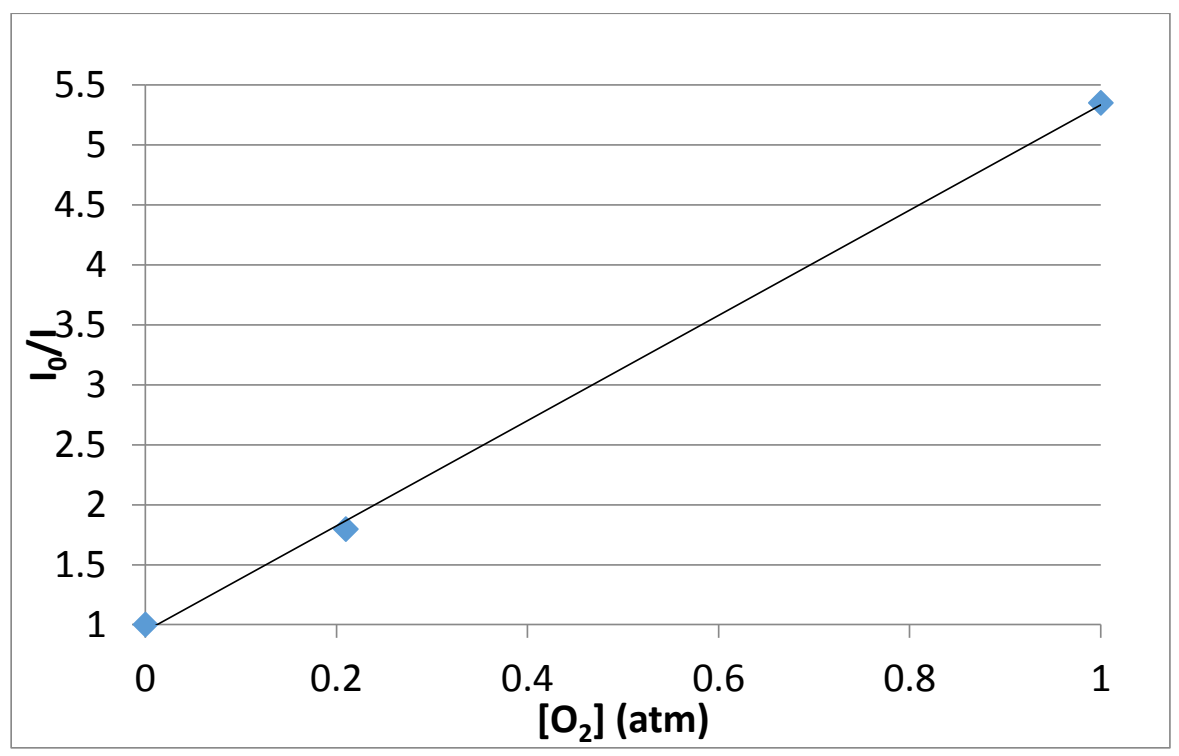

Figure 4.4 Stern-Volmer oxygen quenching plot of $\mathrm{Ru}(\text { phen })_{3}{ }^{2+}$ in $0.045 \mathrm{M} \mathrm{H}_{2} \mathrm{SO}_{4}$. The $\mathrm{SV}$ quenching constant is $4.4 \mathrm{~atm}^{-1}$ and $\mathrm{R}^{2}=0.9992$ 
Because this unusual behavior might have been caused by impurities in the sulfuric acid, a different acid was used. Trichloroacetic acid (TCA) was chosen, because it is not volatile, but a strong acid. A concentration of TCA of $0.07 \mathrm{M}$ was chosen to have a similar proton concentration as $0.05 \mathrm{M} \mathrm{H}_{2} \mathrm{SO}_{4}$. The shape of decay curve for $\mathrm{Ru}(\text { phen })_{3}{ }^{2}$ in TAC as shown in Figure 4.5 is very similar to the decay curve in $\mathrm{H}_{2} \mathrm{SO}_{4}$. The initial intensities decreased by $80 \%$ in 60 seconds under nitrogen, by $92 \%$ in 45 seconds under air, by $95 \%$ in 45 seconds under oxygen. However, the overall recovery time is faster in TCA than in $\mathrm{H}_{2} \mathrm{SO}_{4}$. After 2 minutes, the emission intensity reached at $33 \%$ of the initial intensity under nitrogen. After 3 minutes, the emission intensity reached at $17 \%$ of the initial intensity under air. After 4 minutes, the emission intensity reached at $11 \%$ of the initial intensity under oxygen. Typical photolysis decays are followed after the recovery of emission intensities. A high $\mathrm{R}^{2}$ value of SV quenching plot of $\mathrm{Ru}(\mathrm{phen})_{3}{ }^{2+}$ in TCA confirms accuracy and proper gas saturation of the samples. Also, it assures that the unusual shape of the decay curves are not due to the artifact of the instrument or error in data acquisition. It is rather a chemical reaction unexpectedly happening in the sample in acidic condition. Lastly, the same behaviors, sharp decrease of emission in the beginning of photolysis, observed both in $\mathrm{H}_{2} \mathrm{SO}_{4}$ and TCA ruled out the possibility of oxidizing impurities in sulfuric acid causing the drop. 


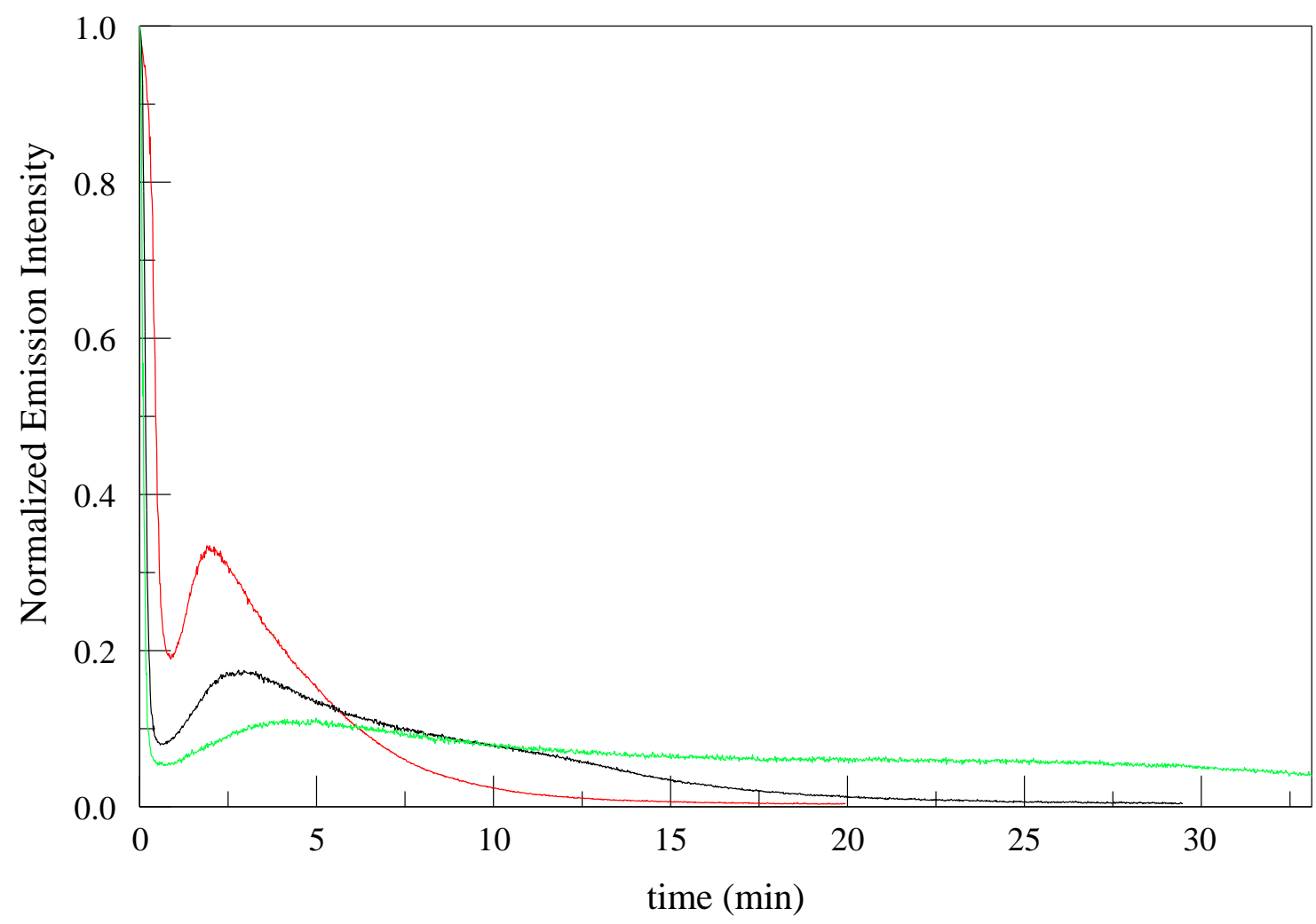

Figure 4.5 Ru(phen) ${ }_{3}{ }^{2+}$ in $0.07 \mathrm{M}$ of TCA. Photolysis decays under different oxygen concentrations are shown as red (nitrogen), black (air) and green (oxygen).

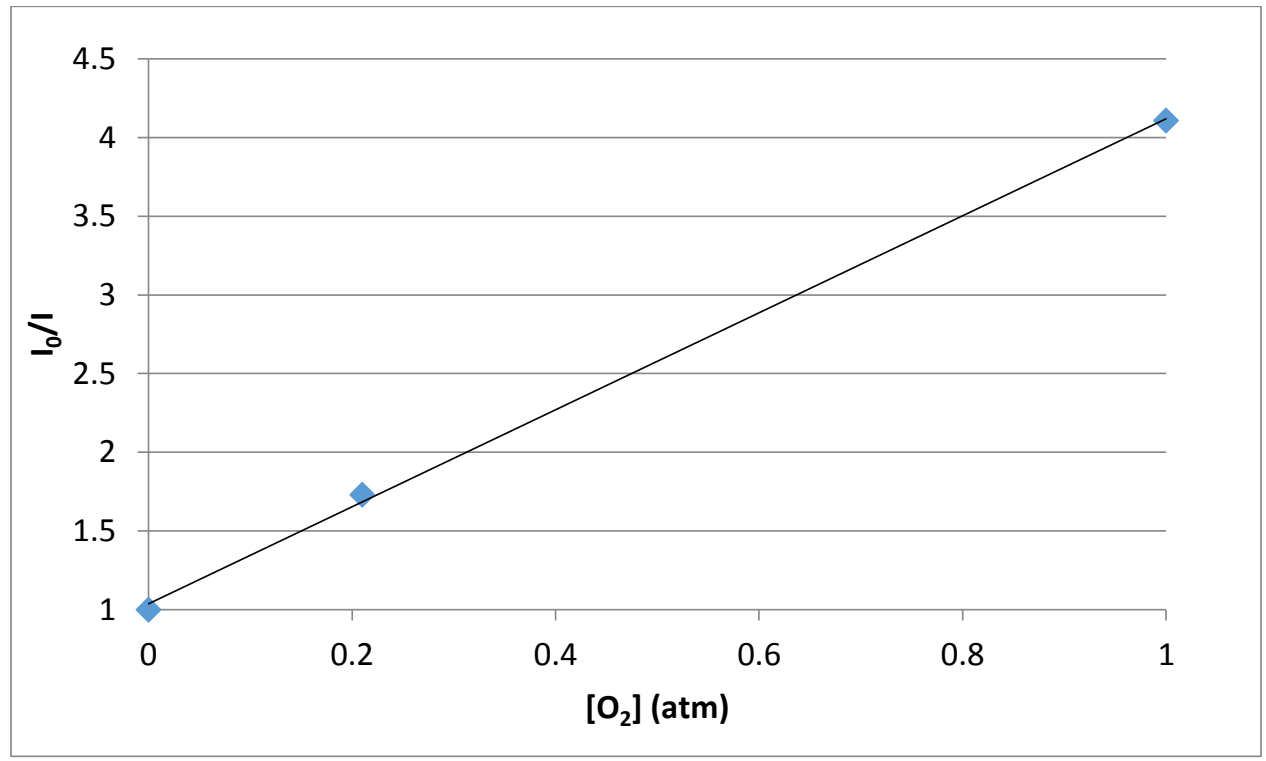

Figure 4.6 Stern-Volmer oxygen quenching plot of Ru(phen $)_{3}{ }^{2+}$ in $0.07 \mathrm{M}$ TCA. The SV quenching constant is $3.1 \mathrm{~atm}^{-1}$ and $\mathrm{R}^{2}=0.9993$. 
Based on similar behaviors of photolysis in $\mathrm{H}_{2} \mathrm{SO}_{4}$ and TCA, the hypothesis of impurities causing the initial drop was rejected. In data acquisition of photolysis, only one wavelength can be recorded in a spectrofluorimeter. However, the entire emission spectra during the photolysis was required in order to test the possibility of a new emissive product generated by photolysis. Due to this limitation, the emission intensity was not recorded as the sample was photolyzed. The sample was irradiated by excitation light for a certain amount time in the sample holder of the instrument and transferred to the spectrofluorimeter to record an emission spectrum. Then, the sample was exposed to the excitation light and a spectrum recorded again.

While a sample of $\mathrm{Ru}(\text { phen })_{3}{ }^{2+}$ in $0.045 \mathrm{M} \mathrm{H}_{2} \mathrm{SO}_{4}$ under ambient air was being photolyzed by the blue LED, emission spectra were recorded after every 30 seconds of irradiation (Figure 4.7) in the spectrofluorimeter. Based on Figure 4.7, no spectral changes were observed during the photolysis, which confirmed new emissive species were not formed during the photolysis.

The emission intensity of $\mathrm{Ru}(\text { phen })_{3}{ }^{2+}$ in $0.045 \mathrm{M} \mathrm{H}_{2} \mathrm{SO}_{4}$ under ambient air deceased by $95 \%$ in 30 seconds during the typical photolysis shown in Figure 4.3. Data presented in Figure 4.7 were re-plotted to compare to the typical photolysis decay (Figure 4.3). In the re-plotted data (Figure 4.8), 75\% of the initial intensity decreased in 30 seconds. The amount of decrease is smaller in this setup, which was expected because the sample is irradiated. However, the overall shape of Figure 4.8 is quite similar to Figure 4.3, which suggests that initial photolysis decay curves were accurate. 


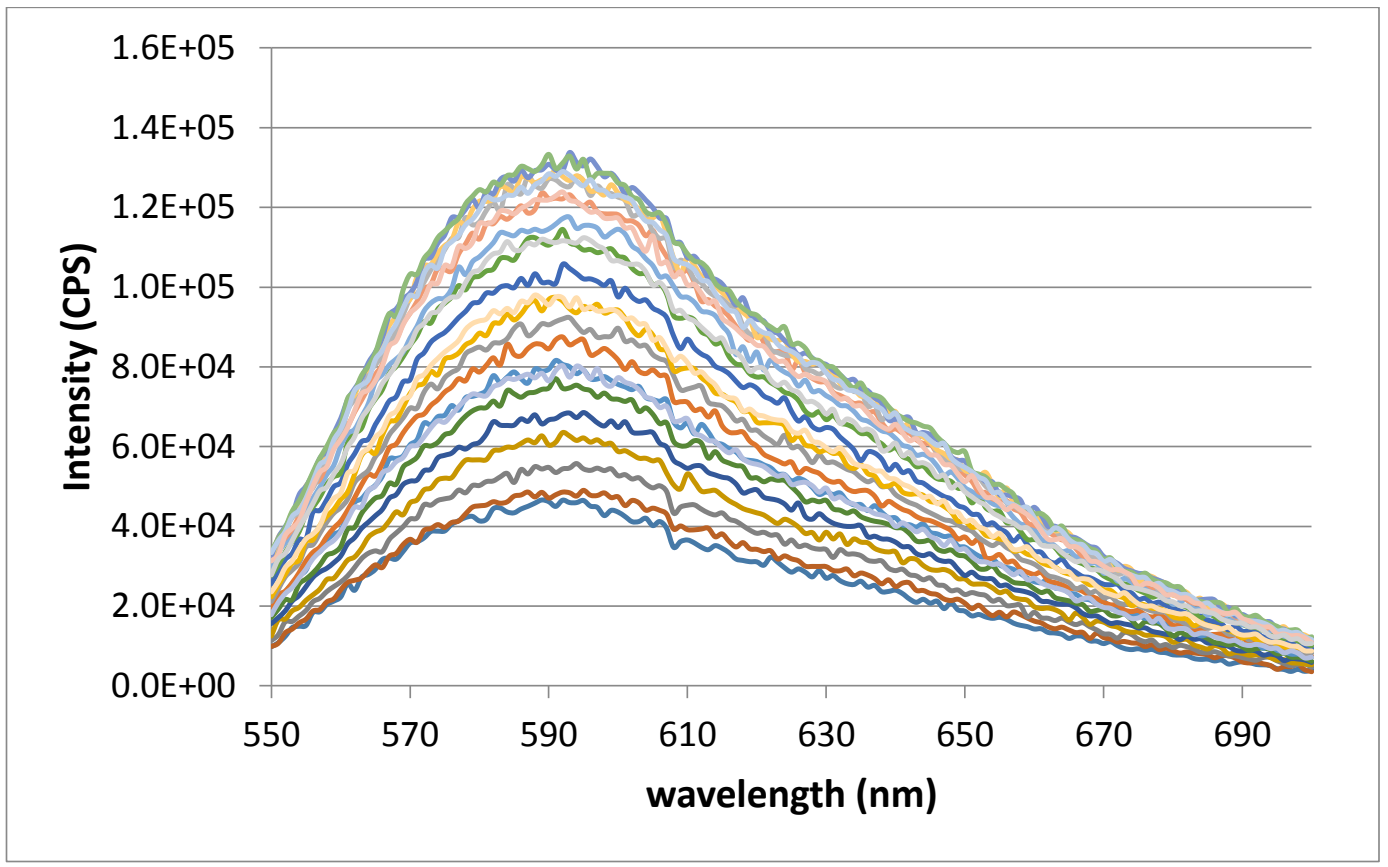

Figure 4.7 Changes of emission spectra during photolysis of $\mathrm{Ru}(\mathrm{phen}){ }_{3}{ }^{2+}$ in $0.045 \mathrm{M} \mathrm{H}_{2} \mathrm{SO}_{4}$ under ambient air condition. No spectral changes were observed. The interval between each spectrum is 30 seconds.

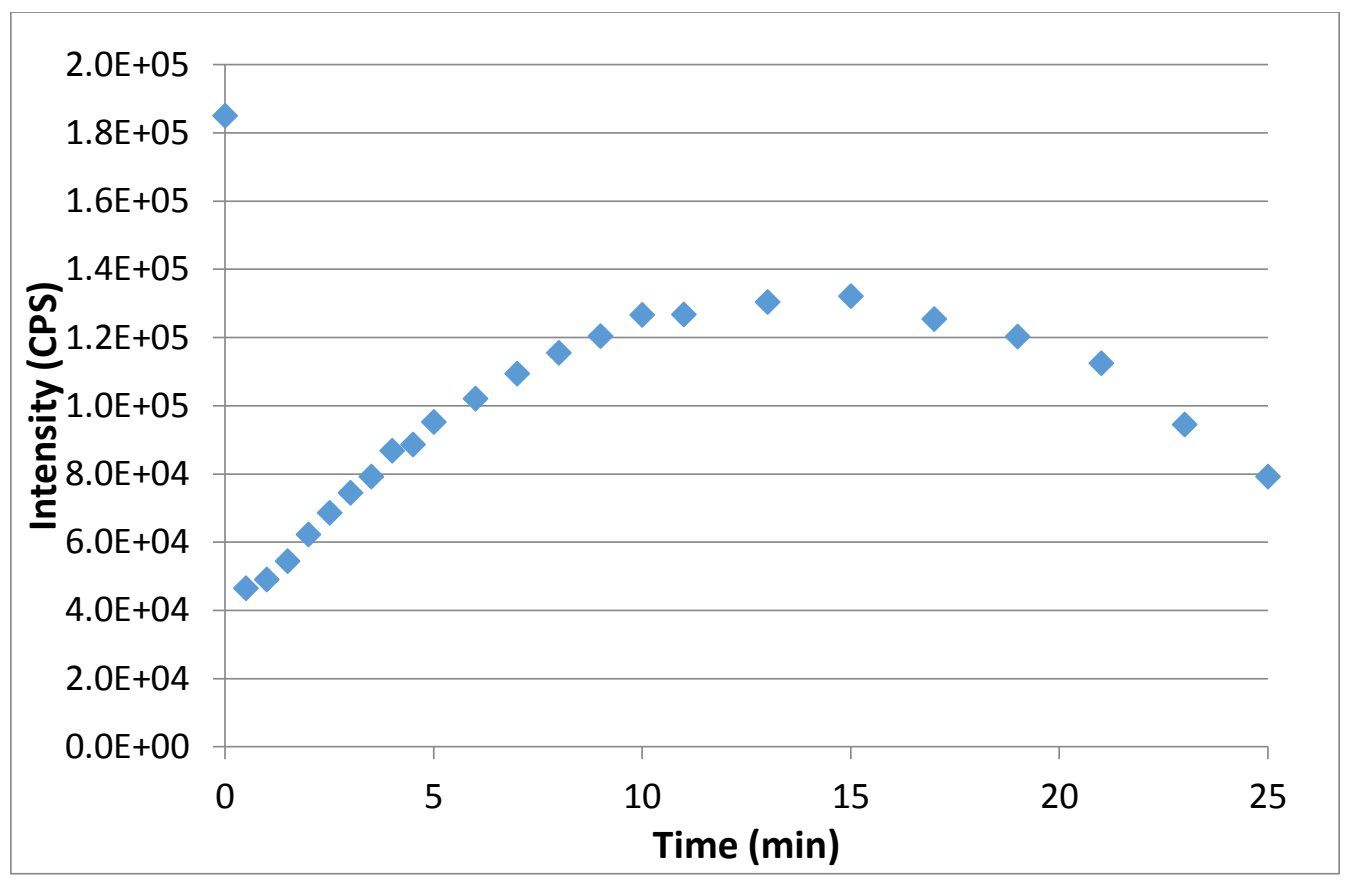

Figure 4.8 Re-plot of the same data presented in Figure 4.7 which is photolysis of $\mathrm{Ru}(\mathrm{phen}) 3^{2+}$ in $0.045 \mathrm{M}$ $\mathrm{H}_{2} \mathrm{SO}_{4}$ at $595 \mathrm{~nm}$. This plot resembles Figure. 4.3. 


\subsection{Oxidation of Ru(II) polypyridyl Complexes in Acid}

As no spectral changes in emission spectra during photolysis of $\mathrm{Ru}(\mathrm{phen})_{3}{ }^{2+}$ in $0.045 \mathrm{M} \mathrm{H}_{2} \mathrm{SO}_{4}$ were observed, this confirmed that the initial drop was not due to a formation of a new emission species. Absorption spectra were required to investigate changes in speciation during photolysis. Changes of absorption spectra compared to an absorption spectrum of non-photolyzed sample were measured. Figure 4.9 shows how overall shapes of absorption spectra changed after 5 minute exposure to the excitation light of $\mathrm{Ru}(\text { phen })_{3}{ }^{2+}$ in $0.045 \mathrm{M} \mathrm{H}_{2} \mathrm{SO}_{4}$ under ambient air. After a 5 minute photolysis, absorption spectra were recorded every 60 seconds to follow changes in speciation. The sample data were plotted as absorbance vs. time at specific wavelengths in Figure 4.10. Absorbance from 400nm to $450 \mathrm{~nm}$, which corresponds to the MLCT band, decreased initially and recovered to the original state after 200 seconds. Peaks at $220 \mathrm{~nm}$ and 264 $\mathrm{nm}$ decreased initially at the end of the 5 minutes of photolysis and then recovered during the monitoring period. Absorbance peaks at $276 \mathrm{~nm}$ and $300 \mathrm{~nm}$ had initially increased but returned back to the initial absorbance after 200 seconds.

These data suggest that $\mathrm{Ru}^{3+}$ is formed upon the initial photolysis and returned back to $\mathrm{Ru}^{2+}$ when further photolysis is not possible. $\mathrm{Ru}^{2+}$, which is emissive, is oxidized by an unknown oxidizing agent under acidic conditions. Then, $\mathrm{Ru}^{3+}$ is reduced back to $\mathrm{Ru}^{2+}$ by solvent ${ }^{6}$ after photolysis. 


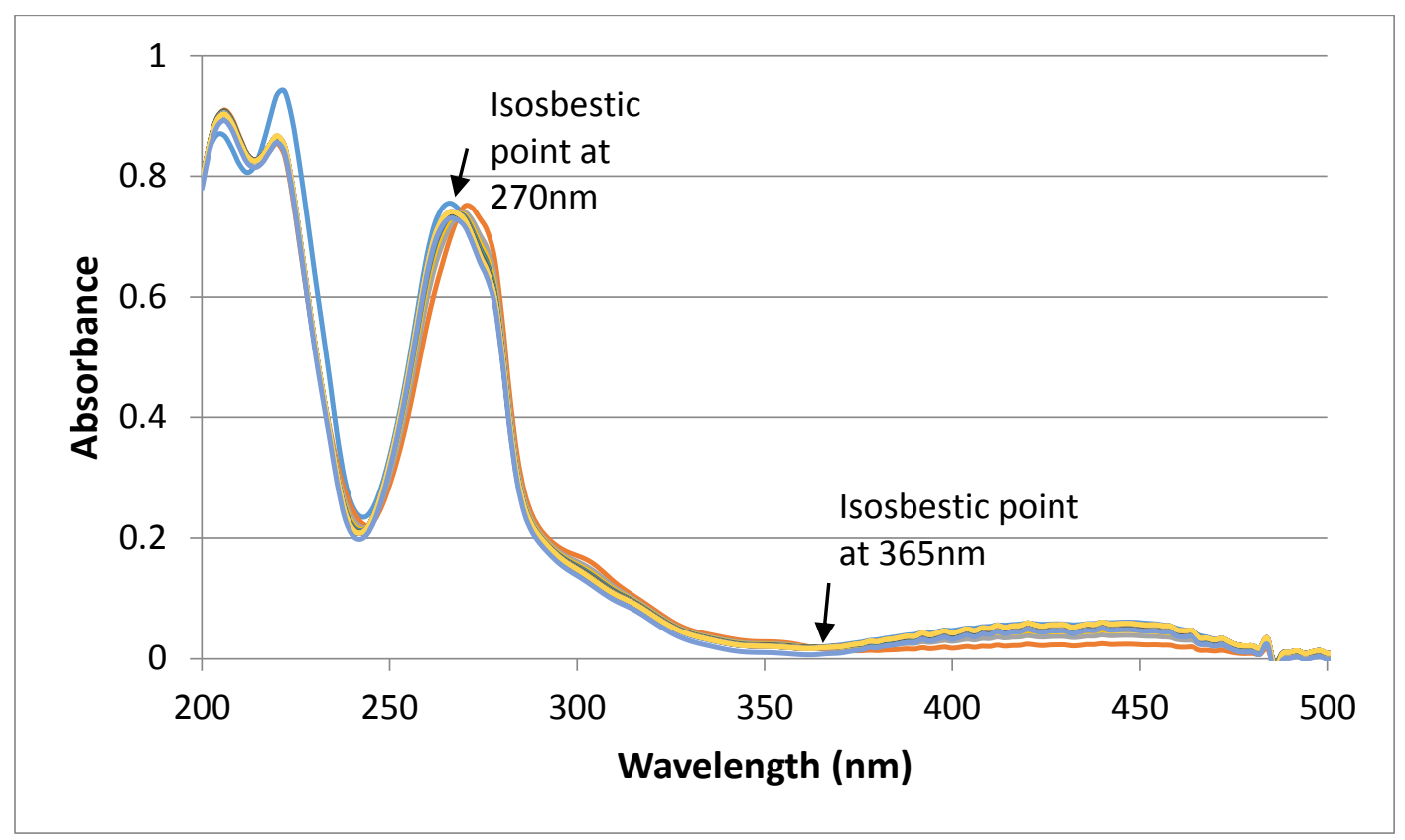

Figure 4.9 Absorption spectra of $\mathrm{Ru}(\mathrm{phen}){ }_{3}{ }^{2+}$ in $0.045 \mathrm{M} \mathrm{H}_{2} \mathrm{SO}_{4}$ under ambient air. Blue line denotes a spectrum of un-photolyzed sample. Each absorption spectrum was acquired at every minute after 5 minutes of exposure of sample to the excitation light. Isosbestic points at $270 \mathrm{~nm}$ and $365 \mathrm{~nm}$.

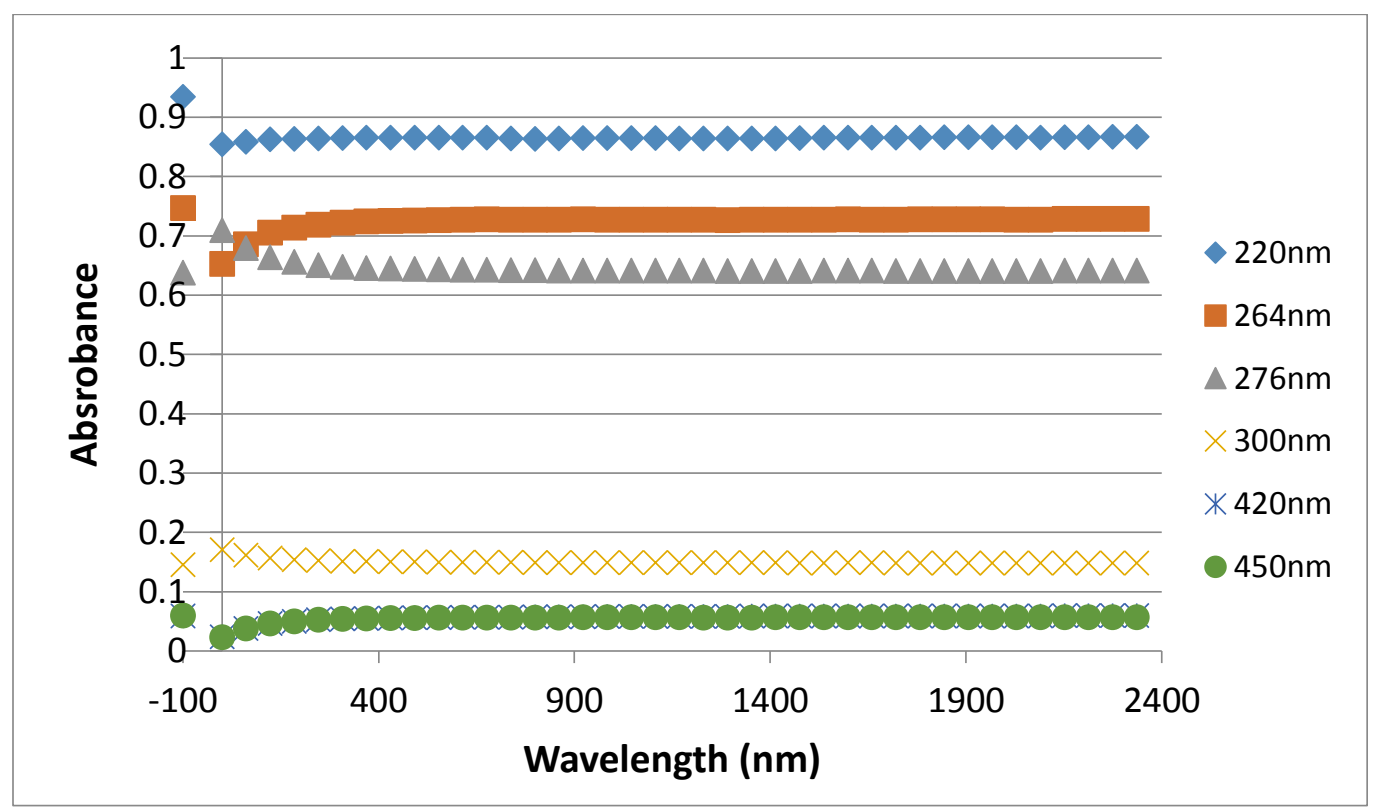

Figure 4.10 Absorption changes of $\mathrm{Ru}(\text { phen })_{3}{ }^{2+}$ in $0.045 \mathrm{M} \mathrm{H}_{2} \mathrm{SO}_{4}$ at specific wavelengths over time. With the exception of $220 \mathrm{~nm}$, absorbances at $264 \mathrm{~nm}, 276 \mathrm{~nm}, 300 \mathrm{~nm}, 420 \mathrm{~nm}$, and $450 \mathrm{~nm}$ recovered back to the initial value of un-photolyzed sample. 
Figure 4.11 shows the same data presented in Figure 4.9, but only from 300nm to $500 \mathrm{~nm}$ for a better visualization. The dashed line represents unphotolyzed $\mathrm{Ru}(\text { phen })_{3}{ }^{2+}$ in $0.045 \mathrm{M} \mathrm{H}_{2} \mathrm{SO}_{4}$. After 5 minutes of photolysis, absorbance of MLCT band decreased compared to unphotolyzed complex. Overtime, the absorbance from $400 \mathrm{~nm}$ to $460 \mathrm{~nm}$ increased, which suggests formation of $\mathrm{Ru}(\mathrm{II})$ from $\mathrm{Ru}(\mathrm{III})$. Ru(III) species under acidic condition are unstable, it will reduce back to $\mathrm{Ru}(\mathrm{II})$ by oxidizing water.

Oxidation of $\mathrm{Ru}$ (phen) ${ }_{3}{ }^{2+}$ in $\mathrm{H}_{2} \mathrm{SO}_{4}$ was tested with $\mathrm{PbO}_{2}$, a solid oxidizer. Figure 4.12 shows changes of absorption spectra of $\mathrm{Ru}(\text { phen })_{3}{ }^{2+}$ in $0.25 \mathrm{M} \mathrm{H}_{2} \mathrm{SO}_{4}$ which was oxidized by $22.5 \mathrm{mg}$ of $\mathrm{PbO}_{2}$. $\mathrm{PbO}_{2}$ was separated by centrifugation and absorption spectra of the oxidized sample were recorded. Upon oxidation, absorbance from 400 $\mathrm{nm}$ to $460 \mathrm{~nm}$ decreased, which indicates oxidation of $\mathrm{Ru}(\mathrm{II})$ to $\mathrm{Ru}(\mathrm{III})$. Similar to the photolysis data, Ru(II) forms back as indicated by increase of absorbance from $400 \mathrm{~nm}$ to $460 \mathrm{~nm}$ overtime.

Photolysis of $\mathrm{Ru}\left(\right.$ phen) ${ }_{3}{ }^{2+}$ in $0.045 \mathrm{M} \mathrm{H}_{2} \mathrm{SO}_{4}$ (Figure 4.11) and oxidation of $\mathrm{Ru}(\text { phen) })_{3}{ }^{2+}$ in $0.25 \mathrm{M} \mathrm{H}_{2} \mathrm{SO}_{4}$ by $\mathrm{PbO}_{2}$ (Figure 4.12) share similarities. Both have an isosbestic point at $365 \mathrm{~nm}$, which indicates that the same chemistry occurs in both cases. Also, the overall shape of absorption spectra are very similar. This data confirms oxidation of $\mathrm{Ru}(\mathrm{II})$ in acid during photolysis. 


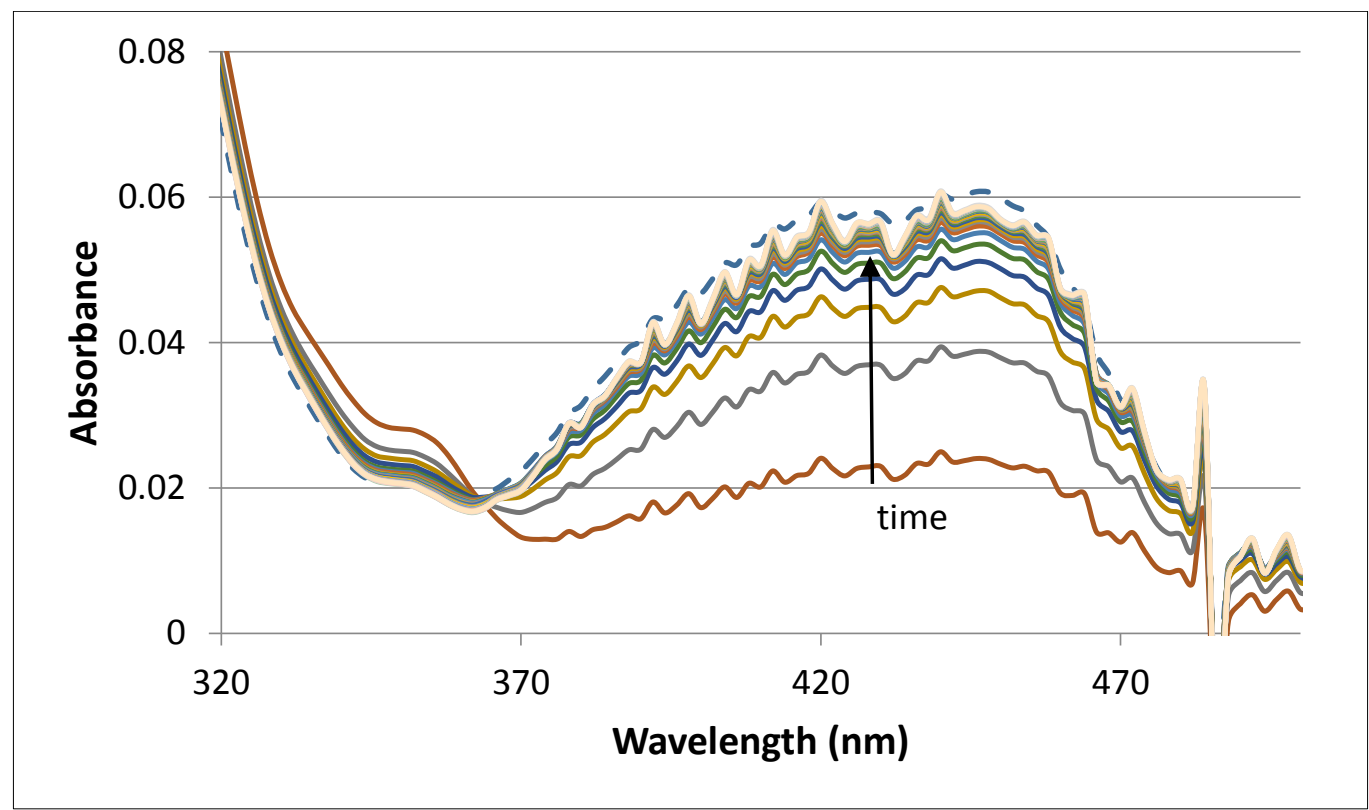

Figure 4.11 Absorption spectra of Ru(phen) ${ }_{3}{ }^{2+}$ in $0.045 \mathrm{M} \mathrm{H}_{2} \mathrm{SO}_{4}$ under ambient air from $300 \mathrm{~nm}$ to 500 $\mathrm{nm}$. The same data in Figure 4.9 replotted for a comparison. Dashed line is absorbance spectrum of unphotolyzed sample. The red line with the lowest absorbance is absorbance spectrum after 5 minutes of photolysis. Each absorption spectrum was taken at every minute after initial photolysis. Absorbance from $400 \mathrm{~nm}$ to $460 \mathrm{~nm}$ increases overtime.

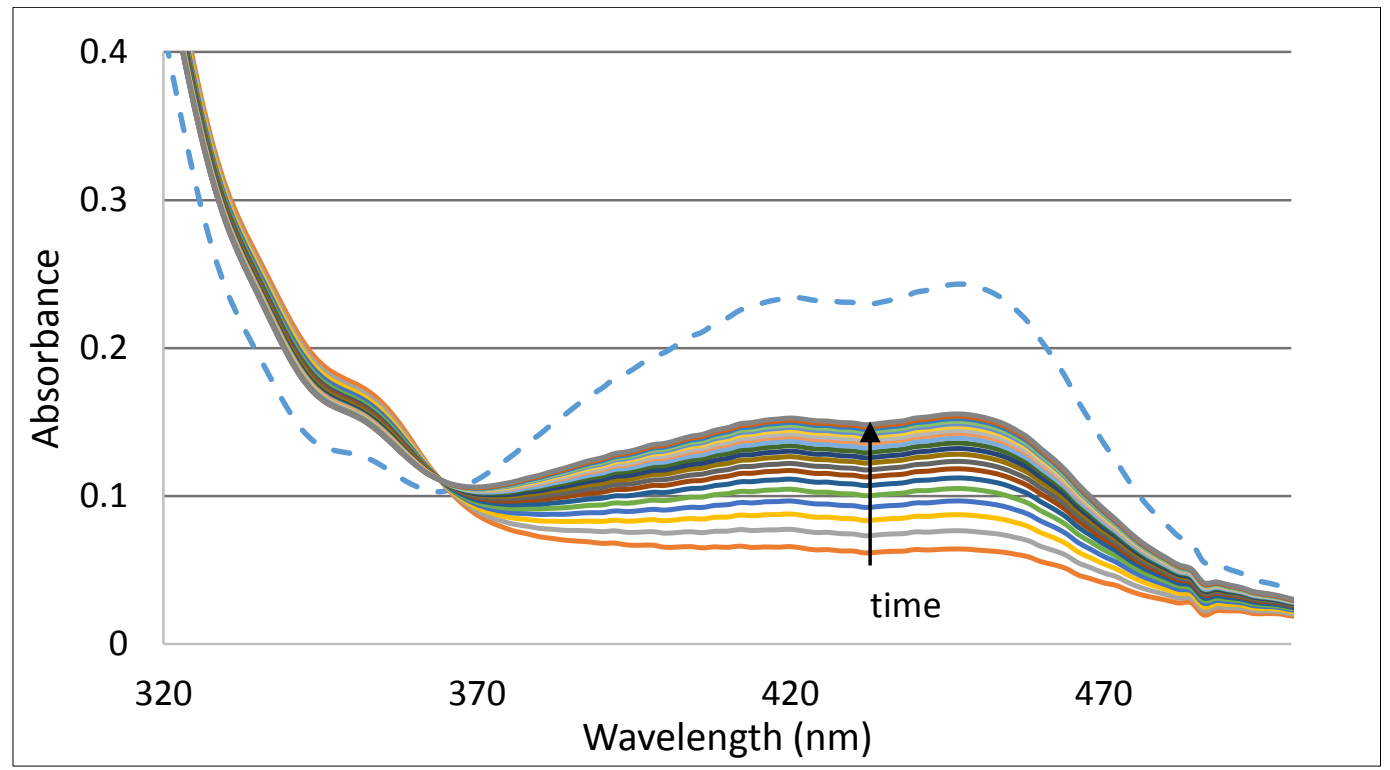

Figure 4.12 Absorption spectra of $\mathrm{Ru}(\text { phen })_{3}{ }^{2+}$ in $0.25 \mathrm{M} \mathrm{H}_{2} \mathrm{SO}_{4}$ under ambient air. The dashed line represents an absorbance of unoxidized $\mathrm{Ru}(\text { phen })_{3}{ }^{2+}$ in $0.25 \mathrm{M} \mathrm{H}_{2} \mathrm{SO}_{4}$. The red line with the lowest absorbance is when the sample is oxidized by $\mathrm{PbO}_{2}$. $\mathrm{Ru}(\mathrm{III})$ reduces back to $\mathrm{Ru}(\mathrm{II})$ after $\mathrm{PbO}_{2}$ is separated by centrifugation, as indicated by the increase in absorption from $400 \mathrm{~nm}$ to $600 \mathrm{~nm}$ 
As proton in acid is suggested as a possible oxidizing agent, the effects of proton concentrations on photolysis of $\mathrm{Ru}(\text { phen })_{3}{ }^{2+}$ in $\mathrm{H}_{2} \mathrm{SO}_{4}$ were explored. If proton oxidized $\mathrm{Ru}(\mathrm{II})$ to $\mathrm{Ru}(\mathrm{III})$, different concentrations of the acid will have an effect on photolysis.

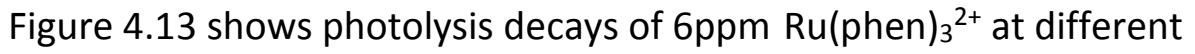
concentrations of $\mathrm{H}_{2} \mathrm{SO}_{4}$. As expected, recovery of emission intensity after the initial drop is slower ( 13 minutes for $0.225 \mathrm{M}$ and 8 minutes for $0.045 \mathrm{M}$ ) in stronger acid. Also, emission intensity recovered more in a less concentrated acid $(10 \%$ of the initial intensity at $0.225 \mathrm{M}$ and $20 \%$ of the initial intensity at $0.045 \mathrm{M}$ ).

If the initial drop is caused by oxidation of $\mathrm{Ru}^{2+}$ to $\mathrm{Ru}^{3+}$ by proton in acid, the percent decrease of the initial intensity should be less in more concentrated $\mathrm{Ru}(\text { phen })_{3}{ }^{2+}$. As expected, $80 \%$ of the initial intensity decreased in 2 minutes with $12 \mathrm{ppm} \mathrm{Ru}(\text { phen })_{3}{ }^{2+}$ and $90 \%$ of the initial intensity decreased in 30 seconds with $6 \mathrm{ppm}$ $\mathrm{Ru}(\text { phen })_{3}{ }^{2+}$ as shown in Figure. 4.14.

This data cannot conclude that a proton is responsible for oxidation of $\mathrm{Ru}(\mathrm{II})$ to $\mathrm{Ru}(\mathrm{II})$ in acid during photolysis. However, the data does not disprove the hypothesis. More experiments are required to correctly identify the oxidizing agent in Ru(II) polypyridyl complexes in acid. 


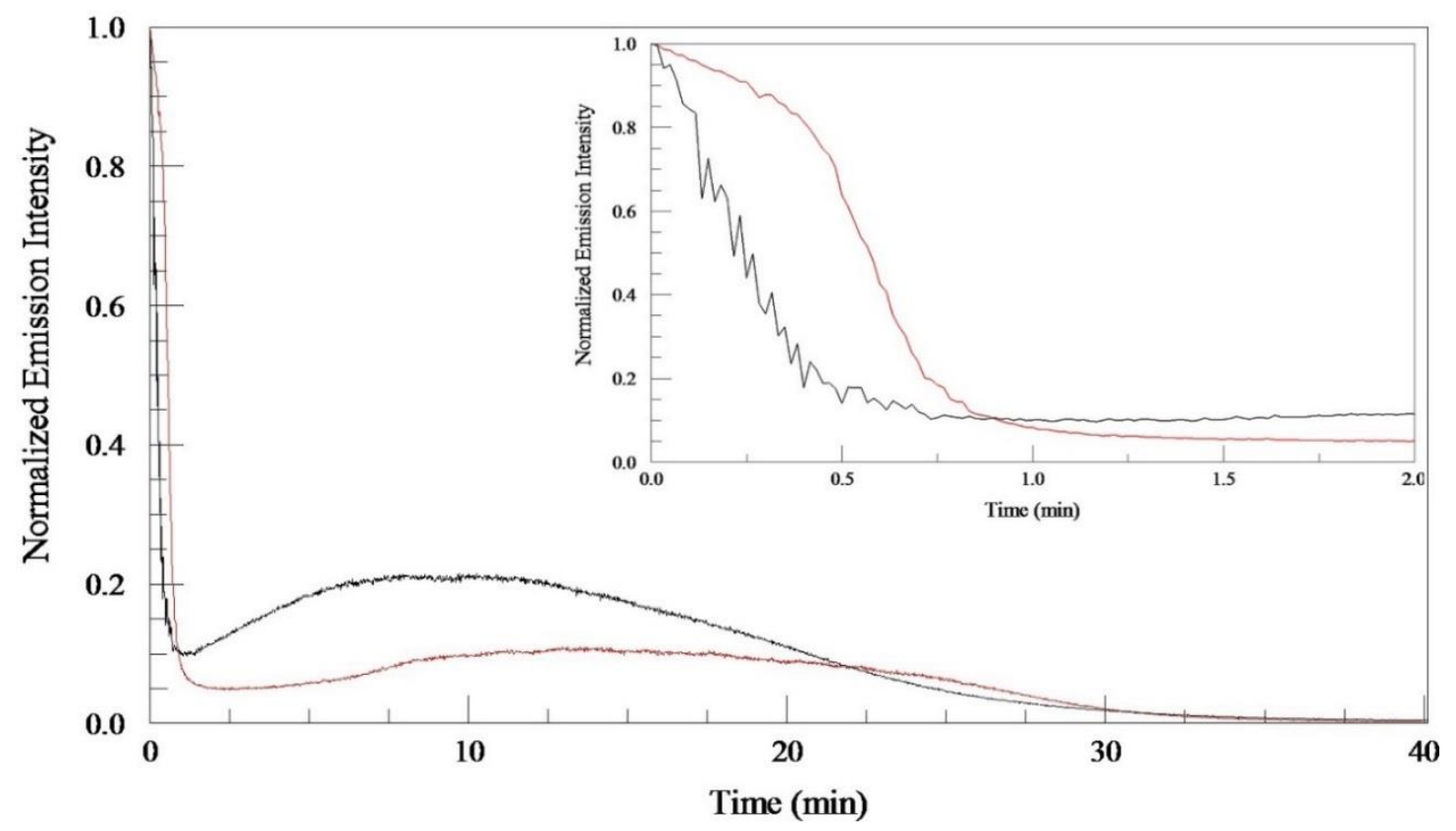

Figure 4.13 Photolysis decay of $\mathrm{Ru}\left(\right.$ phen) ${ }_{3}{ }^{2+}$ in $0.045 \mathrm{M} \mathrm{H}_{2} \mathrm{SO}_{4}$ (black) and $0.225 \mathrm{M} \mathrm{H}_{2} \mathrm{SO}_{4}$ (red). Under higher acid concentration, the recovery of intensity is slower and minimal.

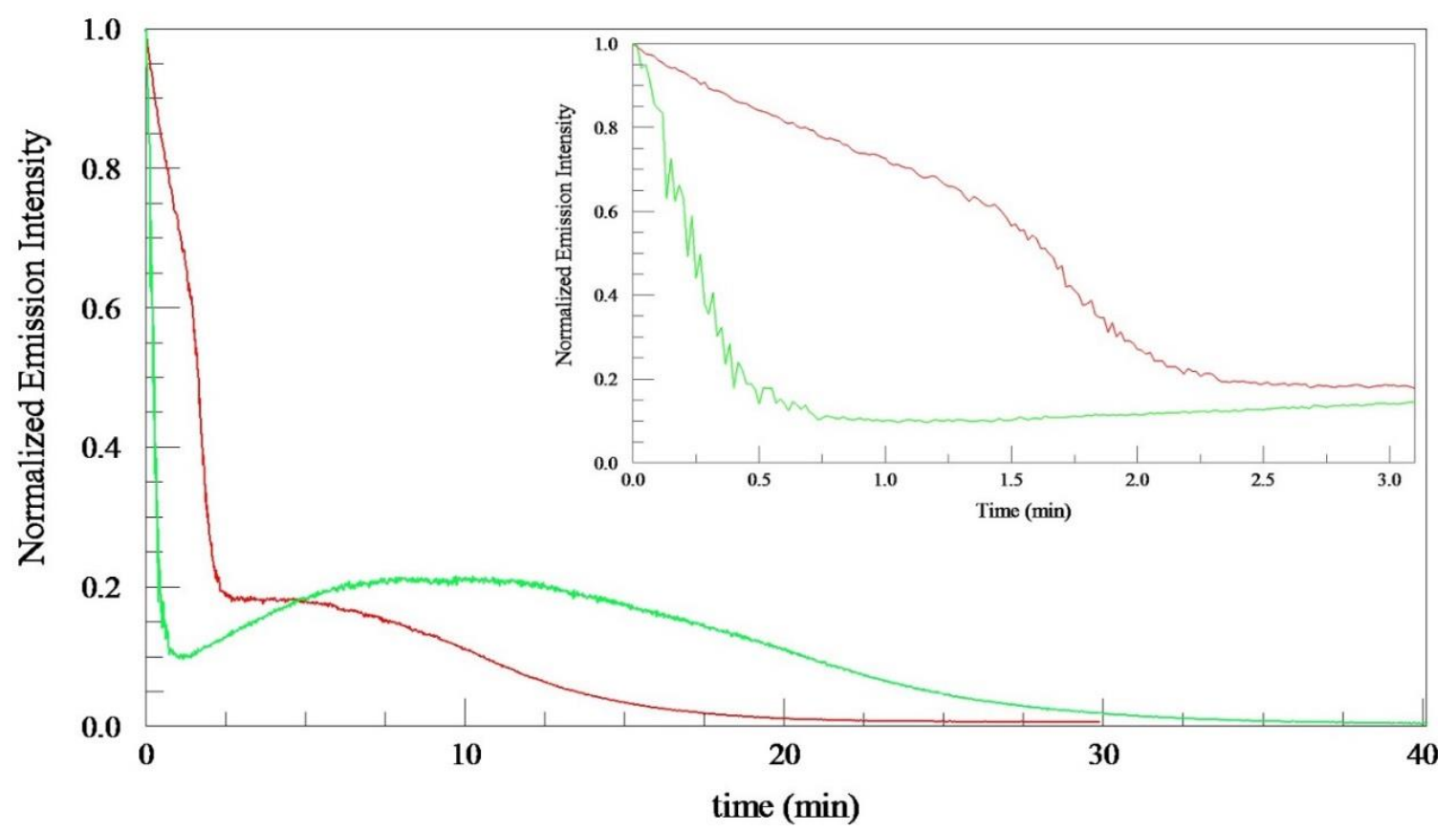

Figure 4.14 Photolysis of Ru(phen) $)_{3}{ }^{2+}$ in $0.045 \mathrm{M} \mathrm{H}_{2} \mathrm{SO}_{4 .}$. 12ppm of Ru(phen) ${ }_{3}{ }^{2+}$ (red), $6 \mathrm{ppm}$ of Ru(phen) $)^{2+}$ (green). 


\subsection{Photolysis Ru(II) polypyridyl Complexes in Acid in the Presence of a Reducing Agent.}

Based on the experimental data, it is confirmed that an oxidizing agent in the acid is causing the initial steep drop in photolysis. In order to prevent the initial drop and achieve the ideal photolysis decay, a reducing agent was added to the sample. If the oxidizing agent is oxidizing $\mathrm{Ru}^{2+}$ to $\mathrm{Ru}^{3+}$, the presence of a reducing agent will reduce $\mathrm{Ru}^{3+}$ back to $\mathrm{Ru}^{2+}$. Ascorbic acid was suggested as a plausible reducing age ${ }^{6}$. Figure 4.15 shows a qualitative preliminary data on effects of ascorbic acid as a reducing agent on photolysis. A couple of crystals of ascorbic acid were added to $\mathrm{Ru}(\mathrm{phen}) 3^{2+}$ in $0.045 \mathrm{M}$ $\mathrm{H}_{2} \mathrm{SO}_{4}$ after 10 seconds after the photolysis started. This is to ensure ascorbic acid is added after $\mathrm{Ru}^{3+}$ was formed. Clearly, ascorbic acid reduced $\mathrm{Ru}^{3+}$ back to $\mathrm{Ru}^{2+}$ and caused an increase in emission intensity at 595nm. After 2 minutes of addition of ascorbic acid, $\mathrm{Ru}(\text { phen })_{3}{ }^{2+}$ in $0.045 \mathrm{M} \mathrm{H}_{2} \mathrm{SO}_{4}$ follows the typical photolysis decay. Figure 4.16 shows more information during first 30 seconds. As clearly seen on the graph, the addition of ascorbic acid has an immediate effect on emission intensity.

The data confirmed the effect of ascorbic acid as a reducing agent. A sample of $\mathrm{Ru}(\text { phen })_{3}{ }^{2+}$ in $0.045 \mathrm{M} \mathrm{H}_{2} \mathrm{SO}_{4}$ was made with $2 \mathrm{mM}$ of ascorbic acid under different oxygen concentrations was photolyzed (Figure 4.15). Unlike previous data (Figure 4.1, 4.3, 4.5), an initial steep drop was not observed in the presence of ascorbic acid. The photolysis decay curves are very similar to the typical photolysis decays. The rate 
constants are $0.31,0.21,0.092 \mathrm{~min}^{-1}$ under nitrogen, air, and oxygen, respectively.

These are significantly faster than $\mathrm{Ru}(\mathrm{phen})_{3}{ }^{2+}$ in water. The rate constants of photolysis of $\mathrm{Ru}(\text { phen })_{3}{ }^{2+}$ in $\mathrm{H}_{2} \mathrm{O}$ are $0.025,0.015,0.0055 \mathrm{~min}^{-1}$ under nitrogen, air, and oxygen, respectively. Under acidic conditions, the rate of photolysis increased by a factor of 10 , which is consistent with the literature ${ }^{5}$.

In Figure 4.17, the photolysis decay under oxygen has a steep drop at 16 minutes. This steep drop of the emission intensity around 16 minutes of photolysis is a clock reaction which never occurred in $\mathrm{Ru}(\text { phen) })_{3}{ }^{2+}$ in $\mathrm{H}_{2} \mathrm{SO}_{4}$ with any concentrations of ascorbic acid under nitrogen. In the presence of oxygen, a singlet oxygen species is generated by oxygen quenching of Ru(II) polypyridyl complexes. The singlet oxygen (or superoxide) is known to attack ascorbic acid and decompose the reducing agent ${ }^{7}$. Once singlet oxygen species degrades all of ascorbic acid, there is no reducing agent present to prevent oxidation of $\mathrm{Ru}(\mathrm{II})$. The time of when this clock reaction happens is directly related to the concentration of the ascorbic acid. The less concentrated ascorbic acid, the faster the clock reaction happens. Also, this clock reaction never occurred in nitrogen which is consistent with the theory a singlet oxygen or superoxide decomposing ascorbic acid. 


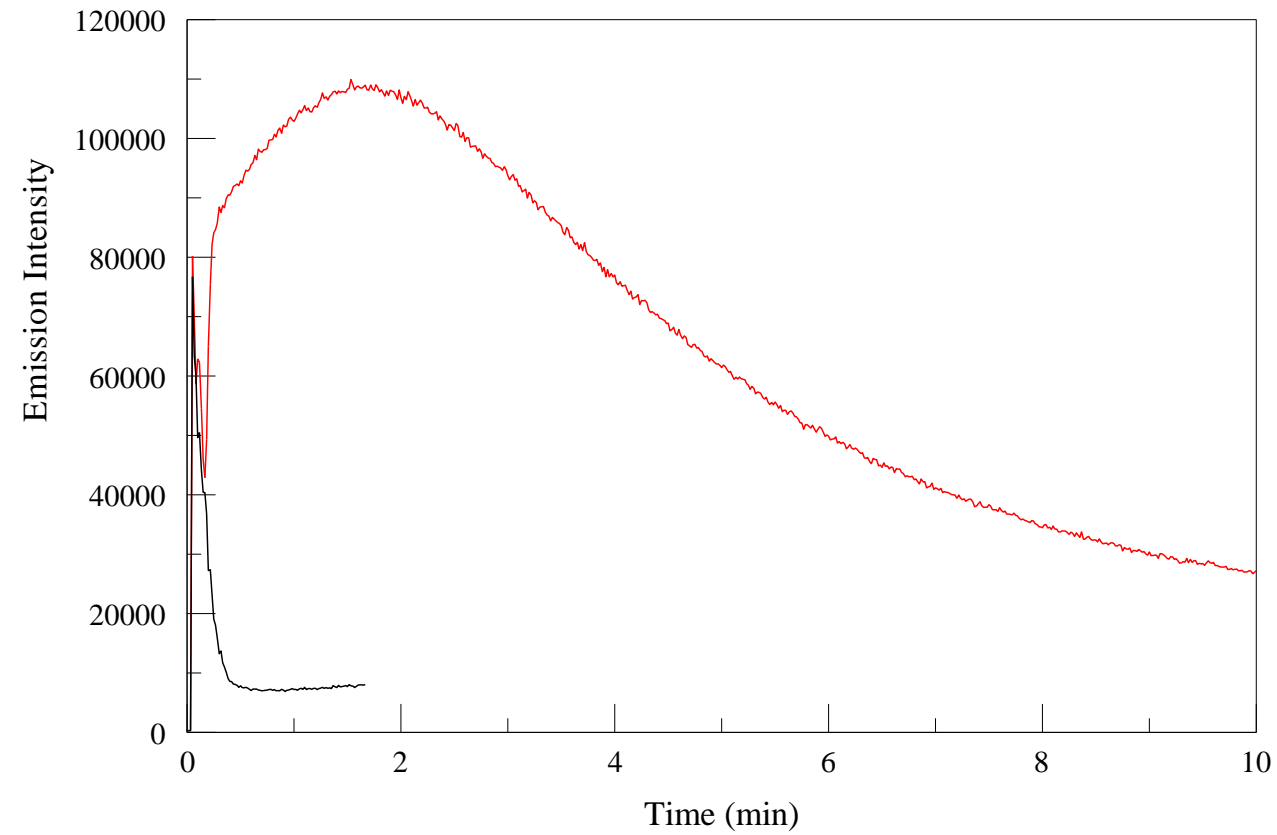

Figure 4.15 Preliminary data of ascorbic acid added to $\mathrm{Ru}(\text { phen) })_{3}{ }^{2+}$ in $0.045 \mathrm{M} \mathrm{H}_{2} \mathrm{SO}_{4}$. The black line denotes a typical photolysis decay in acid, and the red line denotes an addition of ascorbic acid crystal to the sample.

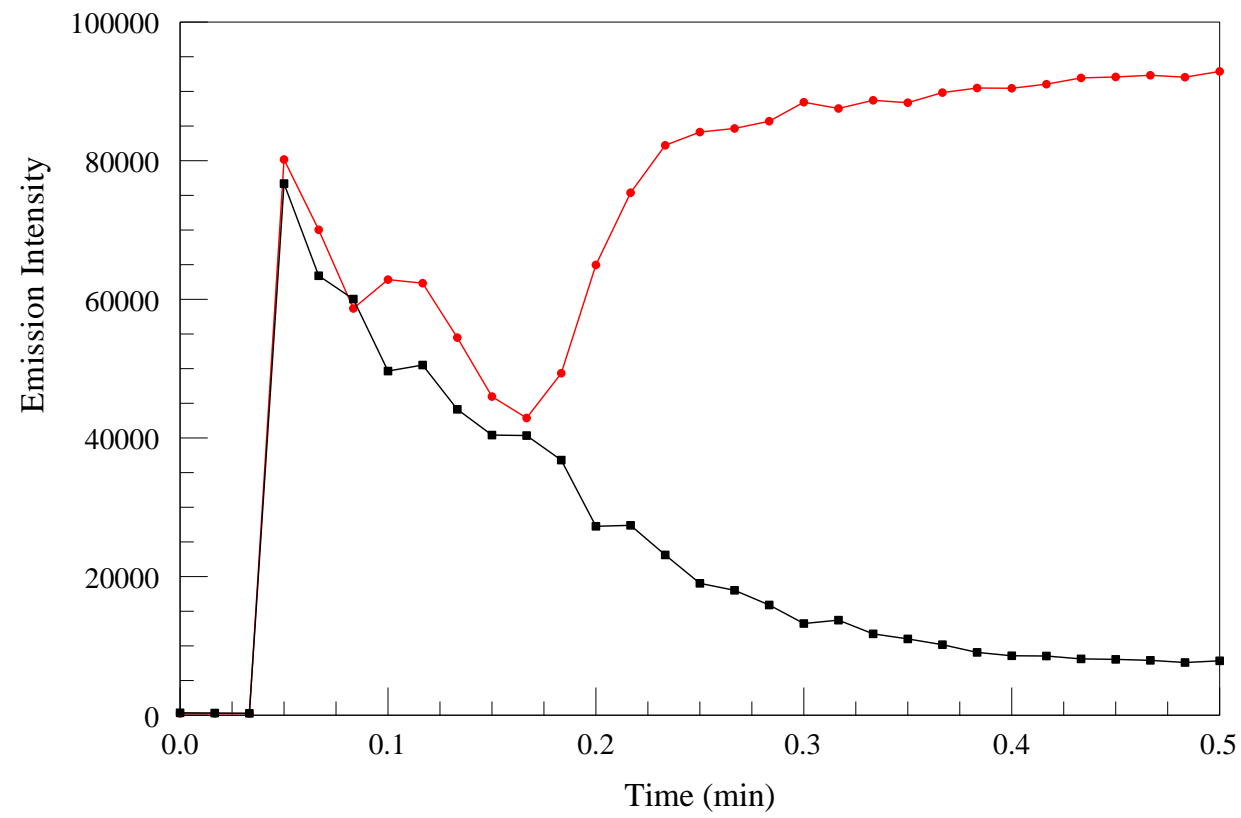

Figure 4.16 Ascorbic acid added to Ru(phen) $)_{3}{ }^{2+}$ in $0.045 \mathrm{M} \mathrm{H}_{2} \mathrm{SO}_{4}$. Emission intensity increased at 10 seconds when a crystals of ascorbic acid is added. The black line denotes a typical photolysis decay in acid, and the red line denotes an addition of ascorbic acid crystal to the sample. 


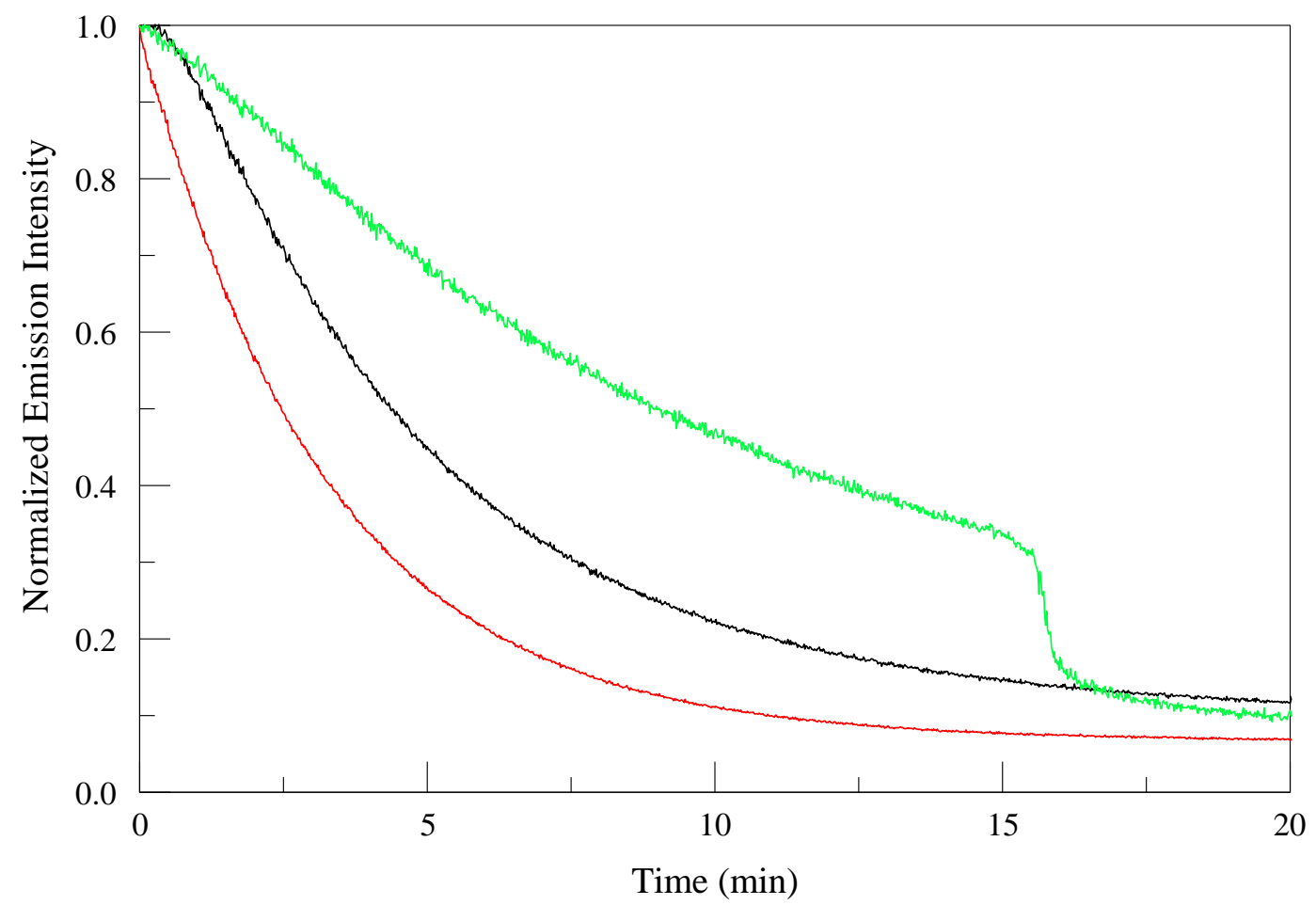

Figure 4.17 Photolysis decays of $\mathrm{Ru}(\text { phen })_{3}{ }^{2+}$ in $0.044 \mathrm{M} \mathrm{H}_{2} \mathrm{SO}_{4}$ and $2 \mathrm{mM}$ ascorbic acid under nitrogen (red), air (black) and oxygen (green).

\subsection{Summary of Chapter 4 \& Future Work}

In this chapter, photolysis of ruthenium (II) polypyridyl complexes was explored in $\mathrm{H}_{2} \mathrm{O}$ and acid. In water. the data are well described by Figure 4.18. Figure 4.18 shows the proposed mechanism for photodecomposition of a luminophore. An excited luminophore can follow one of the following paths. An excited luminophore can relax back to the singlet ground state by emitting a photon or by radiationless decay (path 1). Path 2 describes photooxidation of a luminophore by a singlet oxygen. Path 3 describes photodecomposition of a luminophore and a non-luminescent solvated product. 


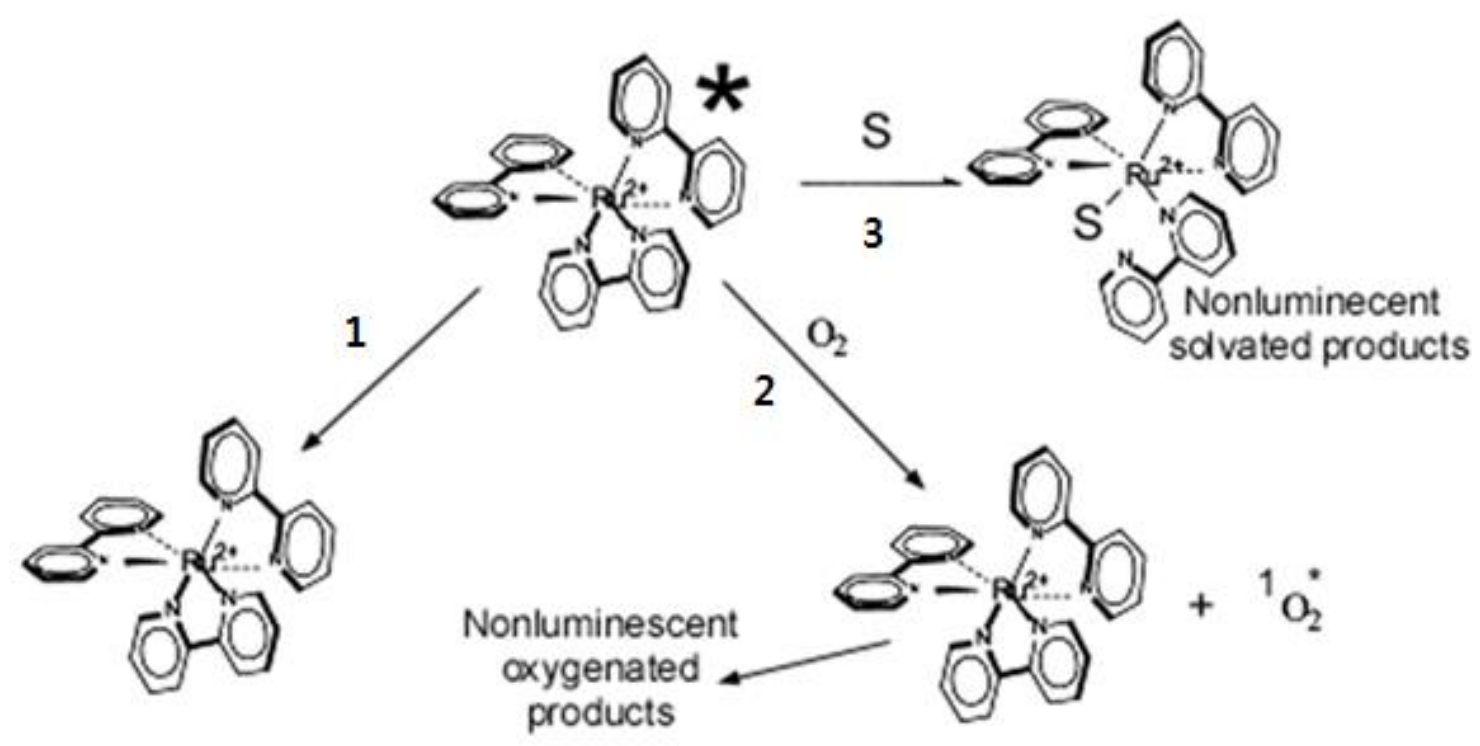

Figure 4.18 Effects of oxygen in photochemistry. $\mathrm{Ru}(\mathrm{bpy})_{3^{2+}}$ is used to illustrate possible paths of the excited state molecule.

In aqueous solution, photodecomposition yield, $\varphi_{d}$, and photooxidation yield, $\varphi_{\mathrm{O}_{2} 0}$, of these complexes were obtained. Ru[4,7-( $\left(\mathrm{C}_{6} \mathrm{H}_{5}\right)_{2}$ phen $]_{3}{ }^{2+}$ is one of most photostable complex among Ru(II) polypyridyl complexes investigated. $\mathrm{Ru}(\mathrm{bpy})_{3}{ }^{2+}$ compound is less photostable than $\mathrm{Ru}(\mathrm{phen})_{3^{2+}}$ in general.

The chemistry is significantly more complex in acid. Our results only begin to explore the complexities of these systems; however, we can draw some conclusions. Under acidic conditions, the emission intensity of luminophores decreased drastically in the first minute. This unusual shape of the photolysis decay curves appears to be due to oxidation of Ru(II) by a oxidizer present in acid. The behavior can be prevented by an 
addition of a reducing agent such as ascorbic acid. Even with the reducing agent, the rate of photolysis in acidic condition is about ten times faster than in water, which is consistent with the previous work. However, it is not yet known what is the oxidizer causing an oxidation of Ru(II) in acid. It is highly likely that it is not cause by impurities, because both $\mathrm{H}_{2} \mathrm{SO}_{4}$ and trichloroacetic acid has the same phenomenon. It is possible that proton is an oxidizing agent in the acid data. This can be tested by monitoring hydrogen gas formation or possibly $\mathrm{pH}$ changes during photolysis.

Several different experiments can be performed in the future. First, more Ru(II) polypyridyl complexes can be investigated in $\mathrm{H}_{2} \mathrm{O}$. Only selected complexes have been explored in this work; however, there are numerous complexes available. Secondly, the photostability of the complexes in different environments such as various solvents and polymers can be measured. Lastly, more detailed analyses of photolysis of Ru(II) polypyridyl in acid are needed. 


\section{Chapter 4 References}

(1) Lin, C.; Böttcher, W.; Chou, M.; Creutz, C.; Sutin, N. Mechanism of the Quenching of the Emission of Substituted Polypyridineruthenium (II) Complexes by Iron (III), Chromium (III), and Europium (III) Ions. J. Am. Chem. Soc. 1976, 98, 6536-6544.

(2) Fuller, Z. J.; Bare, W. D.; Kneas, K. A.; Xu, W. Y.; Demas, J. N.; DeGraff, B. A. Photostability of Luminescent ruthenium(II) Complexes in Polymers and in Solution. Anal. Chem. 2003, 75, 2670-2677.

(3) Prein, M.; Adam, W. The Schenck Ene Reaction: Diastereoselective Oxyfunctionalization with Singlet Oxygen in Synthetic Applications. Angew. Chemie Int. Ed. English 1996, 35, 477-494.

(4) Carraway, E. R.; Demas, J. N.; DeGraff, B. a.; Bacon, J. R. Photophysics and Photochemistry of Oxygen Sensors Based on Luminescent Transition-Metal Complexes. Anal. Chem. 1991, 63, 337-342.

(5) Demas, J. N.; Adamson, A. W. Tris (2,2'-Bipyridine) ruthenium(II) Senstized Reactions of Some Oxalato Complexes. J. Am. Chem. Soc. 1973, 95, 5159-5168.

(6) Macartney, D. H.; Sutin, N. The Oxidation of Ascorbic Acid by Tris(2,2'-Bipyridine) Complexes of osmium(III), ruthenium(III) and nickel(III) in Aqueous Media: Applications of the Marcus Cross-Relation. Inorganica Chim. Acta 1983, 74, 221228.

(7) Kramarenko, G. G.; Hummel, S. G.; Martin, S. M.; Buettner, G. R. Ascorbate Reacts with Singlet Oxygen to Produce Hydrogen Peroxide. Photochem. Photobiol. 2006, 82, 1634-1637. 


\section{Chapter 5 Conclusion}

Luminescence sensors are widely used as an analytical tool ${ }^{1}$. Luminescence spectroscopy has many advantages over other analytical techniques such as high sensitivity, simpler instrumentation, and low cost. Luminophores as a sensor are used to analyze various compounds from $\mathrm{CO}_{2}{ }^{2}, \mathrm{O}_{2}{ }^{3,4}$, glucose ${ }^{5}$, anions ${ }^{6}$ and metal ions such as zinc $^{7}$, potassium ${ }^{8}$, to name a few. Pressure ${ }^{9}$, temperature ${ }^{10}$ and $\mathrm{pH}^{11}$ can be measured by luminescent sensors. When used as a probe, photostability of a luminophore is important to validate the accuracy of measurements. Also understanding photochemical and photophysical properties of luminescent probes are important to develop a better sensor $^{12,13}$.

However, measurements of quantitative photodecomposition yield $\left(\varphi_{d}\right)$ of luminophores require either complicated instrumentation or long experimental time. An instrument was developed to efficiently measure quantitative photostability of relatively stable luminophores.

The final version of the instrument is composed of a high power blue LED with the peak wavelength at $455 \mathrm{~nm}$, a quartz light pipe, a fiber optic for monitoring the emission intensity, a shutter and a fluorimeter. The light pipe efficiently delivers $2.30 \mathrm{~W}$ of blue light to the sample at 5.72 A. Typical photolysis of Ru(II) polypyridyl complexes was run at $5.72 \mathrm{~A}$ at $2.3 \mathrm{~W}$. If more power is needed, the LED can emit at a higher power 
over $4 \mathrm{~W}$ at higher currents. A rotary fan was attached to the heat sink in order to minimize temperature increase in the LED. The sample was stirred by a micro magnetic stirrer as well as purged by appropriate gas while being photolyzed. A muffin fan was used to cool optically dilute sample during photolysis in order to minimize effects of temperature on emission intensity of the luminophore. The emission intensities were recorded by a fluorimeter, FluoroMax 4 , which is delivered from the sample to the detector by a fiber optics.

Accuracy of the photolysis measurements by the developed instrument was confirmed with Fluorescein isothiocyanate in $\mathrm{H}_{2} \mathrm{O} . \varphi_{d}$ of FITC measured by the instrument, $1.09 \times 10^{-4}$ is consistent with literature value of $1.2 \times 10^{-4} 14-16$. The instrument measures $\varphi_{d}$ of very stable ruthenium(II) polypyridyl complexes with $\varphi_{d}$ of $10^{-6}$ to $10^{-7}$, in a shorter time, which is usually 25 to 30 minutes. As less than half of the maximum intensity of the LED was used, more stable complexes can be measured at maximum power. Lastly, the instrument has a good reproducibility of less than $2 \%$ relative standard deviation on three consecutive measurements of the identical sample of $\mathrm{Ru}(\text { bpy })_{3}{ }^{2+}$, tri(bipyridine) ruthenium (II), in $\mathrm{H}_{2} \mathrm{O}$.

Photodecomposition yield, $\varphi_{\mathrm{N}_{2} \mathrm{O}}$ and photooxidation yield, $\varphi_{\mathrm{O}_{2} 0}$ of $\mathrm{Ru}(\mathrm{II})$ polypyridyl complexes in $\mathrm{H}_{2} \mathrm{O}$ were obtained. $\varphi_{N_{2} 0}$ is the photodecomposition yield in the absence of oxygen. $\varphi_{\mathrm{O}_{2} 0}$ is the limiting photooxidation yield when $100 \%$ of the excited state is quenched by oxygen. In all of the selected luminescent Ru(II) complexes 
investigated, $\varphi_{N_{2} 0}$ was higher than $\varphi_{O_{2} 0}$, which indicates that direct photodecomposition is more efficient than photooxidation. $\mathrm{Ru}\left[4,7-\left(\mathrm{C}_{6} \mathrm{H}_{5}\right)_{2} \text { phen }\right]_{3}{ }^{2+}$, tris (4,7-diphenyl-1,10-phenanthroline) ruthenium(II), is one of most photostable complexes among Ru(II) polypyridyl complexes investigated.

The use of mixed ligand complexes is common to tailor the characteristics of the complexes. Photostability of Ru[(phen)(bpy $\left.)_{2}\right]^{2+}$ was investigated. Photodecomposition yield, $\varphi_{N_{2} 0}$, and photooxidation yield $\varphi_{O_{2} 0}$, of $\mathrm{Ru}(\mathrm{bpy})_{3}{ }^{2+}$ are greater than those of $\mathrm{Ru}(\text { phen })_{3}{ }^{2+}$, indicating that phen is a significantly more photostable ligand than bpy in both of photodecomposition and photooxidation. When one of three ligands on $\mathrm{Ru}(\mathrm{bpy})_{3}{ }^{2+}$ is replaced by phen, $\varphi_{\mathrm{N}_{2} 0}$ and $\varphi_{\mathrm{O}_{2} 0}$ increase slightly compared to $\mathrm{Ru}(\mathrm{bpy})_{3}{ }^{2+}$ but significantly greater compared to $\mathrm{Ru}(\text { phen })_{3}{ }^{2+} \cdot \varphi_{\mathrm{N}_{2} 0}$ of $\mathrm{Ru}\left[(\text { phen })(\mathrm{bpy})_{2}\right]^{2+}$ is $1.29 \times 10^{-}$ ${ }^{5}$ which is slightly greater than $\varphi_{N_{2} 0}$ of $\mathrm{Ru}(\mathrm{bpy})_{3}{ }^{2+}$ at $1.03 \times 10^{-5}$ but far greater than $\varphi_{N_{2} 0}$ of $\mathrm{Ru}(\text { phen })_{3}{ }^{2+}$ at $3.98 \times 10^{-6} \cdot \varphi_{O_{2} 0}$ of $\mathrm{Ru}\left[(\text { phen })(\mathrm{bpy})_{2}\right]^{2+}$ is $2.90 \times 10^{-6}$ which is slightly greater than $\varphi_{\mathrm{O}_{2} 0}$ of $\mathrm{Ru}(\mathrm{bpy})_{3}{ }^{2+}$ at $1.95 \times 10^{-6}$ but far greater than $\varphi_{\mathrm{O}_{2} 0}$ of $\mathrm{Ru}(\mathrm{phen})_{3}{ }^{2+}$ at $2.8 \times 10^{-7}$. These results suggests that the photostability of a mixed ligand complex is limited to photostability of the least stable ligand.

While not directly relevant to most sensor design, the photochemistry in acid is far more complex than in pure photochemistry in pure water, and a complete interpretation will require far more work. Under acidic conditions, the emission intensity of luminophores decreased drastically in the first minute. The unusual shape of 
photolysis decay curves is due to oxidation of Ru(II) by an oxidizer presents in acid. The behavior can be prevented by the addition of a reducing agent such as ascorbic acid ${ }^{17}$. The rate of photolysis under acidic conditions is about ten times faster than in water, which is consistent with previous work ${ }^{18}$. However, the oxidizer causing the oxidation of $\mathrm{Ru}(\mathrm{II})$ in acid is yet unknown. It is highly unlikely that it is caused by impurities, because both $\mathrm{H}_{2} \mathrm{SO}_{4}$ and trichloroacetic acid have the same phenomenon. A possible oxidant is a proton; however, this cannot explain all the data. Further experiments are needed in order to accurately identify an oxidizing agent in the photolysis of Ru(II) polypyridyl complexes in acid.

In summary, an instrument to measure quantitative photostability of luminescent complexes was successfully developed. The measurements made by the instrument are reproducible and accurate. Photolysis time to decompose luminophores and obtain quantitative decomposition yields is less than 30 min, which is significantly less than the 90 minutes required in the previous work, simply to obtain qualitative decomposition ${ }^{19}$. 


\section{Chapter 5 References}

(1) Lakowicz, J. Principles of Fluorescence Spectroscopy; 3rd ed.; SpringerScience: New York, NY, 2006; pp. 3-5.

(2) Amao, Y.; Nakamura, N. Optical CO2 Sensor with the Combination of Colorimetric Change of $\alpha$-Naphtholphthalein and Internal Reference Fluorescent Porphyrin Dye. Sensors Actuators B Chem. 2004, 100, 347-351.

(3) Bacon, J. R.; Demas, J. N. Determination of Oxygen Concentrations by Luminescence Quenching of a Polymer-Immobilized Transition-Metal Complex. Anal. Chem. 1987, 59, 2780-2785.

(4) Carraway, E. R.; Demas, J. N.; DeGraff, B. a.; Bacon, J. R. Photophysics and Photochemistry of Oxygen Sensors Based on Luminescent Transition-Metal Complexes. Anal. Chem. 1991, 63, 337-342.

(5) Choudhury, B.; Shinar, R.; Shinar, J. Glucose Biosensors Based on Organic LightEmitting Devices Structurally Integrated with a Luminescent Sensing Element. J. Appl. Phys. 2004, 96, 2949-2954.

(6) Chen, B.; Wang, L.; Zapata, F.; Qian, G.; Lobkovsky, E. B. A Luminescent Microporous Metal - Organic Framework for the Recognition and Sensing of Anions. J. Am. Chem. Soc. 2008, 130, 6718-6719.

(7) Hanaoka, K.; Kikuchi, K.; Kojima, H.; Urano, Y.; Nagano, T. Development of a Zinc Ion-Selective Luminescent Lanthanide Chemosensor for Biological Applications. J. Am. Chem. Soc. 2004, 126, 12470-6.

(8) Thibon, A.; Pierre, V. C. A Highly Selective Luminescent Sensor for the Time-Gated Detection of Potassium. J. Am. Chem. Soc. 2009, 131, 434-5.

(9) Engler, R. H.; Klein, C.; Trinks, O. Pressure Sensitive Paint Systems for Pressure Distribution Measurements in Wind Tunnels and Turbomachines. Meas. Sci. Technol. 2000, 11, 1077-1085.

(10) Harrigan, R. W.; Hager, G. D.; Crosby, G. A. Evidence for Multiple-State Emission from ruthenium(II) Complexes. Chem. Phys. Lett. 1973, 21, 487-490. 
(11) Wong, K. M.-C.; Tang, W.-S.; Lu, X.-X.; Zhu, N.; Yam, V. W.-W. Functionalized Platinum(II) Terpyridyl Alkynyl Complexes as Colorimetric and Luminescence pH Sensors. Inorg. Chem. 2005, 44, 1492-1498.

(12) Berlier, J. E.; Rothe, A.; Buller, G.; Bradford, J.; Gray, D. R.; Filanoski, B. J.; Telford, W. G.; Yue, S.; Liu, J.; Cheung, C.-Y.; et al. Quantitative Comparison of LongWavelength Alexa Fluor Dyes to Cy Dyes: Fluorescence of the Dyes and Their Bioconjugates. J. Histochem. Cytochem. 2003, 51, 1699-1712.

(13) Panchuk-Voloshina, N.; Haugland, R. P.; Bishop-Stewart, J.; Bhalgat, M. K.; Millard, P. J.; Mao, F.; Leung, W.-Y. Alexa Dyes, a Series of New Fluorescent Dyes That Yield Exceptionally Bright, Photostable Conjugates. J. Histochem. Cytochem. 1999, 47, 1179-1188.

(14) Hirschfeld, T. Quantum Efficiency Independence of the Time Integrated Emission from a Fluorescent Molecule. Appl. Opt. 1976, 15, 3135-3139.

(15) Kambara, H.; Nagai, K.; Kawamoto, K. Photodestruction of Fluorophores and Optimum Conditions for Trace DNA Detection by Automated DNA Sequencer. Electrophoresis 1992, 13, 542-546.

(16) Widengren, J.; Rigler, R. Mechanisms of Photobleaching Investigated by Fluorescence Correlation Spectroscopy. Bioimaging 1996, 4, 149-157.

(17) Macartney, D. H.; Sutin, N. The Oxidation of Ascorbic Acid by Tris(2,2'-Bipyridine) Complexes of osmium(III), ruthenium(III) and nickel(III) in Aqueous Media: Applications of the Marcus Cross-Relation. Inorganica Chim. Acta 1983, 74, 221228.

(18) Demas, J. N.; Adamson, A. W. Tris (2,2'-Bipyridine) ruthenium(II) Senstized Reactions of Some Oxalato Complexes. J. Am. Chem. Soc. 1973, 95, 5159-5168.

(19) Fuller, Z. J.; Bare, W. D.; Kneas, K. A.; Xu, W. Y.; Demas, J. N.; DeGraff, B. A. Photostability of Luminescent ruthenium(II) Complexes in Polymers and in Solution. Anal. Chem. 2003, 75, 2670-2677. 